\title{
Annexin A5: shifting from molecular imaging tool to therapeutic agent in cardiovascular diseases
}

Citation for published version (APA):

Schutters, K. (2013). Annexin A5: shifting from molecular imaging tool to therapeutic agent in cardiovascular diseases. [Doctoral Thesis, Maastricht University]. Uitgeverij BOXPress. https://doi.org/10.26481/dis.20131205ks

Document status and date:

Published: 01/01/2013

DOI:

$10.26481 /$ dis.20131205ks

Document Version:

Publisher's PDF, also known as Version of record

\section{Please check the document version of this publication:}

- A submitted manuscript is the version of the article upon submission and before peer-review. There can be important differences between the submitted version and the official published version of record.

People interested in the research are advised to contact the author for the final version of the publication, or visit the DOI to the publisher's website.

- The final author version and the galley proof are versions of the publication after peer review.

- The final published version features the final layout of the paper including the volume, issue and page numbers.

Link to publication

\footnotetext{
General rights rights.

- You may freely distribute the URL identifying the publication in the public portal. please follow below link for the End User Agreement:

www.umlib.nl/taverne-license

Take down policy

If you believe that this document breaches copyright please contact us at:

repository@maastrichtuniversity.nl

providing details and we will investigate your claim.
}

Copyright and moral rights for the publications made accessible in the public portal are retained by the authors and/or other copyright owners and it is a condition of accessing publications that users recognise and abide by the legal requirements associated with these

- Users may download and print one copy of any publication from the public portal for the purpose of private study or research.

- You may not further distribute the material or use it for any profit-making activity or commercial gain

If the publication is distributed under the terms of Article $25 \mathrm{fa}$ of the Dutch Copyright Act, indicated by the "Taverne" license above, 


\section{ANNEXIN A5: \\ SHIFTING FROM MOLECULAR IMAGING TOOL TO THERAPEUTIC AGENT IN CARDIOVASCULAR DISEASES}


(C) Kristof Schutters, Maastricht 2013

ISBN 978-90-8891-765-3

Printed by: Proefschriftmaken.nl || Uitgeverij BOXPress

Published by: Uitgeverij BOXPress, 's-Hertogenbosch 


\section{ANNEXIN A5: \\ SHIFTING FROM MOLECULAR IMAGING TOOL TO THERAPEUTIC AGENT IN CARDIOVASCULAR DISEASES}

\section{PROEFSCHRIFT}

Ter verkrijging van de graad van doctor aan de Universiteit Maastricht, op gezag van de Rector Magnificus,

Prof. Dr. L.L.G. Soete volgens het besluit van het College van Decanen, in het openbaar te verdedigen op donderdag 5 december 2013 om 16.00 u

door

\section{KRISTOF SCHUTTERS}




\section{PROMOTOR}

Prof. dr. C.P.M. Reutelingsperger

\section{CO-PROMOTOR}

Dr. L. J. Schurgers

\section{BEOORDELINGSCOMMISSIE}

Prof dr. E. A. Biessen (voorzitter)

Prof dr. B. Brachvogel (University of Cologne, Cologne, Germany)

Prof dr. L. J. Dewindt

Prof dr. M. Perretti

(Queen Mary University of London, London, United Kingdom)

Prof. dr. F.C.S. Ramaekers

This Study was performed at the Cardiovascular Research Institute Maastricht (CARIM).

Financial support by the Netherlands Heart Foundation for the publication of this thesis is gratefully acknowledged. Additional financial support was kindly provided by MosaMedix and PharmaTarget. 


\section{CONTENTS}

Chapter 1 General introduction

Chapter 2 Plasma annexin A5 levels predict mortality in patients with heart failure

Chapter 3 Annexin A5 deficiency aggravates development of diastolic heart failure in

C57BL/6 mice

Chapter 4 Cell surface expressed phosphatidylserine as therapeutic target to enhance

phagocytosis of apoptotic cells

Chapter 5 The pro-efferocytotic RGD-annexin A5 inhibits de novo atherosclerotic plaque

formation in $\mathrm{ApoE}^{-/-}$-mice

Chapter 6 General discussion

Chapter 7 Summary

Samenvatting

Dankwoord / Acknowledgments

About the author

List of publications 



\section{CHAPTER 1}

\section{GENERAL INTRODUCTION}

\section{Based on:}

Phosphatidylserine targeting for diagnosis and treatment of human diseases. Schutters K, Reutelingsperger C Apoptosis 15(9):1072-1082 


\section{Apoptosis}

Apoptosis, a biochemically regulated process of cell suicide, plays a crucial role in tissue homeostasis in multicellular organisms. Unwanted cells in developing tissues and damaged or senescent cells execute apoptosis and are subsequently removed mainly by phagocytes. A balance between proliferation and cell death is essential to maintain this homeostasis. During apoptosis several intra- and extra-cellular changes occur. There are biochemical and morphological changes, the most defining features of which are the activation of caspases, chromatin condensation and the display of phagocytosis markers on the cell surface ${ }^{1,2}$. One of the most predominant markers expressed on the cell surface upon apoptosis is phosphatidylserine (PS) which in healthy cells resides predominantly in the inner leaflet of the plasma membrane. These features rendered PS-externalization a well-explored phenomenon to image cell death for diagnostic purposes. In addition, it was demonstrated that under certain conditions viable cells express PS at their surface such as endothelial cells of tumor blood vessels, stressed tumor cells and hypoxic cardiomyocytes. Hence, PS has become a potential target for therapeutic strategies.

\section{PS-asymmetry of the plasma membrane}

PS is ubiquitously present in prokaryotic and eukaryotic cells and constitutes about $2-10 \%$ of total cellular lipids depending on species and cell type. PS synthetic pathways differ between bacteria, yeast and mammals ${ }^{3}$. Mammalian cells synthesize PS predominantly by converting enzymatically phosphatidylcholine (PC) and phosphatidylethanolamine (PE) through a serine exchange reaction. The enzymes PS-synthase 1 (substrate PC) and PS-synthase 2 (substrate $\mathrm{PE}$ ) catalyze the conversion and are present in the endoplasmatic reticulum (Figure 1).

PS appears to be crucial to the cell and, as such, is produced by different biosynthetic routes that can compensate each other to maintain a certain minimal level of PS in case one route fails ${ }^{4,5}$. Cellular PS is non-randomly distributed through several transport mechanisms including vesicular transport and lipid-transfer protein mediated lipid-exchange between juxtapositioned bilayers ${ }^{6}$. Once present in the PM it is subject to the action of the aminophospholipid transporter (APLT) which translocates PS rapidly from the exoplasmic to the cytoplasmic leaflet if PS appears in the exoplasmic leaflet. APLT also translocates PE albeit at a lower rate ${ }^{7}$. The aminophospholipids are thus moved across the bilayer against their gradient and the energy required for translocation is derived from hydrolysis of ATP. APLT appears to be a member of the family of P4 type ATPases, a class of ATPases that mediate ATP-dependently the transbilayer movement of phospholipids ${ }^{8}$. APLT activity is present in erythrocytes, platelets and nucleate cells ${ }^{9}$. In the latter APLT resides in the PM and in trans-Golgi and Golgi derived secretory vesicles. PS asymmetry, once established, is a relatively stable steady state, and APLT activity is required again if disturbances caused by for example membrane fusion processes during endo- and exocytosis occur. It has been shown that inhibition of APLT activity only results in a slow rate of PS exposure ${ }^{10}$ indicating that PS asymmetry of the PM is of importance to cell homeostasis. 


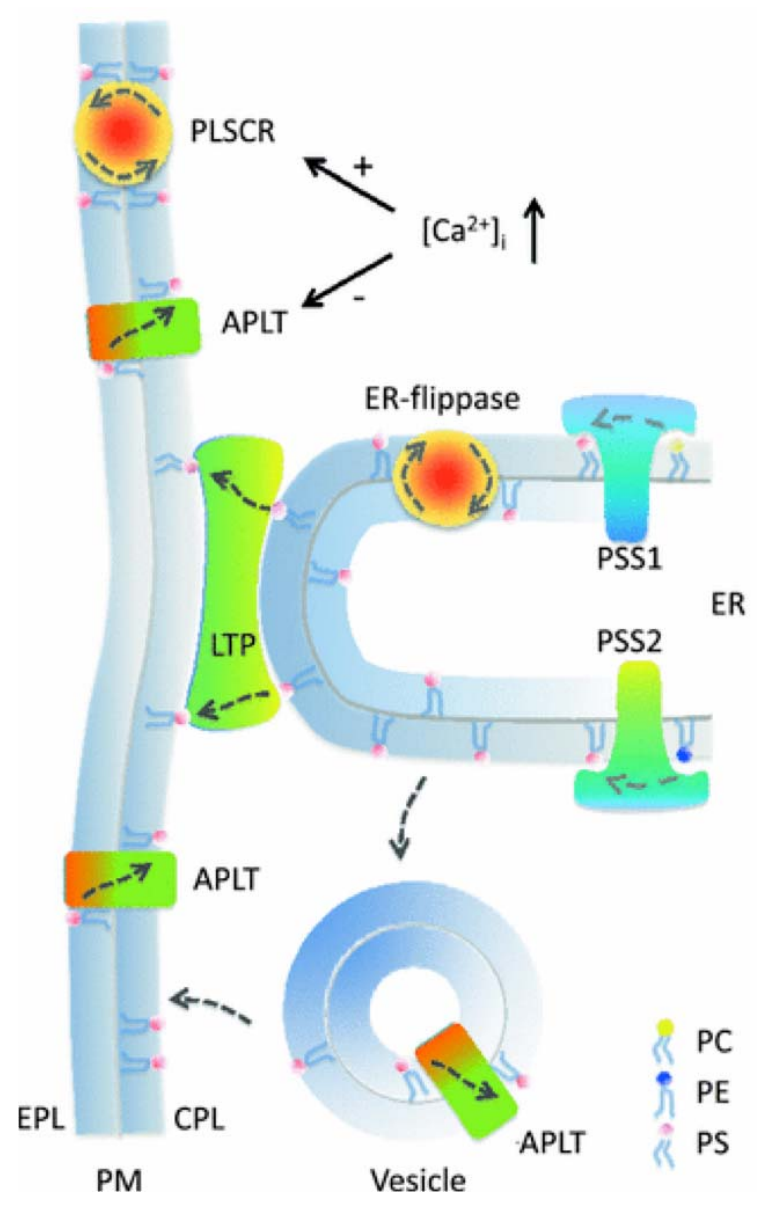

Figure 1: Schematic presentation of synthesis and transport of PS in mammalian cells. PS is synthesized predominantly by PS-synthase 1 and PS-synthase 2 by converting PC and PE through a serine exchange reaction in the endoplasmic reticulum. After synthesis PS is nonrandomly distributed by vesicle transport, membrane fusion and exchange between juxtapositioned bilayers. PS-trafficking pathways are indicated by "dotted arrows". Once present in the PM PS is subject to the action of APLT- and PLSCR-transporters. Increase of cytosolic $\mathrm{Ca}^{2+}$-concentration ([Ca2+]i) inhibits APLT and activates PLSCR. PSS, PSsynthase; LTP, lipid transfer protein; APLT, aminophospholipid translocase; PLSCR, phosholipid scramblase; ER, endoplasmatic reticulum; EPL, exoplasmic leaflet; CPL, cytoplasmic leaflet; PM, plasma membrane; PC, phosphatidylcholine; PE, phosphatidylethanolamine; PS, phosphatidylserine.

\section{Cell surface expression of PS}

Certain conditions may induce cells to release their PS asymmetry of the PM. For example aging of erythrocyte, activation of platelets and apoptosis are accompanied by a sustained appearance of PS in the exoplasmic leaflet ${ }^{11,12}$. As indicated above, inhibition of APLT is insufficient to cause rapid and sustained cell surface exposure of PS. An additional mechanism is required to achieve a steady state level of PS in the exoplasmic leaflet. Current main hypothesis describes a scramblase activity to be responsible for PS appearance at the cell surface. Scramblase translocates phospholipids bidirectionally over the two leaflets of the PM thereby collapsing PS asymmetry. Scrambling is rapid, ATP-independent and nonselective for phospholipid species and it causes randomization of the phospholipids over the two membrane leaflets. Scramblase has been demonstrated to operate in erythrocytes ${ }^{13}$, activated platelets ${ }^{14}$ and apoptotic cells ${ }^{15}$. Several studies have tried to identify the protein(s) 
that scramble the phospholipids of the PM. Isolation and reconstitution experiments delivered the protein phospholipid scramblase 1 (PLSCR1), which is the most serious candidate up to now ${ }^{16}$. Closer inspection, however, casted doubt because cells were able to scramble PM phospholipids in the absence of PLSCR $1^{17}$ and six different cell lines showed a lack of correlation between the level of PLSCR 1 expression and the capacity to externalize PS during apoptosis ${ }^{18}$. No other candidates are proposed as yet indicating complexity of phospholipid scrambling and, likely, diversity in scrambling mechanisms. The latter is illustrated by the finding that platelets of a patient with Scott syndrome fail to express PS upon $\mathrm{Ca}^{2+}$-ionophore treatment (a trigger for healthy platelets to expose PS) whilst Scott B-cells normally translocate PS to the cell surface upon execution of apoptosis ${ }^{19}$.

Recently an alternative hypothesis was postulated that describes PS externalization as part of membrane repair mechanisms that start to operate during apoptosis and involve fusion of lysosomes with $\mathrm{PM}^{20}$. This hypothesis does not require the action of a scramblase protein.

Translocation of PS to the PM exoplasmic leaflet proceeds without compromising the barrier function of the PM. Once in the exoplasmic leaflet PS may participate in a variety of processes depending on type and localization of the PS exposing cell. Circulating erythrocytes for example gradually express PS during aging. PS at the erythrocyte surface functions as an 'eat me' signal towards the reticuloendothelial system, which clears the PS tagged erythrocytes from the circulation by phagocytosis ${ }^{21}$. Platelets can participate in hemostatic and thrombotic processes and while doing so can expose PS at their surface. The PS expressing surface catalyzes coagulation reactions that culminate in the formation of thrombin, which subsequently stabilizes the platelet thrombus by generation of fibrin ${ }^{22}$. Activated macrophages that are engaged to engulf dying cells expose PS at their surface. Inhibition of PS exposure greatly impairs phagocytic capacity of the activated macrophage ${ }^{23}$. Vaccinia virus presents PS at the viral membrane to activate PS dependent macropinocytosis with subsequent infection of the host cell ${ }^{24}$. Macrophages and fibroblasts that are infected with Pichinde Virus express PS at the cell surface ${ }^{25}$.

The most important and abundant cellular process that is accompanied by cell surface expression of PS is apoptosis, a biochemically regulated process of cell suicide ${ }^{1}$. Firstly described for apoptotic lymphocytes ${ }^{12}$ PS exposure is now appreciated as a ubiquitous phenomenon of apoptosis that is independent of cell type and cell death inducing trigger ${ }^{26}$ and that is phylogenetically conserved ${ }^{27}$. PS on the surface of an apoptotic cell is one of the most important 'eat me' flags that not only triggers engulfment but also activates signaling pathways that control cholesterol efflux and expression of anti- and pro-inflammatory cytokines ${ }^{28}$. In addition, PS on the apoptotic cell surface is involved in regulation of immune response towards antigens of the apoptotic cell ${ }^{29}$. Cells that die by executing a non-apoptotic cell death program also activate a machinery that drives cells surface expression of PS ${ }^{2}$ indicating that PS expression is an important phenomenon in dealing with cell death in the context of the multicellular organism. Recognition and engulfment of PS expressing cells are extremely efficient in healthy tissues, which therefore contain, if any, a low steady state level of PS expressing cells. Pathologies can change drastically the balance between appearance and clearance of PS expressing cells towards a sustained presence of PS expressing cells and cell remnants such as apoptotic bodies and cell derived microparticles in diseased tissue. As such surface expressed PS is potentially an informative biomarker for diagnosing disease and evaluating efficacy of therapy. In addition cell surface expressed PS may serve as a target for TDD strategies to deliver therapeutic compounds specifically to diseased tissue. 


\section{4. $\quad$ PS Binding ligands}

In order to exploit fully the potential of PS as a target for Molecular Imaging (diagnosis) and TDD (therapy) ligands should be available that bind selectively and with high affinity to cell surface expressed PS in the complexity of the multicellular organism. To date a variety of PSbinding compounds have been reported in the literature including proteins ${ }^{30}$, peptides ${ }^{31-34}$ and small chemical entities ${ }^{35}$. As Molecular Imaging agents peptides and small chemical compounds generally have the advantage of being quickly and efficiently cleared from the blood circulation. The signal to background ratio is favorably affected by such kinetics. However, the disadvantage of these compounds concerns their low affinity for binding PS. Proteins on the other hand can exhibit higher affinities for PS but proteins are usually cleared from the blood circulation with slower kinetics. The next sections will highlight in particular the proteins annexin A5, synaptotagmin I and lactadherin with which a body of experience has been build about Molecular Imaging of PS expressing cells in vivo in animal models employing a variety of imaging modalities. To date annexin A5 is the only protein that has been used to visualize PS expressing cells in patients using nuclear imaging. Key characteristics of these three proteins are summarized in table 1.

Table 1: Key characteristics of the PS binding proteins annexin A5, synaptotagmin I and lactadherin. *Despite similar nomenclature, the C2-domains of synaptotagmin I and lactadherin do not share sequence homology.

\begin{tabular}{|c|c|c|c|c|c|}
\hline \multirow[t]{2}{*}{ Protein } & \multirow{2}{*}{$\begin{array}{l}\text { MW } \\
(\mathrm{kD})\end{array}$} & \multirow[t]{2}{*}{ Source } & \multicolumn{3}{|c|}{ PS-binding } \\
\hline & & & Domain & $\begin{array}{l}\mathrm{Ca}^{2+}- \\
\text { required }\end{array}$ & $\begin{array}{c}\mathrm{K}_{\mathrm{d}} \\
(\mathrm{nM})\end{array}$ \\
\hline Annexin A5 & 36 & $\begin{array}{c}\text { Human, } \\
\text { expressed in E. } \\
\text { coli }^{36}\end{array}$ & Annexin core & Yes & $0.1-2^{37,38}$ \\
\hline Synaptotagmin I & 65 & $\begin{array}{l}\text { Human, C2A } \\
\text { domain expressed } \\
\text { in E. coli }{ }^{39}\end{array}$ & C2A- domain ${ }^{*}$ & Yes & $15-40^{40}$ \\
\hline Lactadherin & 47 & $\begin{array}{l}\text { Bovine, purified } \\
\text { from milk } 41\end{array}$ & C2-domain ${ }^{*}$ & No & $3-4^{41}$ \\
\hline
\end{tabular}

a. Annexin A5

Annexin A5 was discovered as an anticoagulant protein of vascular tissue ${ }^{42}$. It is a nonglycosylated single chain protein that belongs to the annexin super-gene family [49]. Its polypeptide is organized in an $\mathrm{N}$-terminal tail with a $\mathrm{C}$-terminal core containing four domains that form the annexin-core, a slightly bent surface with a convex shape that interacts with the PS containing phospholipid membrane ${ }^{43,44}$. PS binding of annexin A5 is $\mathrm{Ca}^{2+}$-dependent. $\mathrm{Ca}^{2+}$-ions bind to the annexin core surface at type $\mathrm{II} \mathrm{Ca}^{2+}$-binding sites ${ }^{45}$ and form the prime contact by coordinating carbonyl and carboxyl groups of the protein and phosphoryl moieties of the glycerol backbone of membrane phospholipids ${ }^{44}$. The domains are composed mainly of a-helices and the $\mathrm{Ca}^{2+}$-binding sites protrude as loops (Figure 2). The overall PS binding affinity arises from a collaboration between the $\mathrm{Ca}^{2+}$-binding sites of the four domains with a dominant role for domain $1^{46}$. The complex structure/function relationship of annexin A5 and PS binding has sofar prevented the generation of smaller fragments or mimetics that interact with PS with comparable binding affinity. In solution annexin A5 is present as monomer but once bound to PS-expressing membrane three monomers build a trimer by protein-protein interaction and trimers assemble in a two-dimensional lattice covering the PS expressing surface by trimer-trimer interactions ${ }^{47}$. The two-dimensional protein network of annexin A5 
at a PS expressing cell surface drives internalization of annexin $\mathrm{A} 5{ }^{48}$. Syntaptotagmin I and lactadherin have reported properties neither of two-dimensional crystallisation on the phospholipid surface nor of internalization via the PS portal of cell entry. Annexin A5 binds PS containing membranes with a $K_{d}$ in the range of $0.1-2 \mathrm{nM}$ (table 1).

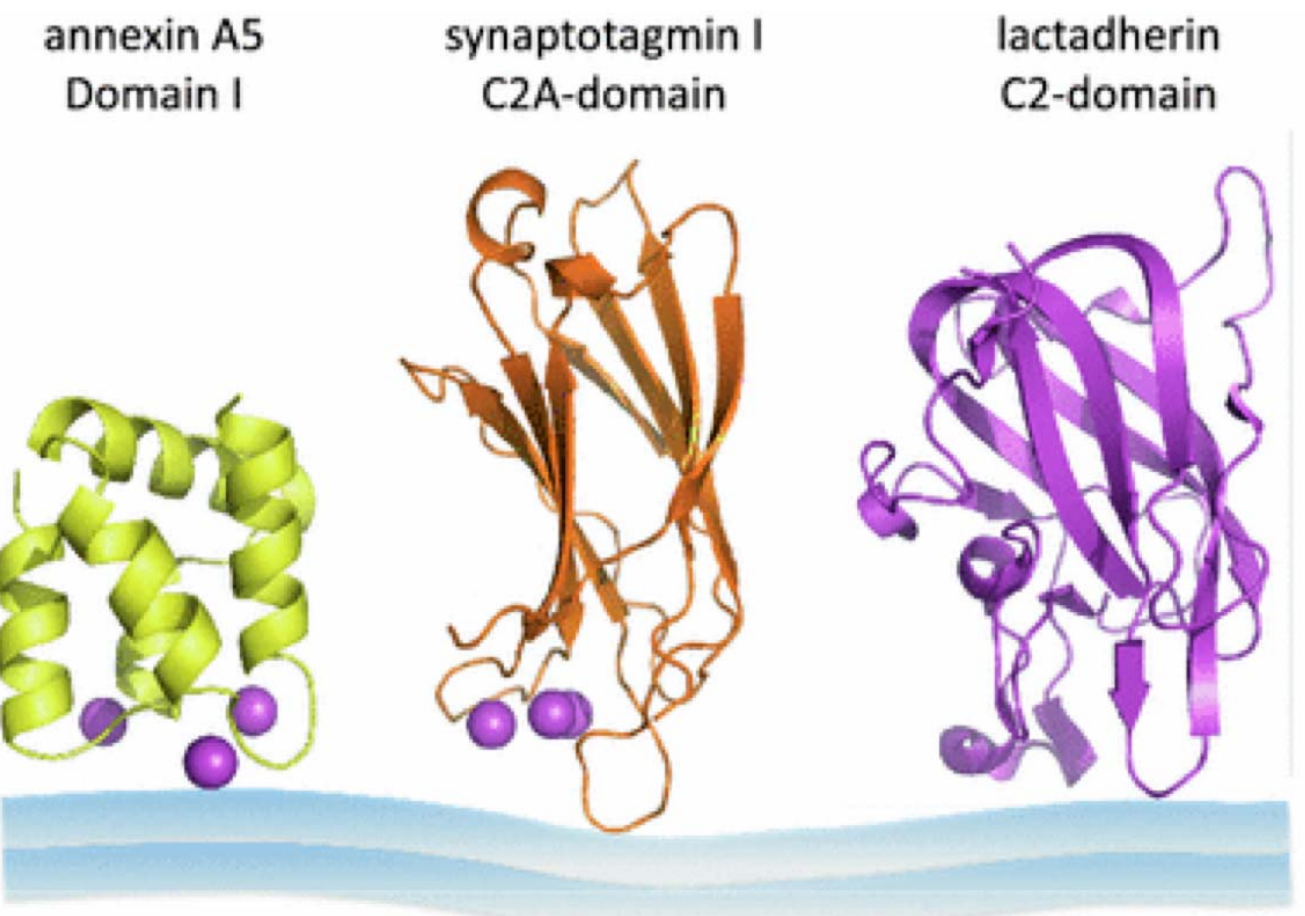

\section{PS-containing membrane}

Figure 2: Ribbon presentations of the structures of the PS binding domains of annexin A5, synaptotagmin I and lactadherin. The structural data were retrieved from the Protein Data Bank (PDB) entries 1AVR, 1BYN and 3BN6, respectively. The purple spheres represent Ca ${ }^{2+}$-ions. This figure was designed by Dr. Gerry Nicolaes (Dept. Biochemistry, Molecular Modeling and Structure Analysis, Maastricht University).

\section{b. $\quad$ Synaptotagmin I}

Synaptotagmin I is a synaptic vesicle membrane protein with a short N-terminal intravesicular sequence, a single transmembrane region, and a cytoplasmic region containing two domains with homology to the $\mathrm{C} 2$-domain of Protein Kinase $\mathrm{C}^{49-51}$. It functions intracellularly as $\mathrm{Ca}^{2+}$ sensor to mediate synaptic vesicle fusion upon rise of cytoplasmic $\mathrm{Ca}^{2+}$-levels. Phospholipid binding of synaptotagmin I is mediated by its C2-domains which bind preferentially the negatively charged phospholipids PS and phosphatidylinositol ${ }^{52,53}$. PS binding can be exhibited by a single $\mathrm{C} 2$ domain as was shown for the first $\mathrm{C} 2$ domain $(\mathrm{C} 2 \mathrm{~A})$ that was expressed recombinantly by E.Coli [37]. The C2A-domain is composed of stable eightstranded-sandwiches with flexible loops emerging from the top and bottom ${ }^{52}$. These loops bind $\mathrm{Ca}^{2+54}$ and acquire subsequently a positive electrostatic potential that becomes attracted by negatively charged phospholipid membranes (Figure 2) ${ }^{55}$. The $\mathrm{C} 2 \mathrm{~B}$ domain can bind phospholipids $\mathrm{Ca}^{2+}$-independently ${ }^{56}$. The dissociation constant $\left(\mathrm{K}_{\mathrm{d}}\right)$ of synaptotagmin I binding to PS is within the $15-40 \mathrm{nM}$-range (table 1).

\section{c. Lactadherin}

Lactadherin is a glycosylated protein that was firstly discovered as a component of milk fat globule membranes ${ }^{57}$. It contains an EGF-like domain harbouring an RGD sequence that mediates interaction with the integrin receptors $a_{v} b_{3 / 5}$. At the C-terminal end of the RGD- 
containing EGF-like domain reside two $\mathrm{C}$ domains bearing homologies with the $\mathrm{C} 1$ and $\mathrm{C} 2$ domains of blood coagulation factors V and VIII. Lactadherin functions as bridging molecule facilitating phagocytosis of dying cells ${ }^{58} 59$. The RGD-motif interacts with integrin receptors on the surface of phagocytes and the $\mathrm{C} 2$-like domain binds in a $\mathrm{Ca}^{2+}$-independent manner with cell surface expressed PS ${ }^{60}$. The $\mathrm{C} 2$-domain of lactadherin contains a b-barrel core with protruding hydrophobic residues that interact $\mathrm{Ca}^{2+}$-independently with PS (Figure 2). The C2domain of lactadherin shows no significant homology with the C2A domain of synaptotagmin I. Interestingly lactadherin binds PS in a stereo-specific manner ${ }^{61}$. Stereo-specificity has not been observed for the PS binding proteins synaptotagmin I and annexin A5. Lactadherin binds to PS containing membranes with a $\mathrm{K}_{\mathrm{d}}$ ranging from 2 - $4 \mathrm{nM}$ (table 1).

\section{d. $\quad$ Other PS binding proteins}

Other PS-binding proteins that have potential to be used as ligands for imaging PS expressing cells include $\mathrm{T}$ cell immunoglobin mucins, $\gamma$-carboxyglutamic acid (Gla) containing proteins and antibodies directed against PS. T cell immunoglobulin mucin 1 and 4 (TIM-1, TIM-4), both members of the TIM-family were originally identified as a marker of $\mathrm{T}$ cell subsets. TIM-proteins are transmembrane proteins that share an immunoglobulin variable domain containing 6 cysteines, and a mucin like domain, a transmembrane domain and a cytoplasmic domain ${ }^{62}$. Both TIM-1 and TIM-4 act as a phagocyte receptor for PS expressed on the apoptotic cell ${ }^{63}$. The immunoglobulin domain binds specifically to PS with a $\mathrm{Kd}$ of approximately $2 \mathrm{nM}^{64}$.

Gla-domain containing proteins such as vitamin K-dependent blood coagulation factors bind PS through a $\mathrm{Ca}^{2+}$-mediated interaction between Gla-residues and PS ${ }^{65}$. Gla-domain containing proteins generally bind PS expressing membranes with a $K_{d}$ in the $n M$ range.

Immunization procedures with PS as antigen may generate antibodies against PS ${ }^{66}$. However, in most cases immunization results in the generation of antibodies that recognize plasma proteins bound to PS. To target PS on tumor vasculature, the murine monoclonal antibody 3G4 was generated ${ }^{67}$. It appeared that $3 \mathrm{G} 4$ does not bind PS directly but through plasma protein 2-glycoprotein 1 that was bound to PS Plasma protein 2-glycoprotein 1 binds weakly to anionic phospholipids whereas in presence of 3G4 its affinity for anionic membranes increases significantly.

\section{Molecular Imaging of PS}

As described above PS expressing cells and cell remnants accumulate in diseased tissues predominantly as a result of the activation of cell death processes and insufficient clearance of the PS expressing cells. Apoptosis is the major process of cell death and plays a role in a wide range of pathologies ${ }^{68-72}$. Therefore non-invasive and tomographic imaging of surface expressed PS has gained interest not only in basic and translational research but also in various clinical disciplines to support diagnosis, localize pathological sites and assess efficacy of therapy. The availability of the PS binding ligand annexin A5 has boosted research and development of Molecular Imaging of PS. To date imaging studies in animal models have been carried out predominantly with various labeled forms of annexin A5. A number of papers have reported about the use of a labeled fusion protein of Gluthation-S-transferase (GST) and the C2A domain of synaptotagmin I. Lactadherin is the less employed one of the three PS binding proteins. Its use has been confined to in vitro studies sofar.

\section{a. $\quad$ Molecular Imaging of PS with Annexin A5}

The recombinantly expressed human annexin A5 exhibits PS binding properties identical to annexin A5 purified from human tissue ${ }^{36}$. Availability of recombinant annexin A5 spurred synthesis of a wide range of labeled forms of annexin A5 to accommodate PS imaging with 
modalities such as optical, radionuclide and magnetic resonance imaging ${ }^{73,74}$. Annexin A5 is labeled with reporter compounds through chemical coupling mostly to primary amino groups of annexin A5. Since these are also present on the surface of the annexin core amine-based coupling may compromise the PS binding potency ${ }^{75,76}$. In order to avoid deleterious effects of coupling, annexin A5 variants have been generated for site-directed labeling at the concave side of the molecule using thiol chemistry. Annexin A5 variants have been generated with thiol-linkage sites in extensions of the N-terminus ${ }^{77,78}$ and thiol-linkage sites within the Nterminal tail and the concave side of annexin A5 to which small compounds (chelators of radionuclides ${ }^{79}$ and fluorochromes ${ }^{80}$ ) as well as particles with diameters ranging from 10$100 \mathrm{~nm}$ (iron oxide nanoparticles ${ }^{81}$ and liposomes ${ }^{82,83}$ ) have been coupled successfully without impairing PS binding. This so-called 'second generation' annexin A5 has improved biodistribution and PS binding properties as compared to amine-labeled wildype annexin A5.

\section{b. $\quad$ Molecular Imaging of PS with C2A domain of Synaptotagmin I}

Synaptotagmin I is less suitable as a whole molecule for Molecular Imaging because of its transmembrane domain. The soluble PS binding C2A domain was expressed recombinantly by E.coli as a fusion protein with GST. Although the affinity for binding PS is higher for C2A $\left(\mathrm{K}_{\mathrm{d}}=20-40 \mathrm{nM}\right)$ as compared to the fusion protein C2A-GST $\left(\mathrm{K}_{\mathrm{d}}= \pm 115 \mathrm{nM}\right)$ it was decided to develop C2A-GST as a Molecular Imaging ligand because labeling of C2A interfered with PS binding ${ }^{40}$. Labeling of GST-C2A likely occurred predominantly at the GST moiety. C2AGST can be conjugated to fluorochromes, radionuclides and superparamagnetic iron oxide particles using random chemical linkage while retaining PS binding property ${ }^{39,84}$. Whether site-directed chemical linkage will yield a superior PS imaging ligand has not been reported so far.

\section{c. $\quad$ Molecular Imaging of PS with lactadherin}

For PS imaging purposes lactadherin was purified from bovine milk ${ }^{85}$. To date PS imaging with lactadherin has been limited to in vitro studies only. Lactadherin has been coupled to fluorescein isothiocyanate via random chemical linkage to accomodate optical imaging ${ }^{85}$. It is claimed that lactadherin has several advantages as a PS imaging agent over annexin A5 and synaptotagmin I. It binds membranes in a way that is proportional to PS content and independent of both phosphatidylethanolamine and $\mathrm{Ca}^{2+61}$. The latter feature is, however, not a benefit in vivo because ionized extracellular $\mathrm{Ca}^{2+}$ levels fluctuate around $1 \mathrm{mM}$ which is more than sufficient to promote binding of annexin A5 and C2A-GST to PS expressing membranes. The drawback of lactadherin is its posttranslational modification which precludes expression of functional lactadherin recombinantly in an E.coli system.

The general picture of all imaging studies utilizing annexin A5 and C2A-GST depicts feasibility of PS imaging with non-invasive techniques including optical, radionuclide and magnetic resonance imaging. Non-invasive PS imaging can be employed to accomplish various goals including understanding pathogenesis of cardiovascular diseases such as heart failure ${ }^{86}$ and atherosclerosis ${ }^{87,88}$ and evaluating therapeutic in vivo efficacy of drugs such as statins ${ }^{89}$ and anti-cancer compounds ${ }^{90,91}$. Most preclinical non-invasive PS imaging has been carried out with radionuclide and magnetic resonance imaging. Low tissue penetration of photons and autofluorescence of extracellular matrix components have been hampering development of non-invasive optical imaging of PS. Recently near-infrared fluorescent (NIRF) probes and fluorescence mediated tomography (FMT) have been developed rendering non-invasive optical imaging feasible ${ }^{92}$. Second generation annexin A5 has been coupled to the NIRF probe Vivo-750 via thiol-chemistry and employed successfully to quantify the anticancer effect of cytotoxic compounds in a mouse cancer model using non-invasive FMT (Figure 3). 
PS imaging has entered the process of translation from preclinical settings to the clinical arena. Availability of clinical grade recombinant human annexin A5 for labeling with Technetium $\left(\mathrm{Tc}^{99 \mathrm{~m}}\right.$ ) and Single Photon Emission Tomography (SPECT) has catalyzed clinical studies with PS imaging in various patients to assess the significance of PS imaging for diagnosis and rapid evaluation of efficacy of therapy. Table 2 summarizes medical fields in which Molecular Imaging of PS has been interrogated in preclinical models and in patients. These studies show promise for non-invasive imaging of PS to catalyze drug development in preclinical settings and to support diagnosis and evaluation efficacy of treatment shortly after start of therapy in the clinic.
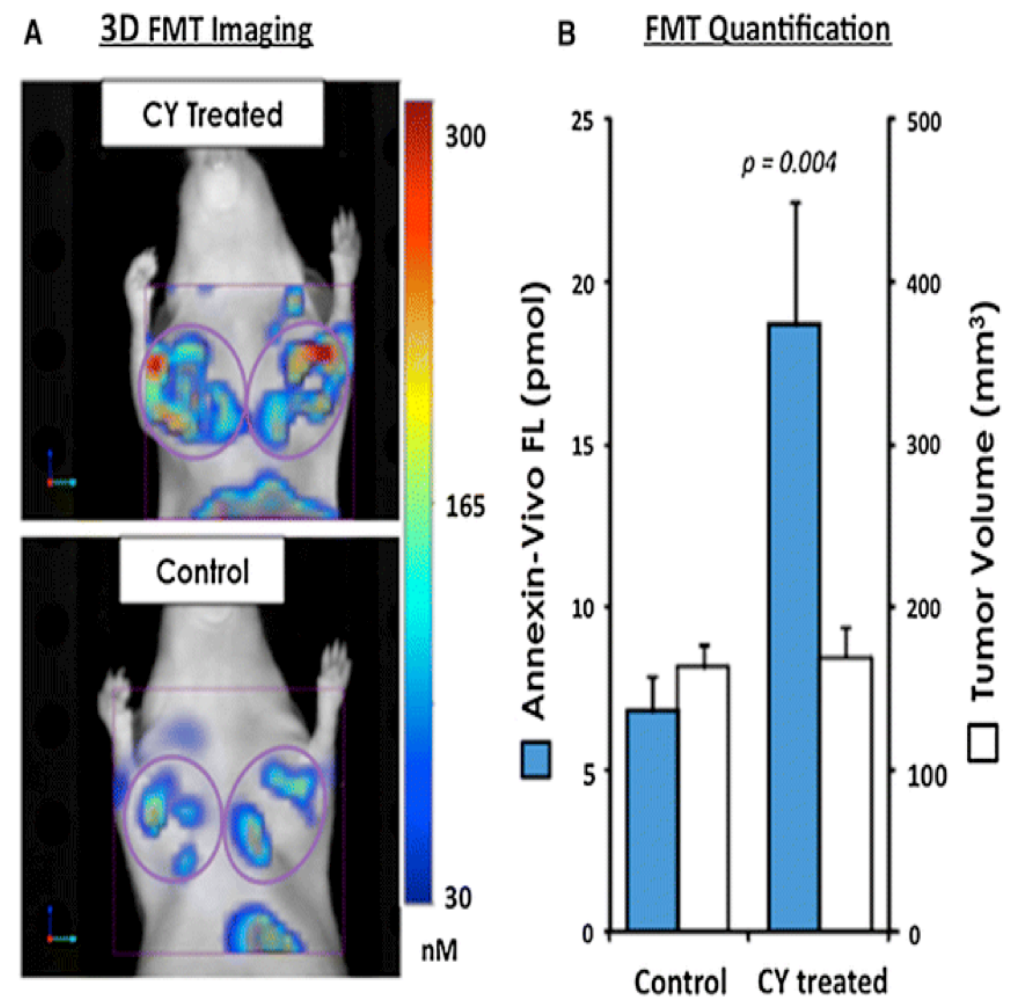

Figure 3: Non-invasive PS-imaging of efficacy of anti-cancer treatment. Mice were implanted with HT-29 human colorectal adenocarcinoma cells in both upper mammary fat pads, and tumors were allowed to grow for 10 days. To assess the acute induction of apoptosis, animals received a single IP injection of cyclophosphamide (CY; $170 \mathrm{mg} / \mathrm{kg})$. Animals were injected with second generation annexin A5 coupled to Vivo 750 (annexin-Vivo 750, VisEn Medical) $24 \mathrm{~h}$ post-CY treatment and imaged $2 \mathrm{~h}$ later by FMT 2500 (VisEn Medical) fluorescence tomography. Representative images of treated and untreated HT-29 mice were selected to reflect the mean group tumor fluorescence intensities. (a) 3D FMT images were acquired, and (b) the effects on tumor fluorescence and volume were assessed. Results indicate anti-cancer efficacy of CY in this model. Data and images courtesy of VisEn Medical Inc., Bedford, MA, USA.

\section{PS as target for therapeutic interventions}

In contrast to PS-targeting strategies, therapeutic applications are very limited. PS targeting is mainly used in targeted drug delivery (TDD) strategies. TDD is a strategy the goal of which is to treat disease effectively with minimal detrimental side-effects. Such strategies are especially of importance to treatments in which toxic substances are needed to combat these diseases. TDD is based on the principle of Paul Ehrlich's 'Magic Bullet' which in fact is a 
therapeutic compound that is guided to the diseased lesion by a targeting function. The targeting function can be an integral part of the therapeutic compound or can be deliberately attached to the drug ${ }^{127}$. Cell surface expressed PS is potentially an attractive target for TDD considering the body of experience with PS as a biomarker for Molecular Imaging ${ }^{127,128}$.

A wide range of diseases may benefit from PS based TDD strategies (see table 2). In general PS is expressed by dying and dead cells and cell remnants that accumulate in diseased lesions such as atherosclerotic plaques and tumors. In such lesions PS may function to accumulate PS seeking 'Magic Bullets' and their therapeutic cargo, which may for example encompass enzymes or cytotoxic substances. Recent experiments indicated that cells, which are not committed to execute cell death, may also express PS on their surface under specific conditions. Endothelial cells of tumor vasculature for example express PS while being alive 129. Cardiomyocytes that have been submitted to brief ischemia express PS before the apoptotic machinery trespasses the point of no return ${ }^{130}$. These cells can be targeted with therapeutic substances that either kill (tumour endothelial cells) or rescue (stressed cardiomyocytes) the PS expressing cell. Efficient intracellular delivery of the therapeutic substance is then necessary. Annexin A5 has been shown to be internalized into the PS expressing cell as a consequence of its property to form a 2-dimensional lattice on the cell surface ${ }^{48}$. C2A-domain of synaptotagmin I and lactadherin have no reported property of internalization into PS expressing cells.

Recent reports underscored feasibility and applicability of the concept of PS targeting in TDD strategies. Annexin A5 was used as vector to target coagulation and fibrinolytic enzymes to sites of PS expressing cells in the vasculature ${ }^{131-133}$. These PS seeking 'Magic bullets' were constructed by molecular fusion ${ }^{131,133}$ or chemical coupling ${ }^{132}$ of annexin A5 and the enzyme. Annexin A5 by itself integrates PS targeting and therapeutic function because once bound to PS it blocks the inflammatory and immunomodulatory activities of surface expressed PS ${ }^{134}$. Recently a homodimer of annexin A5 (diannexin) was constructed with the purpose to prolong the blood circulation time and, hence, to increase therapeutic efficacy of annexin A5 to attenuate ischemia/reperfusion induced injury of organs ${ }^{135}$.

PS has also been targeted with the antibody 3G4 (bavituximab), which binds with high affinity to complexes of 2-glycoprotein I and PS. 3G4 was used therapeutically as adjuvant therapy in viral infections in which PS surface expression is essential to successful infection ${ }^{25}$ and in mouse models of cancer, which have tumor vasculature with PS expressing endothelial cells ${ }^{136,137}$.

Diannexin and bavituximab are the first PS-targeting agents that have entered clinical trials to demonstrate therapeutic activity in patients with kidney transplants, chronic hepatic $\mathrm{C}$ virus and HIV and cancer (http://clinicaltrials.gov). 
Table 2: Overview of preclinical and clinical imaging of PS for a variety of diseases and diagnostic purposes.

\begin{tabular}{|c|c|c|c|}
\hline \multirow[t]{2}{*}{ Medical field } & \multirow{2}{*}{$\begin{array}{c}\text { Diagnostic purpose of PS } \\
\text { imaging }\end{array}$} & \multicolumn{2}{|c|}{ References } \\
\hline & & $\begin{array}{l}\text { preclinical } \\
\text { studies }\end{array}$ & clinical studies \\
\hline \multirow[t]{2}{*}{ Oncology } & $\begin{array}{l}\text { Early assessment of } \\
\text { efficacy of therapy }\end{array}$ & $90,91,93-96$ & $97-100$ \\
\hline & Prognosis of survival & & 101 \\
\hline \multirow[t]{3}{*}{ Cardiology } & $\begin{array}{l}\text { Early diagnosis of heart } \\
\text { failure }\end{array}$ & $69,86,102-105$ & 106 \\
\hline & $\begin{array}{l}\text { Early assessment of cardiac } \\
\text { toxicity }\end{array}$ & 107 & \\
\hline & $\begin{array}{c}\text { Assessment of cardiac } \\
\text { ischemia/reperfusion injury }\end{array}$ & $108-110$ & 111 \\
\hline $\begin{array}{l}\text { Vascular } \\
\text { Medicine }\end{array}$ & $\begin{array}{l}\text { Identification of unstable } \\
\text { atherosclerotic plaque }\end{array}$ & 112,113 & 114 \\
\hline Orthopaedics & $\begin{array}{l}\text { Assessment of infection of } \\
\text { prostheses }\end{array}$ & & 115 \\
\hline $\begin{array}{c}\text { Organ } \\
\text { transplantation }\end{array}$ & Allograft rejection & 116 & 102,117 \\
\hline Gastroenterology & $\begin{array}{l}\text { Assessment of efficacy of } \\
\text { therapy in Crohn's disease }\end{array}$ & & 118 \\
\hline Neurology & $\begin{array}{l}\text { Identifying regions of } \\
\text { cerebral injury }\end{array}$ & 119,120 & 121,122 \\
\hline Ophthalmology & $\begin{array}{l}\text { Assessment of retinal } \\
\text { neurodegeneration }\end{array}$ & 123,124 & \\
\hline $\begin{array}{c}\text { Autoimmune } \\
\text { diseases }\end{array}$ & $\begin{array}{l}\text { Identifying regions of } \\
\text { rheumatoid arthritis }\end{array}$ & 125 & \\
\hline $\begin{array}{l}\text { Metabolic } \\
\text { diseases }\end{array}$ & $\begin{array}{l}\text { Measurement of b-cells } \\
\text { apoptosis }\end{array}$ & 126 & \\
\hline
\end{tabular}

\section{Aim of this thesis}

This thesis aims to develop therapeutic applications employing annexin A5 as PS targeting agent in heart failure and atherosclerosis, the two leading cardiovascular health problems in the Western society. The main aim of this thesis is two-fold 1) to obtain more insight in the role of endogenous anxA5 in the development of heart failure and 2) to shift anxA5 from a diagnostic imaging tool towards a therapeutic realm in diseases where apoptosis and efferocytosis are out of balance.

Chapter 2 addresses the clearance pathway of apoptotic cells as possible source for predictive biomarkers of apoptosis. We clearly show that plasma anxA5 levels are significantly elevated in patients with heart failure as compared with healthy controls. Moreover we found that anxA5 is a strong and independent predictor of adverse outcome, with no association between anxA5 levels and established clinical, functional and biochemical HF measures.

Chapter 3 addresses the role of endogenous anxA5 in the development of heart failure. We clearly showed that anxA $5^{-/-}$mice submitted to thoracic aorta constriction developed a more severe diastolic dysfunction compared to the anxA $5^{+/+}$mice submitted to thoracic aorta constriction. We convincingly showed that endogenous anxA5 has a protective role in the development of diastolic heart failure induced by pressure overload in mice. 
Chapter 4 addresses a novel strategy directed towards enhancing phagocytosis of PS exposing cells. We clearly showed that the introduction of an Arg-Gly-Asp (RGD)-motif in the anxA5 molecule transforms anxA5 from an inhibitor into a stimulator of efferocytosis.

Chapter 5 addresses the influence of the described RGD-anxA5 variants described in chapter 4 on the initial development of atherosclerotic lesions. Surprisingly, we found a complete reduction of atherosclerotic lesion formation in seven out of nine mice. In our search for explanations for this dramatic effect, we propose that RGD-anxA5 can attenuate monocyte infiltration and concomitantly promote the efficient phagocytosis of the leukocytes which achieve plaque infiltration.

\section{References}

1. Hengartner MO. The biochemistry of apoptosis. Nature 2000; 407(6805): 770-6.

2. Leist M, Jaattela M. Four deaths and a funeral: from caspases to alternative mechanisms. Nat Rev Mol Cell Biol 2001; 2(8): 589-98.

3. Yamaji-Hasegawa A, Tsujimoto M. Asymmetric distribution of phospholipids in biomembranes. Biol Pharm Bull 2006; 29(8): 1547-53.

4. Bergo MO, Gavino BJ, Steenbergen R, Sturbois B, Parlow AF, Sanan DA et al. Defining the importance of phosphatidylserine synthase 2 in mice. J Biol Chem 2002; 277(49): 47701-8.

5. Arikketh D, Nelson R, Vance JE. Defining the importance of phosphatidylserine synthase-1 (PSS1): unexpected viability of PSS1-deficient mice. J Biol Chem 2008; 283(19): 12888-97.

6. Holthuis JC, Levine TP. Lipid traffic: floppy drives and a superhighway. Nat Rev Mol Cell Biol 2005; 6(3): 209-20.

7. Morrot G, Herve P, Zachowski A, Fellmann P, Devaux PF. Aminophospholipid translocase of human erythrocytes: phospholipid substrate specificity and effect of cholesterol. Biochemistry 1989; 28(8): 3456-62.

8. Puts CF, Holthuis JC. Mechanism and significance of P4 ATPase-catalyzed lipid transport: lessons from a Na+/K+-pump. Biochim Biophys Acta 2009; 1791(7): 60311.

9. Devaux PF. Protein involvement in transmembrane lipid asymmetry. Annu Rev Biophys Biomol Struct 1992; 21: 417-39.

10. Bitbol M, Fellmann P, Zachowski A, Devaux PF. Ion regulation of phosphatidylserine and phosphatidylethanolamine outside-inside translocation in human erythrocytes. Biochim Biophys Acta 1987; 904(2): 268-82.

11. Zwaal RF, Schroit AJ. Pathophysiologic implications of membrane phospholipid asymmetry in blood cells. Blood 1997; 89(4): 1121-32.

12. Fadok VA, Voelker DR, Campbell PA, Cohen JJ, Bratton DL, Henson PM. Exposure of phosphatidylserine on the surface of apoptotic lymphocytes triggers specific recognition and removal by macrophages. J Immunol 1992; 148(7): 2207-16.

13. Basse F, Stout JG, Sims PJ, Wiedmer T. Isolation of an erythrocyte membrane protein that mediates Ca2+-dependent transbilayer movement of phospholipid. J Biol Chem 1996; 271(29): 17205-10.

14. Williamson P, Bevers EM, Smeets EF, Comfurius P, Schlegel RA, Zwaal RF. Continuous analysis of the mechanism of activated transbilayer lipid movement in platelets. Biochemistry 1995; 34(33): 10448-55.

15. Verhoven B, Schlegel RA, Williamson P. Mechanisms of phosphatidylserine exposure, a phagocyte recognition signal, on apoptotic T lymphocytes. $J$ Exp Med 1995; 182(5): 1597-601. 
16. Zhou Q, Zhao J, Stout JG, Luhm RA, Wiedmer T, Sims PJ. Molecular cloning of human plasma membrane phospholipid scramblase. A protein mediating transbilayer movement of plasma membrane phospholipids. J Biol Chem 1997; 272(29): 18240-4.

17. Zhou Q, Zhao J, Wiedmer T, Sims PJ. Normal hemostasis but defective hematopoietic response to growth factors in mice deficient in phospholipid scramblase 1. Blood 2002; 99(11): 4030-8.

18. Zhou Q, Zhao J, Al-Zoghaibi F, Zhou A, Wiedmer T, Silverman RH et al. Transcriptional control of the human plasma membrane phospholipid scramblase 1 gene is mediated by interferon-alpha. Blood 2000; 95(8): 2593-9.

19. Williamson P, Christie A, Kohlin T, Schlegel RA, Comfurius P, Harmsma M et al. Phospholipid scramblase activation pathways in lymphocytes. Biochemistry 2001; 40(27): 8065-72.

20. Mirnikjoo B, Balasubramanian K, Schroit AJ. Suicidal Membrane Repair Regulates Phosphatidylserine Externalization during Apoptosis. J Biol Chem 2009; 284(34): 22512-6.

21. Allen TM, Williamson P, Schlegel RA. Phosphatidylserine as a determinant of reticuloendothelial recognition of liposome models of the erythrocyte surface. Proc Natl Acad Sci U S A 1988; 85(21): 8067-71.

22. Heemskerk JW, Bevers EM, Lindhout T. Platelet activation and blood coagulation. Thromb Haemost 2002; 88(2): 186-93.

23. Hamon Y, Broccardo C, Chambenoit O, Luciani MF, Toti F, Chaslin S et al. ABC1 promotes engulfment of apoptotic cells and transbilayer redistribution of phosphatidylserine. Nat Cell Biol 2000; 2(7): 399-406.

24. Mercer J, Helenius A. Vaccinia virus uses macropinocytosis and apoptotic mimicry to enter host cells. Science 2008; 320(5875): 531-5.

25. Soares MM, King SW, Thorpe PE. Targeting inside-out phosphatidylserine as a therapeutic strategy for viral diseases. Nat Med 2008; 14(12): 1357-62.

26. Martin SJ, Finucane DM, Amarante-Mendes GP, O'Brien GA, Green DR. Phosphatidylserine externalization during CD95-induced apoptosis of cells and cytoplasts requires ICE/CED-3 protease activity. J Biol Chem 1996; 271(46): 28753.

27. van den Eijnde SM, Boshart L, Baehrecke EH, De Zeeuw CI, Reutelingsperger CP, Vermeij-Keers C. Cell surface exposure of phosphatidylserine during apoptosis is phylogenetically conserved. Apoptosis 1998; 3(1): 9-16.

28. Ravichandran KS, Lorenz U. Engulfment of apoptotic cells: signals for a good meal. Nat Rev Immunol 2007; 7(12): 964-74.

29. Chaurio RA, Janko C, Munoz LE, Frey B, Herrmann M, Gaipl US. Phospholipids: key players in apoptosis and immune regulation. Molecules 2009; 14(12): 4892-914.

30. Stace CL, Ktistakis NT. Phosphatidic acid- and phosphatidylserine-binding proteins. Biochim Biophys Acta 2006; 1761(8): 913-26.

31. Burtea C, Laurent S, Lancelot E, Ballet S, Murariu O, Rousseaux O et al. Peptidic targeting of phosphatidylserine for the MRI detection of apoptosis in atherosclerotic plaques. Molecular pharmaceutics 2009; 6(6): 1903-19.

32. Igarashi K, Kaneda M, Yamaji A, Saido TC, Kikkawa U, Ono Y et al. A novel phosphatidylserine-binding peptide motif defined by an anti-idiotypic monoclonal antibody. Localization of phosphatidylserine-specific binding sites on protein kinase $\mathrm{C}$ and phosphatidylserine decarboxylase. J Biol Chem 1995; 270(49): 29075-8.

33. Laumonier C, Segers J, Laurent S, Michel A, Coppee F, Belayew A et al. A New Peptidic Vector for Molecular Imaging of Apoptosis, Identified by Phage Display Technology. J Biomol Screen 2006. 
34. Thapa N, Kim S, So IS, Lee BH, Kwon IC, Choi K et al. Discovery of a Phosphatidylserine Recognizing Peptide and Its Utility in Molecular Imaging of Tumor Apoptosis. Journal of cellular and molecular medicine 2008.

35. Hanshaw RG, Smith BD. New reagents for phosphatidylserine recognition and detection of apoptosis. Bioorg Med Chem 2005; 13(17): 5035-42.

36. Maurer-Fogy I, Reutelingsperger CP, Pieters J, Bodo G, Stratowa C, Hauptmann R. Cloning and expression of cDNA for human vascular anticoagulant, a Ca2+dependent phospholipid-binding protein. Eur J Biochem 1988; 174(4): 585-92.

37. Andree HA, Reutelingsperger CP, Hauptmann R, Hemker HC, Hermens WT, Willems GM. Binding of vascular anticoagulant alpha (VAC alpha) to planar phospholipid bilayers. J Biol Chem 1990; 265(9): 4923-8.

38. Tait JF, Gibson D, Fujikawa K. Phospholipid binding properties of human placental anticoagulant protein-I, a member of the lipocortin family. J Biol Chem 1989; 264(14): 7944-9.

39. Zhao M, Beauregard DA, Loizou L, Davletov B, Brindle KM. Non-invasive detection of apoptosis using magnetic resonance imaging and a targeted contrast agent. Nat Med 2001; 7(11): 1241-4.

40. Jung HI, Kettunen MI, Davletov B, Brindle KM. Detection of apoptosis using the C2A domain of synaptotagmin I. Bioconjug Chem 2004; 15(5): 983-7.

41. Shi J, Heegaard CW, Rasmussen JT, Gilbert GE. Lactadherin binds selectively to membranes containing phosphatidyl-L-serine and increased curvature. Biochim Biophys Acta 2004; 1667(1): 82-90.

42. Reutelingsperger CP, Hornstra G, Hemker HC. Isolation and partial purification of a novel anticoagulant from arteries of human umbilical cord. Eur J Biochem 1985; 151(3): 625-9.

43. Huber R, Romisch J, Paques EP. The crystal and molecular structure of human annexin $\mathrm{V}$, an anticoagulant protein that binds to calcium and membranes. Embo J 1990; 9(12): 3867-74.

44. Huber R, Schneider M, Mayr I, Romisch J, Paques EP. The calcium binding sites in human annexin $\mathrm{V}$ by crystal structure analysis at $2.0 \mathrm{~A}$ resolution. Implications for membrane binding and calcium channel activity. FEBS Lett 1990; 275(1-2): 15-21.

45. Swairjo MA, Concha NO, Kaetzel MA, Dedman JR, Seaton BA. Ca(2+)-bridging mechanism and phospholipid head group recognition in the membrane-binding protein annexin V. Nat Struct Biol 1995; 2(11): 968-74.

46. Montaville P, Neumann JM, Russo-Marie F, Ochsenbein F, Sanson A. A new consensus sequence for phosphatidylserine recognition by annexins. J Biol Chem 2002; 277(27): 24684-93.

47. Oling F, Bergsma-Schutter W, Brisson A. Trimers, dimers of trimers, and trimers of trimers are common building blocks of annexin a5 two-dimensional crystals. J Struct Biol 2001; 133(1): 55-63.

48. Kenis H, van Genderen H, Bennaghmouch A, Rinia HA, Frederik P, Narula J et al. Cell surface-expressed phosphatidylserine and annexin A5 open a novel portal of cell entry. J Biol Chem 2004; 279(50): 52623-9.

49. Perin MS, Johnston PA, Ozcelik T, Jahn R, Francke U, Sudhof TC. Structural and functional conservation of synaptotagmin (p65) in Drosophila and humans. J Biol Chem 1991; 266(1): 615-22

50. Perin MS, Fried VA, Mignery GA, Jahn R, Sudhof TC. Phospholipid binding by a synaptic vesicle protein homologous to the regulatory region of protein kinase $\mathrm{C}$. Nature 1990; 345(6272): 260-3.

51. Perin MS, Brose N, Jahn R, Sudhof TC. Domain structure of synaptotagmin (p65). $J$ Biol Chem 1991; 266(1): 623-9. 
52. Sutton RB, Davletov BA, Berghuis AM, Sudhof TC, Sprang SR. Structure of the first C2 domain of synaptotagmin I: a novel Ca2+/phospholipid-binding fold. Cell 1995; 80(6): 929-38.

53. Zhang X, Rizo J, Sudhof TC. Mechanism of phospholipid binding by the C2A-domain of synaptotagmin I. Biochemistry 1998; 37(36): 12395-403.

54. Rizo J, Sudhof TC. C2-domains, structure and function of a universal Ca2+-binding domain. J Biol Chem 1998; 273(26): 15879-82.

55. Murray D, Honig B. Electrostatic control of the membrane targeting of C2 domains. Mol Cell 2002; 9(1): 145-54.

56. Kuo W, Herrick DZ, Ellena JF, Cafiso DS. The calcium-dependent and calciumindependent membrane binding of synaptotagmin 1: two modes of C2B binding. $J$ Mol Biol 2009; 387(2): 284-94.

57. Peterson JA, Patton S, Hamosh M. Glycoproteins of the human milk fat globule in the protection of the breast-fed infant against infections. Biol Neonate 1998; 74(2): 14362.

58. Hvarregaard J, Andersen MH, Berglund L, Rasmussen JT, Petersen TE. Characterization of glycoprotein PAS-6/7 from membranes of bovine milk fat globules. Eur J Biochem 1996; 240(3): 628-36.

59. Andersen MH, Berglund L, Rasmussen JT, Petersen TE. Bovine PAS-6/7 binds alpha $\mathrm{v}$ beta 5 integrins and anionic phospholipids through two domains. Biochemistry 1997; 36(18): 5441-6.

60. Andersen MH, Graversen H, Fedosov SN, Petersen TE, Rasmussen JT. Functional analyses of two cellular binding domains of bovine lactadherin. Biochemistry 2000; 39(20): 6200-6.

61. Shi J, Gilbert GE. Lactadherin inhibits enzyme complexes of blood coagulation by competing for phospholipid-binding sites. Blood 2003; 101(7): 2628-36.

62. Savill J, Gregory C. Apoptotic PS to phagocyte TIM-4: eat me. Immunity 2007; 27(6): 830-2.

63. Kobayashi N, Karisola P, Pena-Cruz V, Dorfman DM, Jinushi M, Umetsu SE et al. TIM-1 and TIM-4 glycoproteins bind phosphatidylserine and mediate uptake of apoptotic cells. Immunity 2007; 27(6): 927-40.

64. Miyanishi M, Tada K, Koike M, Uchiyama Y, Kitamura T, Nagata S. Identification of Tim4 as a phosphatidylserine receptor. Nature 2007; 450(7168): 435-9.

65. Huang M, Rigby AC, Morelli X, Grant MA, Huang G, Furie B et al. Structural basis of membrane binding by Gla domains of vitamin K-dependent proteins. Nat Struct Biol 2003; 10(9): 751-6.

66. Umeda M, Igarashi K, Nam KS, Inoue K. Effective production of monoclonal antibodies against phosphatidylserine: stereo-specific recognition of phosphatidylserine by monoclonal antibody. J Immunol 1989; 143(7): 2273-9.

67. Ran S, He J, Huang X, Soares M, Scothorn D, Thorpe PE. Antitumor effects of a monoclonal antibody that binds anionic phospholipids on the surface of tumor blood vessels in mice. Clin Cancer Res 2005; 11(4): 1551-62.

68. Brown JM, Attardi LD. The role of apoptosis in cancer development and treatment response. Nat Rev Cancer 2005; 5(3): 231-7.

69. Yaoita H, Ogawa K, Maehara K, Maruyama Y. Apoptosis in relevant clinical situations: contribution of apoptosis in myocardial infarction. Cardiovasc Res 2000; 45(3): 630-41.

70. Kolodgie FD, Narula J, Guillo P, Virmani R. Apoptosis in human atherosclerotic plaques. Apoptosis 1999; 4(1): 5-10. 
71. Narula J, Pandey P, Arbustini E, Haider N, Narula N, Kolodgie FD et al. Apoptosis in heart failure: release of cytochrome $\mathrm{c}$ from mitochondria and activation of caspase-3 in human cardiomyopathy. Proc Natl Acad Sci U S A 1999; 96(14): 8144-9.

72. Mattson MP. Apoptosis in neurodegenerative disorders. Nat Rev Mol Cell Biol 2000; 1(2): 120-9.

73. Lahorte CM, Vanderheyden JL, Steinmetz N, Van de Wiele C, Dierckx RA, Slegers G. Apoptosis-detecting radioligands: current state of the art and future perspectives. Eur J Nucl Med Mol Imaging 2004; 31(6): 887-919.

74. Faust A, Hermann S, Wagner S, Haufe G, Schober O, Schafers M et al. Molecular Imaging of Apoptosis In vivo with Scintigraphic and Optical Biomarkers - A Status Report. Anticancer Agents Med Chem 2009.

75. Schellenberger EA, Weissleder R, Josephson L. Optimal modification of annexin V with fluorescent dyes. Chembiochem 2004; 5(3): 271-4.

76. Tait JF, Smith C, Levashova Z, Patel B, Blankenberg FG, Vanderheyden JL. Improved detection of cell death in vivo with annexin $\mathrm{v}$ radiolabeled by site-specific methods. J Nucl Med 2006; 47(9): 1546-53.

77. Tait JF, Brown DS, Gibson DF, Blankenberg FG, Strauss HW. Development and characterization of annexin $\mathrm{V}$ mutants with endogenous chelation sites for $(99 \mathrm{~m}) \mathrm{Tc}$. Bioconjug Chem 2000; 11(6): 918-25.

78. Li X, Link JM, Stekhova S, Yagle KJ, Smith C, Krohn KA et al. Site-specific labeling of annexin V with F-18 for apoptosis imaging. Bioconjug Chem 2008; 19(8): 1684-8.

79. De Saint-Hubert M, Mottaghy FM, Vunckx K, Nuyts J, Fonge H, Prinsen K et al. Site-specific labeling of 'second generation' annexin V with $99 \mathrm{mTc}(\mathrm{CO}) 3$ for improved imaging of apoptosis in vivo. Bioorg Med Chem 2010; 18(3): 1356-63.

80. Douma K, Prinzen L, Slaaf DW, Reutelingsperger CP, Biessen EA, Hackeng TM et al. Nanoparticles for Optical Molecular Imaging of Atherosclerosis. Small 2009.

81. Schellenberger E, Schnorr J, Reutelingsperger C, Ungethum L, Meyer W, Taupitz M et al. Linking proteins with anionic nanoparticles via protamine: ultrasmall proteincoupled probes for magnetic resonance imaging of apoptosis. Small 2008; 4(2): 22530.

82. van Tilborg GA, Mulder WJ, Deckers N, Storm G, Reutelingsperger CP, Strijkers GJ et al. Annexin A5-Functionalized Bimodal Lipid-Based Contrast Agents for the Detection of Apoptosis. Bioconjug Chem 2006; 17(3): 741-749.

83. Garnier B, Bouter A, Gounou C, Petry KG, Brisson AR. Annexin A5-Functionalized Liposomes for Targeting Phosphatidylserine-Exposing Membranes. Bioconjug Chem 2009.

84. Zhao M, Zhu X, Ji S, Zhou J, Ozker KS, Fang W et al. 99mTc-Labeled C2A Domain of Synaptotagmin I as a Target-Specific Molecular Probe for Noninvasive Imaging of Acute Myocardial Infarction. J Nucl Med 2006; 47(8): 1367-1374.

85. Shi J, Shi Y, Waehrens LN, Rasmussen JT, Heegaard CW, Gilbert GE. Lactadherin detects early phosphatidylserine exposure on immortalized leukemia cells undergoing programmed cell death. Cytometry A 2006; 69(12): 1193-201.

86. Sosnovik DE, Nahrendorf M, Panizzi P, Matsui T, Aikawa E, Dai G et al. Molecular MRI detects low levels of cardiomyocyte apoptosis in a transgenic model of chronic heart failure. Circ Cardiovasc Imaging 2009; 2(6): 468-75.

87. Isobe S, Tsimikas S, Zhou J, Fujimoto S, Sarai M, Branks MJ et al. Noninvasive Imaging of Atherosclerotic Lesions in Apolipoprotein E-Deficient and Low-DensityLipoprotein Receptor-Deficient Mice with Annexin A5. J Nucl Med 2006; 47(9): 1497-1505.

88. Haider N, Hartung D, Fujimoto S, Petrov A, Kolodgie FD, Virmani R et al. Dual molecular imaging for targeting metalloproteinase activity and apoptosis in 
atherosclerosis: molecular imaging facilitates understanding of pathogenesis. $\mathrm{J} \mathrm{Nucl}$ Cardiol 2009.

89. Hartung D, Sarai M, Petrov A, Kolodgie F, Narula N, Verjans J et al. Resolution of apoptosis in atherosclerotic plaque by dietary modification and statin therapy. $\mathrm{J} \mathrm{Nucl}$ Med 2005; 46(12): 2051-6.

90. Wang F, Fang W, Zhao M, Wang Z, Ji S, Li Y et al. Imaging paclitaxel (chemotherapy)-induced tumor apoptosis with $99 \mathrm{mTc}$ C2A, a domain of synaptotagmin I: a preliminary study. Nucl Med Biol 2008; 35(3): 359-64.

91. Cornelissen B, Lahorte C, Kersemans V, Capriotti G, Bonanno E, Signore A et al. In vivo apoptosis detection with radioiodinated Annexin $\mathrm{V}$ in LoVo tumour-bearing mice following Tipifarnib (Zarnestra, R115777) farnesyltransferase inhibitor therapy. Nucl Med Biol 2005; 32(3): 233-9.

92. Weissleder R, Pittet MJ. Imaging in the era of molecular oncology. Nature 2008; 452(7187): 580-9.

93. Kuge Y, Sato M, Zhao S, Takei T, Nakada K, Seki KI et al. Feasibility of 99mTcannexin $\mathrm{V}$ for repetitive detection of apoptotic tumor response to chemotherapy: an experimental study using a rat tumor model. J Nucl Med 2004; 45(2): 309-12.

94. Krishnan AS, Neves AA, de Backer MM, Hu DE, Davletov B, Kettunen MI et al. Detection of cell death in tumors by using MR imaging and a gadolinium-based targeted contrast agent. Radiology 2008; 246(3): 854-62.

95. Manning HC, Merchant NB, Foutch AC, Virostko JM, Wyatt SK, Shah C et al. Molecular Imaging of Therapeutic Response to Epidermal Growth Factor Receptor Blockade in Colorectal Cancer. Clin Cancer Res 2008; 14(22): 7413-7422.

96. Shah C, Miller TW, Wyatt SK, McKinley ET, Olivares MG, Sanchez V et al. Imaging biomarkers predict response to anti-HER2 (ErbB2) therapy in preclinical models of breast cancer. Clin Cancer Res 2009; 15(14): 4712-21.

97. Kartachova MS, Valdes Olmos RA, Haas RL, Hoebers FJ, van Herk M, Verheij M. 99mTc-HYNIC-rh-annexin-V scintigraphy: visual and quantitative evaluation of early treatment-induced apoptosis to predict treatment outcome. Nucl Med Commun 2008; 29(1): 39-44.

98. Rottey S, Loose D, Vakaet L, Lahorte C, Vermeersch H, Van Belle S et al. (99m)TcHYNIC Annexin-V imaging of tumors and its relationship to response to radiotherapy and/or chemotherapy. Q J Nucl Med Mol Imaging 2007.

99. Kurihara H, Yang DJ, Cristofanilli M, Erwin WD, Yu DF, Kohanim S et al. Imaging and dosimetry of 99mTc EC annexin V: preliminary clinical study targeting apoptosis in breast tumors. Appl Radiat Isot 2008; 66(9): 1175-82.

100. Haas RL, de Jong D, Valdes Olmos RA, Hoefnagel CA, van den Heuvel I, Zerp SF et $a l$. In vivo imaging of radiation-induced apoptosis in follicular lymphoma patients. Int J Radiat Oncol Biol Phys 2004; 59(3): 782-7.

101. Loose D, Vermeersch H, De Vos F, Deron P, Slegers G, Van de Wiele C. Prognostic value of $(99 \mathrm{~m}) \mathrm{Tc}-\mathrm{HYNIC}$ Annexin-V imaging in squamous cell carcinoma of the head and neck. Eur J Nucl Med Mol Imaging 2007.

102. Narula J, Acio ER, Narula N, Samuels LE, Fyfe B, Wood D et al. Annexin-V imaging for noninvasive detection of cardiac allograft rejection. Nat Med 2001; 7(12): 134752.

103. Martinet W, Kockx MM. Apoptosis in atherosclerosis: focus on oxidized lipids and inflammation. Curr Opin Lipidol 2001; 12(5): 535-41.

104. Rossig L, Dimmeler S, Zeiher AM. Apoptosis in the vascular wall and atherosclerosis. Basic Res Cardiol 2001; 96(1): 11-22.

105. McCarthy NJ, Bennett MR. The regulation of vascular smooth muscle cell apoptosis. Cardiovasc Res 2000; 45(3): 747-55. 
106. Kietselaer BL, Reutelingsperger CP, Boersma HH, Heidendal GA, Liem IH, Crijns HJ et al. Noninvasive detection of programmed cell loss with 99mTc-labeled annexin A5 in heart failure. J Nucl Med 2007; 48(4): 562-7.

107. Gabrielson KL, Mok GS, Nimmagadda S, Bedja D, Pin S, Tsao A et al. Detection of dose response in chronic doxorubicin-mediated cell death with cardiac technetium 99m annexin V single-photon emission computed tomography. Mol Imaging 2008; 7(3): 132-8.

108. Zhu X, Migrino RQ, Hellman RS, Brahmbhatt T, Zhao M. Early uptake of 99mTc$\mathrm{C} 2 \mathrm{~A}$ in the acute phase of myocardial infarction as a prognostic indicator for followup cardiac dysfunction. Nucl Med Commun 2008; 29(9): 764-9.

109. Dumont EA, Reutelingsperger CP, Smits JF, Daemen MJ, Doevendans PA, Wellens $\mathrm{HJ}$ et al. Real-time imaging of apoptotic cell-membrane changes at the single-cell level in the beating murine heart. Nat Med 2001; 7(12): 1352-5.

110. Fang W, Wang F, Ji S, Zhu X, Meier HT, Hellman RS et al. SPECT imaging of myocardial infarction using $99 \mathrm{mTc}$-labeled C2A domain of synaptotagmin I in a porcine ischemia-reperfusion model. Nucl Med Biol 2007; 34(8): 917-23.

111. Hofstra L, Liem IH, Dumont EA, Boersma HH, van Heerde WL, Doevendans PA et $a l$. Visualisation of cell death in vivo in patients with acute myocardial infarction. Lancet 2000; 356(9225): 209-12.

112. Johnson LL, Schofield L, Donahay T, Narula N, Narula J. 99mTc-Annexin V Imaging for In Vivo Detection of Atherosclerotic Lesions in Porcine Coronary Arteries. J Nucl Med 2005; 46(7): 1186-93.

113. Kolodgie FD, Petrov A, Virmani R, Narula N, Verjans JW, Weber DK et al. Targeting of apoptotic macrophages and experimental atheroma with radiolabeled annexin $\mathrm{V}$ : a technique with potential for noninvasive imaging of vulnerable plaque. Circulation 2003; 108(25): 3134-9.

114. Kietselaer BL, Reutelingsperger CP, Heidendal GA, Daemen MJ, Mess WH, Hofstra L et al. Noninvasive detection of plaque instability with use of radiolabeled annexin A5 in patients with carotid-artery atherosclerosis. N Engl J Med 2004; 350(14): 14723 .

115. Lorberboym M, Feldbrin Z, Hendel D, Blankenberg FG, Schachter P. The use of 99mTc-recombinant human annexin $\mathrm{V}$ imaging for differential diagnosis of aseptic loosening and low-grade infection in hip and knee prostheses. J Nucl Med 2009; 50(4): 534-7.

116. Blankenberg FG, Robbins RC, Stoot JH, Vriens PW, Berry GJ, Tait JF et al. Radionuclide imaging of acute lung transplant rejection with annexin V. Chest 2000; 117(3): 834-40.

117. Kown MH, Strauss HW, Blankenberg FG, Berry GJ, Stafford-Cecil S, Tait JF et al. In vivo imaging of acute cardiac rejection in human patients using $(99 \mathrm{~m})$ technetium labeled annexin V. Am J Transplant 2001; 1(3): 270-7.

118. Van den Brande JM, Koehler TC, Zelinkova Z, Bennink RJ, te Velde AA, ten Cate FJ et al. Prediction of antitumour necrosis factor clinical efficacy by real-time visualisation of apoptosis in patients with Crohn's disease. Gut 2007; 56(4): 509-17.

119. Blankenberg FG, Kalinyak J, Liu L, Koike M, Cheng D, Goris ML et al. 99mTcHYNIC-annexin V SPECT imaging of acute stroke and its response to neuroprotective therapy with anti-Fas ligand antibody. Eur J Nucl Med Mol Imaging 2006; 33(5): 56674.

120. Mari C, Karabiyikoglu M, Goris ML, Tait JF, Yenari MA, Blankenberg FG. Detection of focal hypoxic-ischemic injury and neuronal stress in a rodent model of unilateral MCA occlusion/reperfusion using radiolabeled annexin V. Eur J Nucl Med Mol Imaging 2004; 31(5): 733-9. 
121. Lampl Y, Lorberboym M, Blankenberg FG, Sadeh M, Gilad R. Annexin V SPECT imaging of phosphatidylserine expression in patients with dementia. Neurology 2006; 66(8): 1253-4.

122. Lorberboym M, Blankenberg FG, Sadeh M, Lampl Y. In vivo imaging of apoptosis in patients with acute stroke: Correlation with blood-brain barrier permeability. Brain Res 2006; 1103(1): 13-9.

123. Schmitz-Valckenberg S, Guo L, Maass A, Cheung W, Vugler A, Moss SE et al. Realtime in vivo imaging of retinal cell apoptosis after laser exposure. Invest Ophthalmol Vis Sci 2008; 49(6): 2773-80.

124. Cordeiro M, Guo1 L, Coxon K, Duggan J, Nizari S, Normando E et al. Imaging multiple phases of neurodegeneration: a novel approach to assessing cell death in vivo. Citation: Cell Death and Disease (2010) 1, e3; doi:10.1038/cddis.2009.32010.

125. Post AM, Katsikis PD, Tait JF, Geaghan SM, Strauss HW, Blankenberg FG. Imaging cell death with radiolabeled annexin $\mathrm{V}$ in an experimental model of rheumatoid arthritis. J Nucl Med 2002; 43(10): 1359-65.

126. Medarova Z, Bonner-Weir S, Lipes M, Moore A. Imaging beta-cell death with a nearinfrared probe. Diabetes 2005; 54(6): 1780-8.

127. Kenis H, Reutelingsperger C. Targeting phosphatidylserine in anti-cancer therapy. Curr Pharm Des 2009; 15(23): 2719-23.

128. Kenis H, Hofstra L, Reutelingsperger CP. Annexin A5: shifting from a diagnostic towards a therapeutic realm. Cell Mol Life Sci 2007; 64(22): 2859-62.

129. Ran S, Thorpe PE. Phosphatidylserine is a marker of tumor vasculature and a potential target for cancer imaging and therapy. Int J Radiat Oncol Biol Phys 2002; 54(5): 1479-84.

130. Kenis H, Zandbergen HR, Hofstra L, Petrov AD, Dumont EA, Blankenberg FD et al. Annexin a5 uptake in ischemic myocardium: demonstration of reversible phosphatidylserine externalization and feasibility of radionuclide imaging. $\mathrm{J} \mathrm{Nucl} \mathrm{Med}$ 2010; 51(2): 259-67.

131. Tait JF, Engelhardt S, Smith C, Fujikawa K. Prourokinase-annexin V chimeras. Construction, expression, and characterization of recombinant proteins. J Biol Chem 1995; 270(37): 21594-9.

132. Tanaka K, Einaga K, Tsuchiyama H, Tait JF, Fujikawa K. Preparation and characterization of a disulfide-linked bioconjugate of annexin $\mathrm{V}$ with the B-chain of urokinase: an improved fibrinolytic agent targeted to phospholipid-containing thrombi. Biochemistry 1996; 35(3): 922-9.

133. Huang X, Ding WQ, Vaught JL, Wolf RF, Morrissey JH, Harrison RG et al. A soluble tissue factor-annexin $\mathrm{V}$ chimeric protein has both procoagulant and anticoagulant properties. Blood 2006; 107(3): 980-6.

134. van Genderen HO, Kenis H, Hofstra L, Narula J, Reutelingsperger CP. Extracellular annexin A5: Functions of phosphatidylserine-binding and two-dimensional crystallization. Biochim Biophys Acta 2008; 1783(6): 953-63.

135. Kuypers FA, Larkin SK, Emeis JJ, Allison AC. Interaction of an annexin V homodimer (Diannexin) with phosphatidylserine on cell surfaces and consequent antithrombotic activity. Thromb Haemost 2007; 97(3): 478-486.

136. Huang X, Bennett M, Thorpe PE. A monoclonal antibody that binds anionic phospholipids on tumor blood vessels enhances the antitumor effect of docetaxel on human breast tumors in mice. Cancer Res 2005; 65(10): 4408-16.

137. He J, Luster TA, Thorpe PE. Radiation-enhanced vascular targeting of human lung cancers in mice with a monoclonal antibody that binds anionic phospholipids. Clin Cancer Res 2007; 13(17): 5211-8. 



\section{CHAPTER 2}

\section{PLASMA ANNEXIN A5 LEVELS PREDICT MORTALITY IN PATIENTS WITH HEART FAILURE}

Based on: Plasma annexin A5 levels predict mortality in patients with heart failure. Leon J. Schurgers, Thor Ueland, Kristof Schutters, Svend Aakhus, Mathias Burgmaier, Leo Hofstra, Lars Gullestad, Pål Aukrust, Jagat Narula, Chris P. Reutelingsperger. Submitted for publication 


\section{ABSTRACT}

Objective: To determine the association between circulating annexin A5 (anxA5) levels and clinical outcome in high risk patients with heart failure (HF).

Background: Cardiomyocyte apoptosis is associated with progression of HF. Stressed cardiomyocytes express reversibly the 'eat me' signal phosphatidylserine (PS) on the sarcolemma. AnxA5 is a PS binding protein that inhibits PS-dependent phagocytosis. Here we investigated the relationship between levels of plasma anxA5 and mortality of HF patients.

Methodology/Principal findings: We measured plasma levels of anxA5, N-terminal fragment of pro-B-type natriuretic peptide (NT-proBNP) and C-reactive protein (CRP) in 179 patients with both ischemic and dilative HF (ages, 56 \pm 13 years; Male:Female, 140:39; New York Heart Association class II-IV), and followed the patients up for a period of 7.5 years with death as endpoint. anxA5 levels were significantly elevated in all stages of HF compared to control subjects. Uni and multivariate regression analysis demonstrated that anxA5 is a strong predictor of all-cause mortality and independent of clinical, functional and biochemical measures of HF including NT-proBNP and CRP.

Conclusion: A single measurement of plasma anxA5 at the time of enrollment provides strong independent information to predict mortality in high risk HF patients.

\section{INTRODUCTION}

Heart Failure (HF) is a complex disease with various etiologies and associated with a high morbidity and mortality. Circulating biomarkers are evaluated to assess risk of mortality, to guide treatment intensity and to facilitate decisions for disease management in HF. In addition to the established biomarkers BNP and NT-proBNP ${ }^{1}$ a variety of novel candidate biomarkers have emerged that represent different biological processes in the myocardium ${ }^{2,3}$. Apoptosis is believed to account for loss of functional cardiomyocytes and to contribute to pathogenesis and progression of $\mathrm{HF}^{4-6}$. Apoptosis is a gene-regulated process of cell suicide executed by a core cell death machinery comprised of caspases and regulated by intra- and extracellular inhibitors and activators ${ }^{7}$. It was demonstrated that pro-apoptotic activity of serum predicts mortality of HF patients indicating a relationship between soluble apoptotic factors and disease $^{8}$. Soluble factors related to extrinsic activation of apoptosis have been shown to have a predictive value for adverse outcomes in heart disease. However, the unraveled relationships are not expected on basis of the pro- and anti-apoptotic activities of the markers. Soluble Fas (sFas), an inhibitor of cardiomyocyte apoptosis 9,10 , correlates positively with unfavorable prognosis of patients with advanced HF whereas levels of soluble TRAIL, an enhancer of stretch-induced apoptosis of cardiomyocytes ${ }^{11}$, inversely associates with clinical events in these patients ${ }^{12}$. These findings indicate a complex relationship between circulating markers of the extrinsic pathway of apoptosis and HF.

In this paper we addressed the clearance pathway of apoptotic cells as possible source for predictive biomarkers of apoptosis. During apoptosis cells express "find me" and "eat me" signals to attract phagocytes and to trigger removal by phagocytosis ${ }^{13}$. Cell surface expressed phosphatidylserine (PS) is the best characterized "eat me" signal ${ }^{13,14}$ that is also present on apoptotic cardiomyocytes in the myocardium ${ }^{15}$. Recently it was postulated that stressed cardiomyocytes of the failing heart can initiate apoptosis without progressing towards full execution ${ }^{16}$. Accordingly it was demonstrated that stressed cardiomyocytes in vivo express $\mathrm{PS}$ in a caspase 3 -dependent manner while remaining viable ${ }^{17}$. Activated caspase 3 was unraveled as master switch that controls death and survival pathways in stressed 
cardiomyocytes ${ }^{18}$. These new insights indicate towards mechanisms that protect stressed, PS expressing cardiomyocytes from being engulfed.

Annexin A5 (anxA5), a $36 \mathrm{kDa}$ protein of the annexin multigene family, binds PS with high affinity ${ }^{19}$, inhibits phagocytosis of PS expressing cells ${ }^{20}$, delays apoptosis ${ }^{21}$ and promotes repair of injured cellular membranes ${ }^{22}$. AnxA5 levels are increased in plasma of patients with hypertensive heart disease and in the myocardium of these patients in the absence of upregulation of myocardial anxA5 mRNA ${ }^{23}$. We postulated that increases in circulating anxA5 represent defense mechanisms for PS expressing stressed cardiomyocytes, and hypothesized that circulating anxA5 levels reflect risk of mortality for HF patients. We therefore measured anxA5 levels as a potential biomarker of disease progression in patients with chronic HF. anxA5 levels were compared to etiology, New York Heart Association (NYHA) classification, LV function and circulating biomarkers including NT-proBNP and CRP.

\section{MATERIALS AND METHODS}

Patients - 179 consecutive patients (ages, 56 \pm 13 years; M:F, 140:39) with preexisting HF for at least 6-month duration were included in the study (Table 1). Patients who sustained acute coronary syndrome during the last 6 months and those with significant comorbid conditions, such as infection, malignancy, or autoimmune disease, were excluded. The etiology of HF was determined on the basis of disease history, coronary angiography and echocardiography. 76 patients had ischemic, 94 dilated cardiomyopathy and 9 patients had other etiologies of HF. The patients were New York Heart Association (NYHA) functional class II-IV symptomatic. The study also included 33 age- and sex-matched healthy individuals (mean age $56 \pm 7$ years) as a control population for comparison.

Ethics Statement - The study was approved by the local ethical committee (Regional ethics committee of Helse Sør-Øst; Permit number S-05172) and conducted according to the ethical guidelines outlined in the Declaration of Helsinki for use of human tissue and subjects. Informed written consent was obtained from all subjects. Inability and unwillingness to participate and to provide voluntary consent were considered strict exclusion criteria.

Blood sampling and biochemistry - Blood was collected from the anticubital vein, drawn into chilled glass tubes containing EDTA $(1 \mathrm{mg} / \mathrm{mL}$ blood $)$ and placed on ice, centrifuged within 20 minutes at $4^{\circ} \mathrm{C}(2000 \mathrm{~g}$ in 20 minutes $)$ before plasma was aspirated and stored at $80^{\circ} \mathrm{C}$ until use. Samples were submitted to 3 cycles of thawing/freezing before measurement. Plasma anxA5 was measured using a commercial enzyme immunoassay (Hyphen BioMed, Neuville-sur-Oise, France) according to the instructions of the manufacturers. Intra- and interassay coefficients of variation amounted $1.4 \%$ and $3.8 \%$ for anxA5. NT-pro-BNP and high-sensitivity CRP were assayed on a MODULAR platform (Roche Diagnostics, Basel, Switzerland). Plasma levels of low-density lipoprotein (LDL) cholesterol, high-density lipoprotein (HDL) cholesterol and creatinine were measured enzymatically on a Roche/Hitachi 917 analyzer (Roche Diagnostics, Mannheim, Germany). Estimated glomerular filtration rate (eGFR) was calculated based on the Cockcroft-Gault formula.

Echocardiography - Conventional echocardiographic imaging of the heart was performed from parasternal and apical views by use of a GE Vivid 7 ultrasonic digital scanner (GE Vingmed, Horten, Norway). Two-dimensional images were obtained, M-mode and color Doppler as well as pulsed wave Doppler recordings of blood flow velocities in the LV outflow tract. Doppler echocardiographic calculations of stroke volume and cardiac output 
were performed on the basis of the cross-sectional area of flow and aortic annular flow velocity data. LV regional wall motion was analyzed in a 16 segment model excluding the apical cap. LV ejection fraction (LVEF) was obtained by the biplane Simpson method ${ }^{24}$. We have previously reported inter- and intraobserver variability for EF of $1.1 \pm 4.9 \%($ mean \pm SD) and $2.5 \pm 4.2 \%$, and interobserver variability for WMSI of $0.04 \pm 0.13^{25}$.

Statistical analysis - Differences between groups were analyzed with unpaired parametric or non-parametric tests depending on distribution (assessed with the D'Agostino \& Pearson omnibus normality test) and number of groups. Proportions were compared using the chi square test. The relationship between quartiles of anxA5 and all-cause mortality and the combination of all-cause and anticipated mortality (i.e. heart transplantation) were visualized by Kaplan-Meier plots. The importance of anxA5 as a risk factor for mortality was investigated by Cox proportional hazard analysis including variables associated with anxA5 levels (Table 1) or variables imbalanced between survivors and non-survivors (Table 2): age, etiology, NYHA class, eGFR, CRP and NT-proBNP. P values are two-sided and considered significant when $<0.05$.

\section{RESULTS}

AnxA5 levels in healthy subjects and HF patients - We firstly measured normal range of circulating anxA5 in 33 healthy subjects (age 56 \pm 7 years). The anxA5 level of the control group was $0.47 \pm 0.29 \mathrm{ng} / \mathrm{mL}$ (mean $\pm \mathrm{SD}$ ). Median [and interquartile range (IQR)] circulating anxA5 level in $179 \mathrm{HF}$ patients was 1.37 [IQR $0.94,2.06$ ] $\mathrm{ng} / \mathrm{mL}$, which is significantly higher than median anxA5 levels in healthy subjects 0.44 [0.24,0.54] (Figure 1). All HF patients showed markedly elevated anxA5 levels irrespective of NYHA classification and etiology (Table 1). There was a trend indicating increasing anxA5 levels with severity of heart disease (NHYA classification) $(\mathrm{p}=0.064$, Table 1$)$. No significant differences were observed between quartiles of anxA5 and markers of inflammation and neurohormonal activation (CRP and NT-proBNP), cardiac function or medication, except for an association between high anxA5 levels and low eGFR (Table 1).

Patient outcome and anxA5 levels - Of 179 HF patients, 59 patients died $(n=48)$ or underwent heart transplantation (i.e. anticipated mortality, $\mathrm{n}=11$ ) during a follow-up period of 6.5 [IQR 2.7,6.3] years. As shown in Table 3, non-survivors were older, had a higher proportion of CAD and NYHA III and IV (compared to NYHA II). Further, they had a lower eGFR and increased levels of CRP and NT-proBNP (Table 2). Finally, non-survivors more frequently used aldosteron antagonists, diuretics and statins (Table 2). When investigating anxA5 levels in relation to adverse outcome we found that non-survivors displayed elevated levels of anxA5 compared to survivors, $1.68[1.16,2.95]$ vs. $1.22[0.89,1.86] \mathrm{p}=0.002$. Kaplan-Meier analyses demonstrated higher mortality with increased AnxA5 levels, particularly in the fourth quartile in relation to all-cause mortality (Figure 1A) and allcause/anticipated mortality (Figure 1B).

Table 3 summarizes uni- and multi-variable analyses of predictors of all-cause and anticipated mortality. Univariate predictors included in these models were those that were either associated with elevated anxA5 levels (i.e. eGFR, Table 1) or imbalanced between survivors and non-survivors (Table 2). These variables included age, etiology, NYHA class, eGFR, CRP and NT-proBNP and anxA5, with continuous variables entered log transformed and expressed per $1 \mathrm{SD}$ change. Forced multi-variable cox-regression indicated that anxA5 together with eGFR and NYHA were the strongest predictors of both all-cause mortality and all-cause/anticipated mortality. 
Table 1: Characteristics of the study population $(n=$ significantly elevated in patients with heart failure significantly elevated in patients with heart failure) according to anxA5 levels (quartiles); CAD, coronary artery disease; CRP, C-reactive protein; DM2, diabetes mellitus type 2; eGFR, estimated glomerular filtration rate; HF, heart failure; IDCM, idiopathic dilated cardiomyopathy; LV, left ventricular; LVEF, LV ejection fraction; LVEDV, LV end-diastolic volume; LVEDS, LVEDV, LV end-systolic volume; NT-proBNP, N-terminal pro-brain natriuretic peptide; NYHA, New York Heart Association; WMSI, wall motion score index. Continuous data are given as mean $\pm \mathrm{SD}$ or median and interquartile range depending on distribution.

\begin{tabular}{|c|c|c|c|c|c|}
\hline & $\begin{array}{l}\text { AnxA5 Q1 } \\
(\leq 0.94) \\
(\mathrm{n}=44)\end{array}$ & $\begin{array}{l}\text { AnxA5 Q2 } \\
(0.95-1.37) \\
(\mathrm{n}=46)\end{array}$ & $\begin{array}{l}\text { AnxA5 Q3 } \\
(1.38-2.05) \\
(n=45)\end{array}$ & $\begin{array}{l}\text { AnxA5 Q4 } \\
(>2.06) \\
(n=44)\end{array}$ & P-value \\
\hline Age & $56 \pm 11$ & $57 \pm 12$ & $56 \pm 14$ & $55 \pm 14$ & 0.94 \\
\hline Male (\%) & $33(75)$ & $38(83)$ & $37(84)$ & $31(71)$ & 0.36 \\
\hline $\begin{array}{lc}\text { Cause } & \text { of } \\
\text { CAD/IDCM/other }\end{array} \quad$ HF, & $16 / 27 / 1$ & $18 / 24 / 4$ & $18 / 23 / 4$ & $24 / 20 / 0$ & 0.25 \\
\hline NYHA class II/III/IV & $19 / 13 / 12$ & $13 / 19 / 14$ & $9 / 23 / 13$ & $9 / 26 / 9$ & 0.064 \\
\hline Hypertension, $\mathrm{n}(\%)$ & $6(14)$ & $9(20)$ & $5(12)$ & $6(14)$ & 0.74 \\
\hline DM2, n (\%) & $5(11)$ & $7(15)$ & $5(12)$ & $5(11)$ & 0.93 \\
\hline Previous Infarction, n (\%) & $16(36)$ & $18(39)$ & $13(30)$ & $14(32)$ & 0.80 \\
\hline $\operatorname{LVEF}(\%)$ & $28(21,42)$ & $30(20,39)$ & $27(20,36)$ & $29(21,40)$ & 0.84 \\
\hline LVEDV & $218(150,278)$ & $215(155,306)$ & $212(168,302)$ & $214(146,288)$ & 0.90 \\
\hline LVESV & $149(97,213)$ & $157(95,243)$ & $166(109,245)$ & $172(95,204)$ & 0.87 \\
\hline WMSI & $2.3(1.9,2.4)$ & $2.3(2.0,2.5)$ & $2.4(2.0,2.5)$ & $2.3(1.8,2.4)$ & 0.64 \\
\hline Cardiac Index & $2.0(1.7,2.4)$ & $1.9(1.8,2.2)$ & $2.0(1.4,2.5)$ & $1.8(1.5,2.2)$ & 0.32 \\
\hline \multicolumn{6}{|l|}{ Biochemistry } \\
\hline $\mathrm{eGFR}(\mu M)$ & $87(71,100)$ & $72(49,91)$ & $72(51,91)$ & $78(64,96)$ & 0.038 \\
\hline $\mathrm{CRP}(\mathrm{mg} / \mathrm{L})$ & $3.0(1.4,5.6)$ & $3.5(1.4,7.9)$ & $3.0(1.8,5.7)$ & $4.5(2.1,10.7)$ & 0.39 \\
\hline NT-proBNP (pM) & $204(71,314)$ & $275(57,466)$ & $309(134,547)$ & $277(288,533)$ & 0.23 \\
\hline White blood count & $6.7(5.7,8.1)$ & $7.3(6.3,8.6)$ & $6.8(5.6,7.9)$ & $7.4(6.2,9.6)$ & 0.15 \\
\hline \multicolumn{6}{|l|}{ Medication, $\mathrm{n}$} \\
\hline $\mathrm{ACE}$ or $\mathrm{ARB}, \mathrm{n}(\%)$ & $37(84)$ & $41(89)$ & $37(82)$ & $38(86)$ & 0.81 \\
\hline Aldost. antagonist, $\mathrm{n}(\%)$ & $13(30)$ & $16(35)$ & $23(52)$ & $23(52)$ & 0.055 \\
\hline $\mathrm{BB}, \mathrm{n}(\%)$ & $34(77)$ & $35(76)$ & $38(86)$ & $36(82)$ & 0.60 \\
\hline Diuretics, n (\%) & $28(64)$ & $33(72)$ & $38(86)$ & $28(64)$ & 0.060 \\
\hline Statins, n (\%) & $18(41)$ & $19(41)$ & $18(41)$ & $23(52)$ & 0.64 \\
\hline Warfarin, $\mathrm{n}(\%)$ & $14(32)$ & $21(46)$ & $21(48)$ & $20(46)$ & 0.41 \\
\hline ASA, n $(\%)$ & $23(52)$ & $17(37)$ & $18(41)$ & $19(43)$ & 0.51 \\
\hline
\end{tabular}


Table 2: Characteristics of the study population $(\mathrm{n}=176)$ according to long-term survival; CAD, coronary artery disease; CRP, C-reactive protein; DM2, diabetes mellitus type 2; eGFR, estimated glomerular filtration rate; HF, heart failure; IDCM, idiopathic dilated cardiomyopathy; LV, left ventricular; LVEF, LV ejection fraction; LVEDV, LV end-diastolic volume; LVEDS, LVEDV, LV end-systolic volume; NT-proBNP, N-terminal pro-brain natriuretic peptide; NYHA, New York Heart Association; WMSI, wall motion score index. Continuous date are given as mean \pm SD or median and interquartile range depending on distribution.

\begin{tabular}{llll}
\hline & $\begin{array}{l}\text { Survivors } \\
(\mathrm{n}=131)\end{array}$ & $\begin{array}{l}\text { Non-survivors } \\
(\mathrm{n}=48)\end{array}$ & P-value \\
\hline Age & $54 \pm 13$ & $60 \pm 12$ & 0.007 \\
Male $(\%)$ & $103(79)$ & $36(77)$ & 0.77 \\
Cause of HF, CAD/IDCM/other & $47 / 78 / 6$ & $29 / 16 / 3$ & 0.014 \\
NYHA class II/III/IV & $46 / 57 / 28$ & $4 / 24 / 20$ & 0.001 \\
Hypertension, n (\%) & $19(15)$ & $7(15)$ & 0.96 \\
DM2, n $(\%)$ & $13(10)$ & $9(19)$ & 0.10 \\
Previous Infarction, n $(\%)$ & $41(32)$ & $20(43)$ & 0.17 \\
LVEF $(\%)$ & $28(20,40)$ & $29(23,35)$ & 0.38 \\
LVEDV & $211(151,292)$ & $252(146,288)$ & 0.84 \\
LVESV & $148(95,227)$ & $170(110,204)$ & 0.87 \\
WMSI & $2.3(1.9,2.5)$ & $2.3(2.1,2.5)$ & 0.66 \\
Cardiac Index & $2.0(1.6,2.4)$ & $1.9(1.6,2.3)$ & 0.95 \\
\hline Biochemistry & & & \\
AnxA5 (ng/ml) & $1.22(0.89,1.86)$ & $1.68(1.16,2.95)$ & 0.002 \\
eGFR ( $\mu M)$ & $79(64,97)$ & $68(47,92)$ & 0.013 \\
CRP $(m g / L)$ & $3.0(1.4,6.0)$ & $4.7(2.1,11.0)$ & 0.016 \\
NT-proBNP (pM) & $206(58,427)$ & $305(196,602)$ & 0.008 \\
White blood count & $7.1(5.9,8.5)$ & $7.3(6.5,8.6)$ & 0.29 \\
\hline & & & \\
Medication, n & $112(86)$ & $41(85)$ & 0.99 \\
ACE or ARB, n $(\%)$ & $48(37)$ & $27(56)$ & 0.020 \\
Aldost. antagonist, n $(\%)$ & $104(80)$ & $39(81)$ & 0.85 \\
BB, n $(\%)$ & $87(67)$ & $40(83)$ & 0.032 \\
Diuretics, n $(\%)$ & $51(39)$ & $27(56)$ & 0.042 \\
Statins, n $(\%)$ & $51(39)$ & $35(52)$ & 0.12 \\
Warfarin, n $(\%)$ & $59(45)$ & $18(38)$ & 0.35 \\
ASA, n $(\%)$ & & &
\end{tabular}


Table 3. Multi-variable analyses: anxA5 as a predictor of adverse outcome in patients with chronic HF.

\begin{tabular}{|c|c|c|c|c|c|c|c|c|}
\hline \multirow[b]{3}{*}{ Variable } & \multicolumn{4}{|c|}{ All-cause mortality } & \multicolumn{4}{|c|}{ All-cause mortality/HTx } \\
\hline & \multicolumn{2}{|l|}{ Unadjusted } & \multicolumn{2}{|l|}{ Forced } & \multicolumn{2}{|l|}{ Unadjusted } & \multicolumn{2}{|l|}{ Forced } \\
\hline & $\begin{array}{l}\mathrm{HR} \\
(95 \% \mathrm{CI})\end{array}$ & $\mathrm{p}$ & $\begin{array}{l}\mathrm{HR} \\
(95 \% \mathrm{CI})\end{array}$ & $\mathrm{P}$ & $\begin{array}{l}\mathrm{HR} \\
(95 \% \mathrm{CI})\end{array}$ & $\mathrm{p}$ & $\begin{array}{l}\mathrm{HR} \\
(95 \% \mathrm{CI})\end{array}$ & $\mathrm{p}$ \\
\hline Age/10 & $1.41(1.07-1.85)$ & 0.015 & $1.30(0.95-1.77)$ & 0.10 & $1.26(1.00-1.60)$ & 0.055 & $1.15(0.88-1.50)$ & 0.37 \\
\hline NYHA & $2.48(1.64-3.76)$ & $<0.001$ & $2.32(1.43-3.78)$ & 0.001 & $2.78(1.89-4.07)$ & $<0.001$ & $2.54(1.63-3.96)$ & $<0.001$ \\
\hline Etiology (vs. CAD) & $0.56(0.33-0.96)$ & 0.033 & $0.68(0.39-1.16)$ & 0.68 & $0.56(0.35-0.91)$ & 0.019 & $0.67(0.41-1.08)$ & 0.10 \\
\hline$\left[\log _{\mathrm{e}}\right]$ eGFR & $0.66(0.52-0.84)$ & 0.001 & $0.66(0.48-0.92)$ & 0.013 & $0.66(0.53-0.82)$ & $<0.001$ & $0.67(0.50-0.90)$ & 0.008 \\
\hline$\left[\log _{e}\right] \mathrm{CRP}$ & $1.31(1.01-1.71)$ & 0.042 & $1.04(0.76-1.44)$ & 0.79 & $1.29(1.02-1.64)$ & 0.034 & $0.99(0.74-1.31)$ & 0.99 \\
\hline [Loge $]$ NT-proBNP & $1.72(1.24-2.39)$ & 0.001 & $1.16(0.77-1.75)$ & 0.48 & $1.86(1.38-2.53)$ & 0.001 & $1.30(0.89-1.89)$ & 0.17 \\
\hline$\left[\log _{e}\right]$ anxA5 & $1.64(1.23-2.20)$ & 0.001 & $1.58(1.17-2.12)$ & 0.003 & $1.47(1.13-1.90)$ & 0.004 & $1.42(1.09-1.86)$ & 0.010 \\
\hline
\end{tabular}

AnxA5, annexin 5; CRP, C-reactive protein; eGFR, estimated glomerular filtration rate; MI, myocardial infarction; NYHA,

New York Heart Association; NT-proBNP, N-terminal pro-brain natriuretic peptide. The inclusion of medication that was associated with mortality from table 1, or LVEF, had no impact on the regression analysis. Continous variablers expressed per 1 SD. 

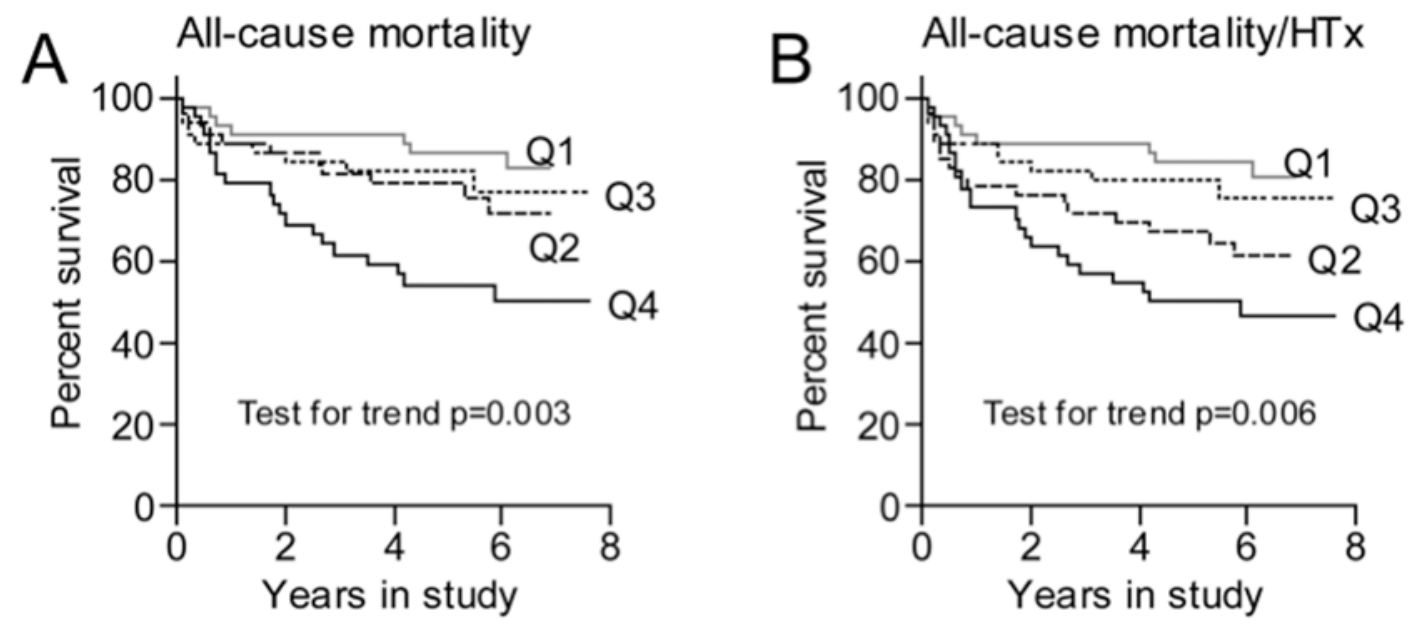

Figure 1. Plasma anxA5 and mortality in HF patients. Kaplan-Meier plot for the association between quarterly increases in anxA5 (A) and incidence of all-cause/anticipated mortality (i.e. heart transplantation, HTx) (B).

\section{DISCUSSION}

The present study evaluated circulating anxA5 as a biomarker in HF. We hypothesized that circulating levels of anxA5 contribute to preventing stressed cardiomyocytes with active caspase 3 and externalized PS from execution of apoptosis. Apoptosis is appreciated as an important process in the pathogenesis of $\mathrm{HF}^{5,6}$. It is accompanied by cytochrome c release, activation of caspase 3 and cell surface expression of PS ${ }^{26}$. All three phenomena were observed in the failing heart ${ }^{4,27}$ and in contrast to general belief, presence of these phenomena not necessarily signifies death of cardiomyocytes ${ }^{17,28}$. In stead, stressed cardiomyocytes utilize active caspase 3 as master switch to divert from apoptosis by activating the survival factor Akt ${ }^{18}$. There is simultaneous upregulation of multiple antiapoptotic survival factors (such as XIAP) and downregulation of pro-apoptotic factors (such as DIABLO). Active caspase 3 also drives reversible externalization of PS by cardiomyocytes exposed to mild hypoxia ${ }^{17}$. Cell surface expressed PS attracts phagocytes for engulfment of the PS expressing cell ${ }^{13}$. The externalized PS catalyzes thrombin generation in the presence of myocardial Tissue Factor (TF) ${ }^{29,30}$, and create a potentially pro-inflammatory environment resulting in engulfment if cell surface expressed PS is not concealed. We argued that anxA5 may contribute to dampening adverse effects of PS on the surface of stressed cardiomyocytes. I) anxA5 is a normally circulating protein that accumulates in end-stage human failing heart 31. II) anxA5 binds with high affinity to the anionic cell membrane PS ${ }^{32}$ and inhibits engulfment of PS expressing cells ${ }^{33,34}$ and the PS-dependent TF pathway leading to thrombin formation ${ }^{35}$. III) Extracellular anxA5 is part of a membrane-repair kit that protects cardiomyocytes from irreversible damage to the sarcolemma ${ }^{36}$. IV) AnxA5 inhibits progression of an activated apoptotic programme ${ }^{21}$. Hence, circulating anxA5 levels may reflect the need of salvaging stressed cardiomyocytes. A recent imaging and immunopathology study support this proposal substantially ${ }^{37}$. Radiolabeled anxA5 was administered to patients with decompensated HF; $60 \%$ of patients demonstrated significant anxA5 uptake and a 10\% absolute decrease in LVEF upon one-year follow up. The patients with no anxA5 uptake recovered their LVEF by a mean of $7 \%$. 
Therefore we explored a possible relationship between circulating anxA5 levels and mortality of HF patients. We measured anxA5 levels in EDTA-anticoagulated blood in order to dissociate anxA5 from PS exposing structures such as microparticles and activated cells. Interestingly, the mean level of anxA5 in healthy subjects in our study was lower as compared to other studies ${ }^{23}$. The difference likely resulted from differences in blood sample handling. We observed that the procedure of blood sampling influenced measured anxA5 levels and that reproducible results with low variance were obtained by collecting blood in EDTA-containing chilled glass tubes and preparing plasma at temperature between 0 and $4^{\circ} \mathrm{C}$.

The findings of the current study demonstrate that plasma anxA5 levels are significantly elevated in patients with HF (NYHA classes II-IV) as compared with healthy controls. Moreover, anxA5 was a strong and independent predictor of adverse outcome, even after adjusting for established clinical, hemodynamic and neurohormonal parameters including NTproBNP. An intriguing finding in the present study was that although anxA5 was a strong predictor of adverse outcome in this HF population, we found no association between anxA5 levels and established clinical, functional and biochemical HF measures. The reason for this finding is not entirely clear, but could indicate that anxA5 reflects part of the HF pathophysiology involving cell surface expressed PS which does not vary substantially with transient changes in clinical status or natriuretic peptide levels that track acute status changes.

Hence, by its ability to reflect specific pathogenic pathways in the progression of HF, anxA5 could give added prognostic information in patients with chronic HF beyond that of established biomarkers and may provide rationalized strategies to treat HF by targeting cell surface expressed PS (Figure 2).

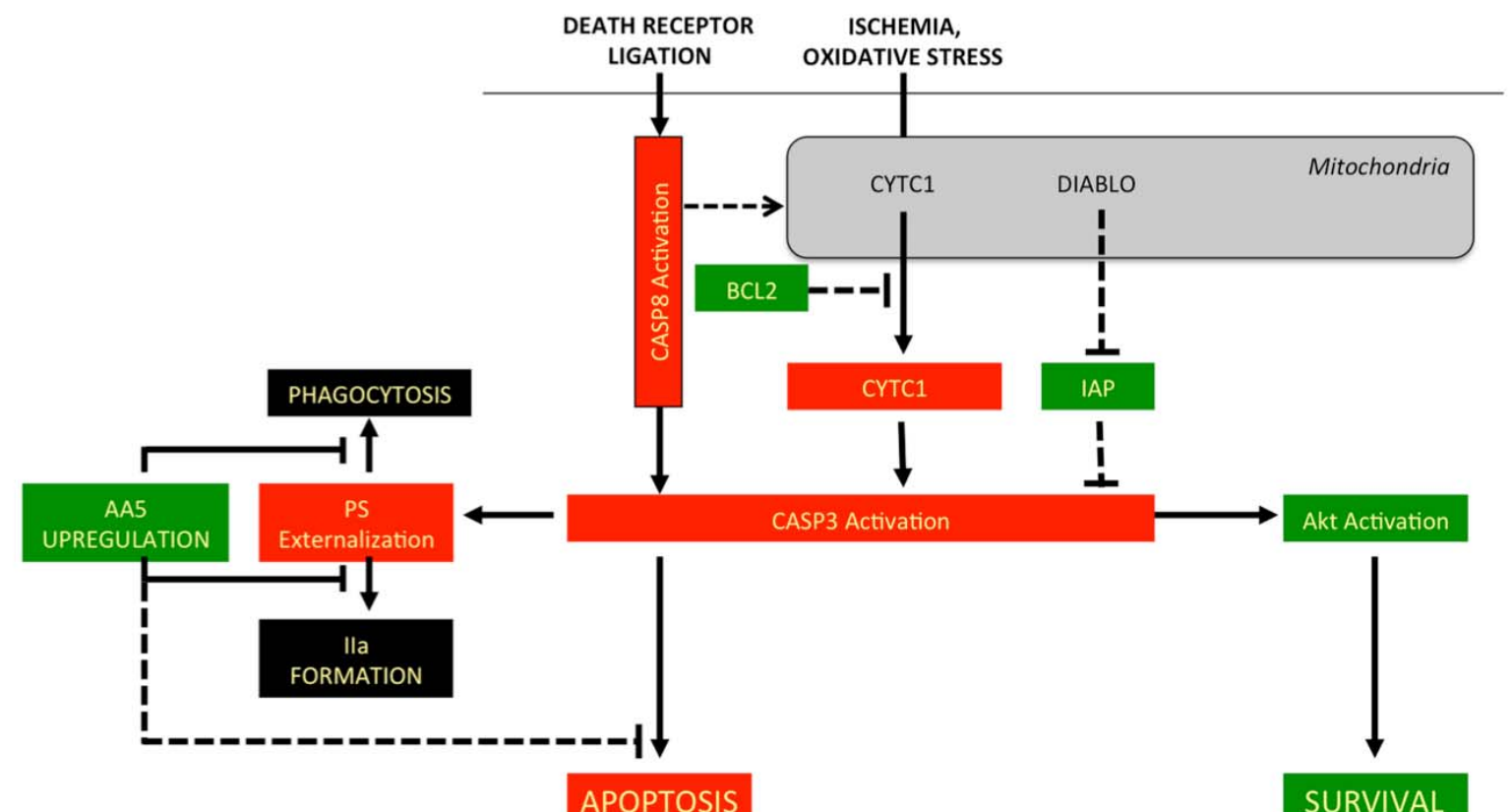

Figure 2. Schematic presentation of anxA5's contribution to decision of life and death of stressed cardiomyocytes. CASP, caspase; CYTC1, cytochrome c; IAP, inhibitor of apoptosis protein; Akt, Protein Kinase B; AA5, annexin A5; PS, phosphatidylserine; IIa, thrombin. 


\section{ACKNOWLEDGMENT}

The authors thank Petra Lux for her excellent technical assistance.

\section{DISCLOSURES}

None

\section{REFERENCES}

1. Jessup M, Abraham WT, Casey DE, Feldman AM, Francis GS, Ganiats TG et al. 2009 focused update: ACCF/AHA Guidelines for the Diagnosis and Management of Heart Failure in Adults: a report of the American College of Cardiology Foundation/American Heart Association Task Force on Practice Guidelines: developed in collaboration with the International Society for Heart and Lung Transplantation. Circulation 2009; 119(14): 1977-2016.

2. Kalogeropoulos AP, Georgiopoulou VV, Butler J. Clinical adoption of prognostic biomarkers: the case for heart failure. Prog Cardiovasc Dis 2012; 55(1): 3-13.

3. van Kimmenade RR, Januzzi JL, Jr. Emerging biomarkers in heart failure. Clinical chemistry 2012; 58(1): $127-38$.

4. Narula J, Pandey P, Arbustini E, Haider N, Narula N, Kolodgie FD et al. Apoptosis in heart failure: release of cytochrome $\mathrm{c}$ from mitochondria and activation of caspase-3 in human cardiomyopathy. Proc Natl Acad Sci U S A 1999; 96(14): 8144-9.

5. Olivetti G, Abbi R, Quaini F, Kajstura J, Cheng W, Nitahara JA et al. Apoptosis in the failing human heart. The New England journal of medicine 1997; 336(16): 1131-41.

6. Narula J, Haider N, Virmani R, DiSalvo TG, Kolodgie FD, Hajjar RJ et al. Apoptosis in myocytes in end-stage heart failure. The New England journal of medicine 1996; 335(16): 1182-9.

7. Hengartner MO. The biochemistry of apoptosis. Nature 2000; 407(6805): 770-6.

8. Rossig L, Fichtlscherer S, Heeschen C, Berger J, Dimmeler S, Zeiher AM. The pro-apoptotic serum activity is an independent mortality predictor of patients with heart failure. European heart journal 2004; 25(18): 1620-5.

9. Cheng J, Zhou T, Liu C, Shapiro JP, Brauer MJ, Kiefer MC et al. Protection from Fas-mediated apoptosis by a soluble form of the Fas molecule. Science 1994; 263(5154): 1759-62.

10. Wollert KC, Heineke J, Westermann J, Ludde M, Fiedler B, Zierhut W et al. The Cardiac Fas (APO1/CD95) Receptor/Fas Ligand System : Relation to Diastolic Wall Stress in Volume-Overload Hypertrophy In Vivo and Activation of the Transcription Factor AP-1 in Cardiac Myocytes. Circulation 2000; 101(10): 1172-1178.

11. Liao X, Wang X, Gu Y, Chen Q, Chen LY. Involvement of death receptor signaling in mechanical stretch-induced cardiomyocyte apoptosis. Life sciences 2005; 77(2): 160-74.

12. Niessner A, Hohensinner PJ, Rychli K, Neuhold S, Zorn G, Richter B et al. Prognostic value of apoptosis markers in advanced heart failure patients. European heart journal 2009; 30(7): 789-96.

13. Ravichandran KS. Beginnings of a good apoptotic meal: the find-me and eat-me signaling pathways. Immunity 2011; 35(4): 445-55.

14. Fadok VA, Bratton DL, Frasch SC, Warner ML, Henson PM. The role of phosphatidylserine in recognition of apoptotic cells by phagocytes. Cell death and differentiation 1998; 5(7): 551-62.

15. Dumont EA, Reutelingsperger CP, Smits JF, Daemen MJ, Doevendans PA, Wellens HJ et al. Real-time imaging of apoptotic cell-membrane changes at the single-cell level in the beating murine heart. Nat Med 2001; 7(12): 1352-5.

16. Narula J, Haider N, Arbustini E, Chandrashekhar Y. Mechanisms of disease: apoptosis in heart failure-seeing hope in death. Nat Clin Pract Cardiovasc Med 2006; 3(12): 681-8.

17. Kenis H, Zandbergen HR, Hofstra L, Petrov AD, Dumont EA, Blankenberg FD et al. Annexin a5 uptake in ischemic myocardium: demonstration of reversible phosphatidylserine externalization and feasibility of radionuclide imaging. J Nucl Med 2010; 51(2): 259-67.

18. Khalil H, Peltzer N, Walicki J, Yang JY, Dubuis G, Gardiol N et al. Caspase-3 protects stressed organs against cell death. Molecular and cellular biology 2012.

19. Boersma HH, Kietselaer BL, Stolk LM, Bennaghmouch A, Hofstra L, Narula J et al. Past, present, and future of annexin A5: from protein discovery to clinical applications. J Nucl Med 2005; 46(12): 2035 50 .

20. Kenis H, van Genderen H, Deckers NM, Lux PA, Hofstra L, Narula J et al. Annexin A5 inhibits engulfment through internalization of PS-expressing cell membrane patches. Exp Cell Res 2006; 312(6): 719-26. 
21. Gidon-Jeangirard C, Solito E, Hofmann A, Russo-Marie F, Freyssinet JM, Martinez MC. Annexin V counteracts apoptosis while inducing $\mathrm{Ca}(2+)$ influx in human lymphocytic $\mathrm{T}$ cells. Biochemical and biophysical research communications $1999 ; \mathbf{2 6 5}(3)$ : 709-15.

22. Bouter A, Gounou C, Berat R, Tan S, Gallois B, Granier T et al. Annexin-A5 assembled into twodimensional arrays promotes cell membrane repair. Nat Commun 2011; 2: 270.

23. Ravassa S, Gonzalez A, Lopez B, Beaumont J, Querejeta R, Larman M et al. Upregulation of myocardial Annexin A5 in hypertensive heart disease: association with systolic dysfunction. Eur Heart J 2007.

24. Lang RM, Bierig M, Devereux RB, Flachskampf FA, Foster E, Pellikka PA et al. Recommendations for chamber quantification: a report from the American Society of Echocardiography's Guidelines and Standards Committee and the Chamber Quantification Writing Group, developed in conjunction with the European Association of Echocardiography, a branch of the European Society of Cardiology. $J$ Am Soc Echocardiogr 2005; 18(12): 1440-63.

25. Beitnes JO, Gjesdal O, Lunde K, Solheim S, Edvardsen T, Arnesen H et al. Left ventricular systolic and diastolic function improve after acute myocardial infarction treated with acute percutaneous coronary intervention, but are not influenced by intracoronary injection of autologous mononuclear bone marrow cells: a 3 year serial echocardiographic sub-study of the randomized-controlled ASTAMI study. Eur $J$ Echocardiogr 2011; 12(2): 98-106.

26. Taylor RC, Cullen SP, Martin SJ. Apoptosis: controlled demolition at the cellular level. Nat Rev Mol Cell Biol 2008; 9(3): 231-41.

27. Kietselaer BL, Reutelingsperger CP, Boersma HH, Heidendal GA, Liem IH, Crijns HJ et al. Noninvasive detection of programmed cell loss with 99mTc-labeled annexin A5 in heart failure. $J$ Nucl Med 2007; 48(4): 562-7.

28. Haider N, Arbustini E, Gupta S, Liu H, Narula N, Hajjar R et al. Concurrent upregulation of endogenous proapoptotic and antiapoptotic factors in failing human hearts. Nat Clin Pract Cardiovasc Med 2009; 6(3): 250-61.

29. Zwaal RF, Schroit AJ. Pathophysiologic implications of membrane phospholipid asymmetry in blood cells. Blood 1997; 89(4): 1121-32.

30. Drake TA, Morrissey JH, Edgington TS. Selective cellular expression of tissue factor in human tissues. Implications for disorders of hemostasis and thrombosis. The American journal of pathology 1989; 134(5): 1087-97.

31. Benevolensky D, Belikova Y, Mohammadzadeh R, Trouvé P, Marotte F, Russo-Marie F et al. Expression and localization of the annexins II, V, and VI in myocardium from patients with end-stage heart failure. Laboratory investigation; a journal of technical methods and pathology 2000; 80(2): 123133.

32. Leventis PA, Grinstein S. The distribution and function of phosphatidylserine in cellular membranes. Annual review of biophysics 2010; 39: 407-427.

33. Kenis H, van Genderen H, Deckers N, Lux P, Hofstra L, Narula J et al. Annexin A5 inhibits engulfment through internalization of PS-expressing cell membrane patches. Exp Cell Res 2006; 312(6): 719-26.

34. Schutters K, Kusters DH, Chatrou ML, Montero-Melendez T, Donners M, Deckers NM et al. Cell surface-expressed phosphatidylserine as therapeutic target to enhance phagocytosis of apoptotic cells. Cell Death and Differentiation 2012.

35. van Genderen HO, Kenis H, Hofstra L, Narula J, Reutelingsperger CP. Extracellular annexin A5: Functions of phosphatidylserine-binding and two-dimensional crystallization. Biochim Biophys Acta 2008; 1783(6): 953-63.

36. Bouter A, Gounou C, Bérat R, Tan S, Gallois B, Granier T et al. Annexin-A5 assembled into twodimensional arrays promotes cell membrane repair. Nature communications 2011; 2: 270.

37. Kietselaer BLJH, Reutelingsperger CPM, Boersma HH, Heidendal GAK, Liem IH, Crijns HJGM et al. Noninvasive detection of programmed cell loss with $99 \mathrm{mTc}$-labeled annexin A5 in heart failure. $\mathrm{J} \mathrm{Nucl}$ Med 2007; 48(4): 562-7. 



\section{CHAPTER 3}

\section{ANNEXIN A5-DEFICIENCY AGGRAVATES DEVELOPMENT OF DIASTOLIC DYSFUNCTION OF PRESSURE-OVERLOADED MURINE HEART}

Based on: Annexin A5-deficiency aggravates development of diastolic dysfunction of pressure-overloaded murine heart. Kristof Schutters, Gustavo J.J. Silva, Lisette Ungethüm, Nicole J. Bitch, Bent Brachvogel, Mathias Burgmaier, Leon J. Schurgers, Leon J. De Windt, Chris P.M. Reutelingsperger 


\begin{abstract}
The process of loss of heart contractile cells during heart failure (HF) development is associated with phosphatidylserine (PS) externalization on the sarcolemma. Additionally, PS binds with nanomolar affinity annexin A5 (anxA5), a $35 \mathrm{kDa}$ plasma protein, which has been used as a non-invasive molecular imaging tool to visualize PS expressing cells in HF. Recently plasma determination of HF patients demonstrated that anxA5 was a strong predictor of all-cause mortality. Here we investigated the loss-of-function of endogenous anxA5 in the development of HF. Pressure-overload was induced in anxA5 knockout mice $\left(\operatorname{anxA} 5^{-/-}\right)$and anxA5 wild-type mice $\left(\operatorname{anxA} 5^{+/+}\right.$) by thoracic aorta constriction (TAC). Echocardiographic measurements were performed before and 10 weeks after TAC in order to evaluate both diastolic and systolic functions. A very slight reduction in ejection fraction and an increase in the E/E' ratio indicated the development of diastolic heart failure in the wildtype mice 10 weeks after TAC. Interestingly, anxA5-deficiency impaired the ventricular filling pattern and increased the E/A ratio as compared to wild-type mice subjected to comparable pressure overload gradient. In addition, anxA5-deficiency was associated with increased TAC-induced hypertrophy without changing significantly the apoptotic index and collagen deposition in the left ventricular wall. Furthermore, TAC-induced hypertrophy caused redistribution of anxA5 in cardiomyocytes. We conclude that endogenous anxA5 confers a protective role during high-pressure induced development of diastolic dysfunction with preserved ejection fraction.
\end{abstract}

\title{
INTRODUCTION
}

Heart failure (HF) is a multifactorial disease in which the heart is no longer able to pump sufficient amounts of blood throughout the body. Initially, compensatory mechanisms restore and maintain the cardiovascular function through remodeling. At the cardiomyocyte level, first hypertrophy occurs and finally apoptosis takes place. Apoptosis or programmed cell death is believed to contribute to continuous decline of ventricular function in heart failure ${ }^{1}$. Preclinical studies have shown a reduction in occurrence or severity of HF after anti-apoptotic interventions. In 2006, Narula et al. postulated that stressed cardiomyocytes of the failing heart can initiate apoptosis including reversible PS exposition without progressing towards full execution ${ }^{2}$ with a pivotal role for caspase $3^{3}$. Activated caspase 3 was unraveled as a regulator that controls death and survival pathways in stressed cardiomyocytes ${ }^{4}$.

Annexin A5 (anxA5), a circulating $35 \mathrm{kDa}$ plasma protein with nanomolar affinity for PS ${ }^{5,6}$, is used for the detection and imaging of cell death, including cell death in heart failure ${ }^{7}$. Ravassa et al. showed that anxA5 was upregulated and secreted during apoptosis activation in heart failure. Recently, we measured anxA5 levels in different stages of HF using an anxA5ELISA and showed that circulating anxA5 levels in patients were significantly elevated in all stages of HF compared to control subjects. Multivariate analysis demonstrated that high levels of anxA5 significantly correlated with all-cause mortality (unpublished observation, chapter 2). Previous observations show that binding of anxA5 to PS inhibits efferocytosis of PS expressing cells ${ }^{8,9}$, delays apoptosis ${ }^{10}$ and promotes the repair of injured cell membranes ${ }^{11}$. Therefore, we postulate that endogenous anxA5 can delay the execution of apoptosis and protect cardiomyocytes in heart failure. To test this hypothesis, we induced HF in anxA5 knock out $\left(\right.$ anxA $\left.5^{-/}\right)$and wild type $\left(\operatorname{anxA} 5^{+/+}\right)$mice by constriction of the thoracic aorta (TAC). We found that both groups presented a preserved ejection fraction, however anxA $5^{-/}$animals submitted to TAC developed a more severe diastolic dysfunction observed by a restrictive pattern in the transmitral flow measurements. 


\section{MATERIALS AND METHODS}

Animal Model - The heterozygote anxA5 knockout animals ${ }^{12}$ were kindly provided by Prof. Dr. B. Brachvogel (Center for Molecular Medicine Cologne, Cologne, Germany). Male anxA5 $5^{-/-}$and anxA5 $5^{+/+}$littermates of 15 weeks of age were used for this experiment. The animal regulatory authority of Maastricht University approved the experimental protocol.

Thoracic aorta constriction - TAC or sham surgery was performed in the anx $\mathrm{A} 5^{-/-}$and anx $\mathrm{A}^{+/+}$mice by subjecting the aorta to a defined 27-gauge constriction between the first and second truncus of the aortic arch, as described previously by Rockman et al ${ }^{13}$. SHAM operated mice underwent the whole operational procedure except TAC and serve as control.

Transthoracic echocardiography - For doppler echocardiography, mice were shaved, anaesthetized with isoflurane (induction: 4\%, during measurements $2-3 \%$ in oxygen). Echocardiographic measurements were performed using a VisualSonics Vevo 770 highresolution imaging system equipped with a $30 \mathrm{MHz}$ RMV-707B scanning head before and 10 weeks after TAC as described previously ${ }^{14}$. In M-mode, the following parameters were obtained: Intraventricular septum (IVS) thickness, left ventricular internal diameter (LVID) and posterior wall (PW) thickness during diastole (d) and systole (s). Left ventricular mass $(\mathrm{LV})$, fractional shortening (FS) and ejection fraction (EF) as systolic parameters were calculated. FS was calculated as (LVIDd-LVIDs)/LVIDd $\times 100$, echocardiographic LV mass (mg) was calculated by use of an uncorrected cube assumption as LV mass = [(LVIDd + LVPWd + IVSd $\left.)^{3}-(\text { LVIDd })^{3}\right](1000)$, as described previously ${ }^{15}$. Diastolic function was assessed using pulsed Doppler echocardiography. An apical four-chamber view was used to identify the mitral valve and the Doppler flow spectra recorded at the center of the left atrioventricular orifice. Early (E) and Atrial (A) ventricular filling was identified and E/A ratio calculated. Tissue Doppler Imaging (TDI) was performed at the septal corner of the mitral annulus and the mitral annulus velocity at early (E') and late (A') filling stages were recorded. Three weeks after ligation pressure gradient over the ligation was calculated between proximal and distal site of TAC. Only mice with a pressure gradient $>50 \mathrm{~mm} \mathrm{Hg}$ were included.

Tissues harvesting - Mice were anesthetized with $4 \%$ isoflurane and kept under anesthesia using $1.5-2.5 \%$ isoflurane. Blood was collected via the portal vein using an EDTA $(0.5 \mathrm{M})$ flushed needle and plasma aliquots were frozen at $-20^{\circ} \mathrm{C}$. Before collecting the heart, the cardiovascular system was perfused with $30 \mathrm{ml}$ fixating saline solution (150 mM saline, 2.5 $\mathrm{mM} \mathrm{CaCl}_{2}, 5 \mathrm{mM} \mathrm{KCl}, 1 \mathrm{mM} \mathrm{MgCl} 2$ and $1 \%$ paraformaldehyde in HEPES, $\mathrm{pH} \mathrm{7.3)} \mathrm{via} \mathrm{the}$ portal vein. The heart was fixed in HEPES buffered formaldehyde $1 \%(\mathrm{v} / \mathrm{v})$ containing 2.5 $\mathrm{mM}$ calcium, $5 \mathrm{mM}$ potassium, $1 \mathrm{mM}$ magnesium and $150 \mathrm{mM}$ saline for 20 hours at room temperature. Next, vascular tissue was transferred to $70 \%$ ethanol followed by paraffinembedding. Other tissues (brain, liver, spleen, kidney, pancreas and lungs) were isolated, snap frozen in Tissue-Tek (Sakura, Tokyo, Japan) and stored at $-80^{\circ} \mathrm{C}$.

Histology and immunohistochemistry - Apical paraffin cross sections $(4 \mu \mathrm{m})$ of the heart were stained with hematoxylin and eosin (Klinipath, Duiven, The Netherlands) to determine the structure of the ventricular wall. Cell death was visualized using the TdT-mediated dUTP$\mathrm{X}$ nick end labeling (TUNEL) assay according to the manufacturer's protocol (In situ cell death detection kit, POD -Roche Applied Science). Nuclei were counterstained with DAPI. 3 images of 3 sections of each heart were collected at $20 \mathrm{x}$ magnification (Leica DM 2000) and 3000 nuclei were counted per heart. Amount of cell death was expressed as \% TUNEL 
positive nuclei. Masson trichrome staining (Sigma, Warrington, UK) was performed according manufacturer's instructions to analyze the amount of collagen. In addition we evaluates the LV wall thickness was measured on these masson trichrome stained crosssections of the heart using ImageJ software.

Annexin A5 ELISA - Plasma anxA5 was measured using a commercial enzyme immunoassay (Hyphen BioMed, Neuville-sur-Oise, France) according to the instructions of the manufacturers.

Cardiac troponin T determination - Cardiac troponin T (cTNT) in plasma of the mice was measured with the commercial high-sensitivity cTNT kit ${ }^{16}$ on the Elecsys 2010 instrument (Roche Diagnostics, Penzberg, Germany) according to the instructions of the manufacturers. The kit contains antibodies against human cTNT that exhibit cross reactivity with mouse cardiac troponin $\mathrm{T}$.

Statistics - Data are shown as mean \pm standard error of the mean (SEM). One-way ANOVA followed by Tukey posthoc test were performed to identify the statistical differences between the groups. P-values < 0.05 were adopted as significant level.

\section{RESULTS}

AnxA5 deficiency does not influence geometry of the heart after TAC - First, we determined alterations in left ventricular geometry by echocardiographic measurements before and 10 weeks after TAC procedure. Under isoflurane anesthesia heart rate values during the echocardiogram exams were kept similar between the experimental groups (data not shown). Ten weeks after pressure-overload stimulus induced by TAC in anxA5 deficiency mice, IVS during diastole was significantly reduced $(\mathrm{p}=0.02)$ in anxA5 $5^{-/-}$animals (Table 1$)$. We assume that this difference is based on coincidence because lacking significant differences in LVIDd, LVIDs, PWs, PWd and IVSs (Table 1). TAC procedure induced similar pressure gradients (Figure 1A). 
Table 1: Geometry of the heart measured by echocardiography in anxA5 $\%_{-}$and anxA5 $5^{+/+}$ mice before and 10 weeks after transverse aortic constriction. Data are expressed as mean+SEM. One asterisks represent P-values < 0.05. IVS, intraventricular septal wall thickness; PW, left ventricular posterior wall thickness; LVID, left ventricular internal diameter.

\begin{tabular}{|c|c|c|c|c|c|c|}
\hline & \multicolumn{3}{|c|}{$0 \mathrm{Wks}$} & \multicolumn{3}{c|}{$10 \mathrm{Wks}$} \\
\hline & anxA5 & anxA5 & p-value & anxA5 & anxA5 & p-value \\
\hline LVID $(\mathrm{mm})$ & $2.44 \pm 0.43$ & $2.35 \pm 0.40$ & n.s. & $2.99 \pm 0.28$ & $2.94 \pm 0.45$ & n.s. \\
\hline $\begin{array}{c}\text { LVID } \\
(\mathrm{mm})\end{array}$ & $3.69 \pm 0.36$ & $3.47 \pm 0.34$ & n.s. & $4.08 \pm 0.15$ & $3.97 \pm 0.36$ & n.s. \\
\hline $\mathrm{IVS}_{\mathrm{s}}(\mathrm{mm})$ & $1.12 \pm 0.15$ & $1.16 \pm 0.18$ & n.s. & $1.17 \pm 0.19$ & $1.29 \pm 0.20$ & n.s. \\
\hline $\mathrm{IVS}_{\mathrm{d}}(\mathrm{mm})$ & $0.76 \pm 0.10$ & $0.78 \pm 0.12$ & n.s. & $0.81 \pm 0.13$ & $0.99 \pm 0.16$ & $\mathbf{0 . 0 2}$ \\
\hline $\mathrm{PW}_{\mathrm{s}}(\mathrm{mm})$ & $1.03 \pm 0.22$ & $1.02 \pm 0.22$ & n.s. & $1.20 \pm 0.21$ & $1.20 \pm 0.21$ & n.s. \\
\hline \begin{tabular}{c}
$\mathrm{PW}_{\mathrm{d}}(\mathrm{mm})$ \\
\hline $\begin{array}{c}\mathrm{LV} \text { mass } \\
(\mathrm{mg})\end{array}$
\end{tabular} & $0.77 \pm 0.17$ & $0.75 \pm 0.13$ & n.s. & $0.97 \pm 0.22$ & $0.94 \pm 0.21$ & n.s. \\
\hline
\end{tabular}

AnxA5 deficiency does not influence systolic function - Following the geometry measurement, we evaluated systolic function by calculating the fractional of shortening and ejection fraction before and after TAC. We observed a comparable slight drop in systolic function determined as the fractional of shortening and ejection fraction in both the anx $\mathrm{A} 5^{-/-}$ and anxA5 $5^{+/+}$-groups subjected to TAC (Figure 1B).

AnxA5 deficiency aggravates development of diastolic dysfunction- In order to determine the diastolic function we performed tissue Doppler imaging and transmitral flow measurements. Both anx $5^{+/+}$and anxA5 $5^{-/-}$groups display a similar increase in the E/E' ratio $\left(35.2 \pm 7.2\right.$ vs. $33.8 \pm 10.4$ for anxA5 $5^{-/-}$and anxA $5^{+/+}$animals, respectively) 10 weeks after TAC as compared to the SHAM operated animals (Figure 1D). Although a similar increase in the E/E' measurements, TAC operated anxA $5^{-/}$animals developed a more severe diastolic dysfunction. AnxA5 $5^{-/-}$-mice showed a restrictive pattern, characterized by an increased $\mathrm{E}$ velocity and a decreased $A$ velocity resulting in an increased E/A ratio $(2.7 \pm 1.04$ vs. $1.64 \pm 0.99, \mathrm{p}=0.035$, for anxA5 $5^{-/-}$and anxA $5^{+/+}$, respectively)(Fig. 1E). Whether this protective effect of anxA5 is associated with elevated anxA5 levels in blood was determined by an anxA5 ELISA.

Ten weeks TAC does not influence anxA5 plasma concentrations - Previously we showed elevated anxA5 plasma levels in HF patients (unpublished observation, chapter 2). Here, no significant alterations in the anxA5 plasma levels could be found among the SHAM and the TAC animals (Data not shown). These results can be a consequence of the small animal group $(n=8)$ compared to the large patient group $(n=176)$, the artificial rapid induction of hypertrophy in the TAC model or because a to early sacrifice point. An anxA5 staining on the hearts was performed to evaluate alterations of anxA5-expression in the wild-type heart. 


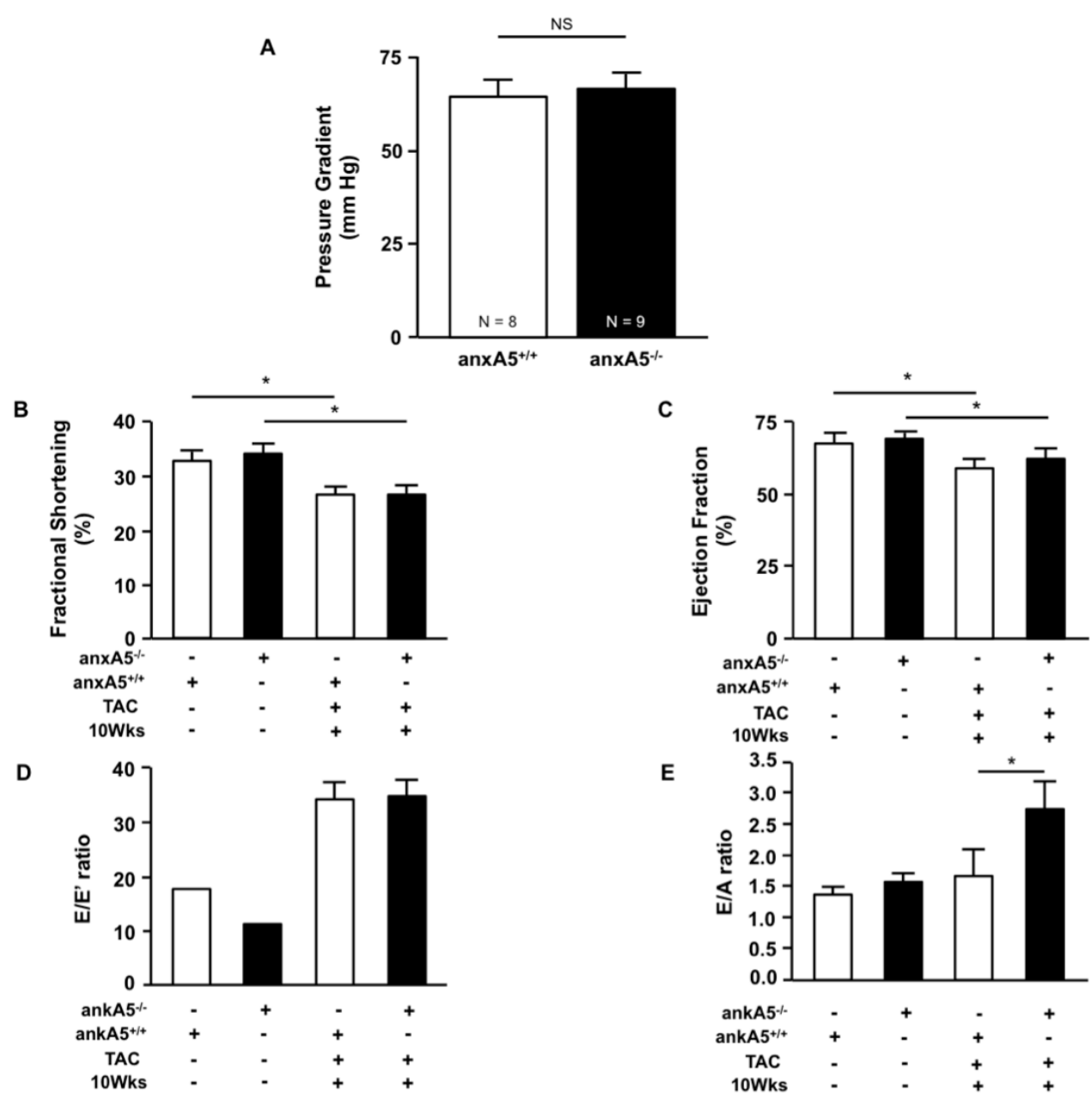

Figure 1: A) Pressure gradient generated by aortic constriction was measured non-invasively using Doppler echocardiography. Only mice with a pressure gradient $>50 \mathrm{~mm} \mathrm{Hg}$ were included in the study. Note that both anxA $5^{+/+}$and anxA $5^{-/-}$groups submitted to TAC presented similar pressure gradients. B) Left ventricular fractional shortening and C) ejection fraction in the SHAM and TAC animals as measures for the systolic function are shown. D) E/E' and E) E/A-ratio determined by tissue Doppler echocardiography were shown as measures for the diastolic function. One asterisks represent $\mathrm{P}$-values $<0.05$.

TAC causes a redistribution of anxA5 in the heart - Ravassa et al. showed that anxA5 is relocated to the sarcolemma during heart failure in patients ${ }^{17}$. Immunohistochemical staining of anxA $5^{+/+}$murine hearts showed that TAC induced a translocation of anxA5 towards the sarcolemma (Fig. 2A, B) similar to the reported translocation in the human failing heart. Following from these findings we would like to postulate that the redistribution of anxA5 in the cardiomyocytes occurs prior to the release of anxA5 into the blood stream.

AnxA5-deficiency does not alter collagen content in the heart - In hypertensive heart disease, reactive myocardial fibrosis represents as an excessive accumulation of fibrillar collagen within the normal connective tissue structures of the myocardium ${ }^{18}$. It was shown that anxA5 has the ability to bind to collagen ${ }^{19}$ and has the unique ability to form 2D crystals on injured living cells which is crucial for membrane repair ${ }^{20}$. Therefore we analyzed the collagen content in the different groups. Masson trichrome stained cardiac histological sections did not show any signs of differences between the anxA5 $5^{-1-}$ and anxA $5^{+/+}{ }_{-m i c e}$ 
submitted to TAC (data not shown). To find clues of the involved mechanism of the protective effect of anxA5, we evaluated the amount of apoptosis and hypertrophy after TAC.
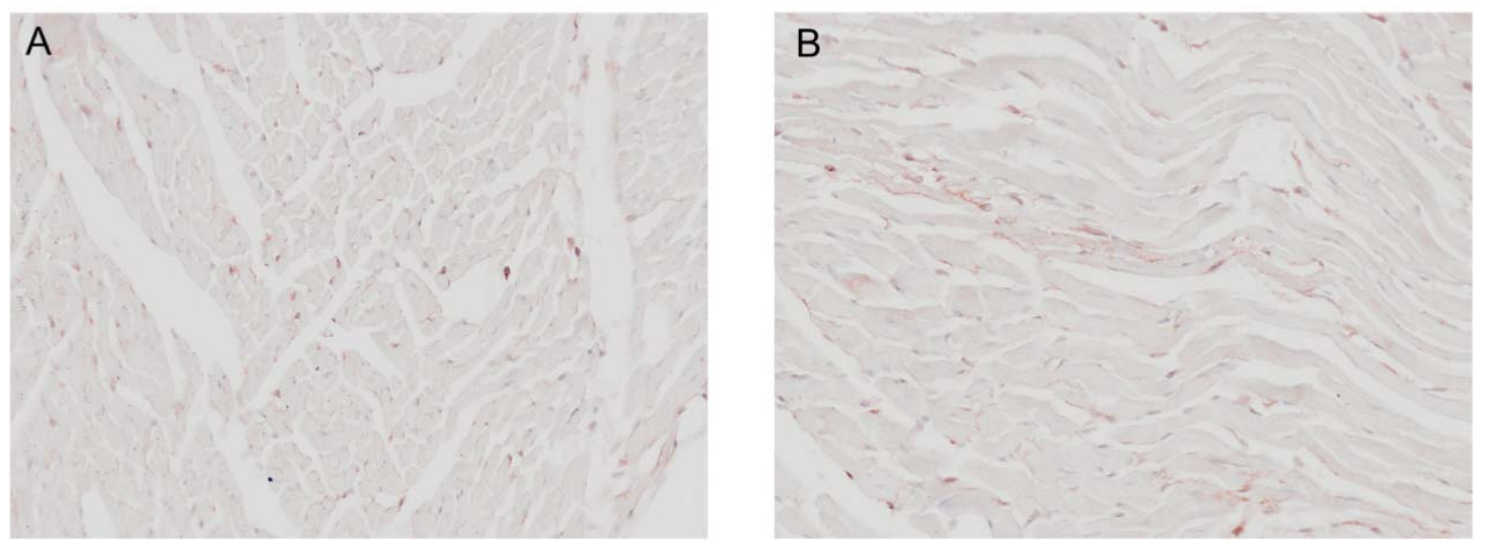

Figure 2: Ex vivo anxA5 staining on an apical paraffin cross sections $(4 \mu \mathrm{m})$ of the left ventricle of a SHAM (A) and 10 weeks after TAC (B) operated anxA5 $5^{+/+}$-mice. A clear redistribution in the TAC operated group is clearly shown.

AnxA5-deficiency does not alter apoptotic index in the heart - Recently it was postulated that activated caspase 3 is a master switch controlling death and survival pathways in stressed cardiomyocytes ${ }^{21}$. It was shown that cleaved caspase 3 also drives reversible externalization of PS by stressed cardiomyocytes ${ }^{22}$. Shielding of PS by anxA5 can rescue these stressed cells from being phagocytosed ${ }^{23,24}$. Therefore we analyzed apoptotic cell content in the left ventricle of the heart. We found that TAC was associated with a low level of apoptosis in the left ventricular wall of the heart of wild-type mice (Fig. 3A, B) AnxA5-deficiency did not significantly change the extent of apoptosis (Fig 3B). It is therefore unlikely that apoptosis contributes significantly to the worsening of diastolic dysfunction in our model. Hence, anxA5 exhibits protection via mechanisms that are not directly related to apoptosis.
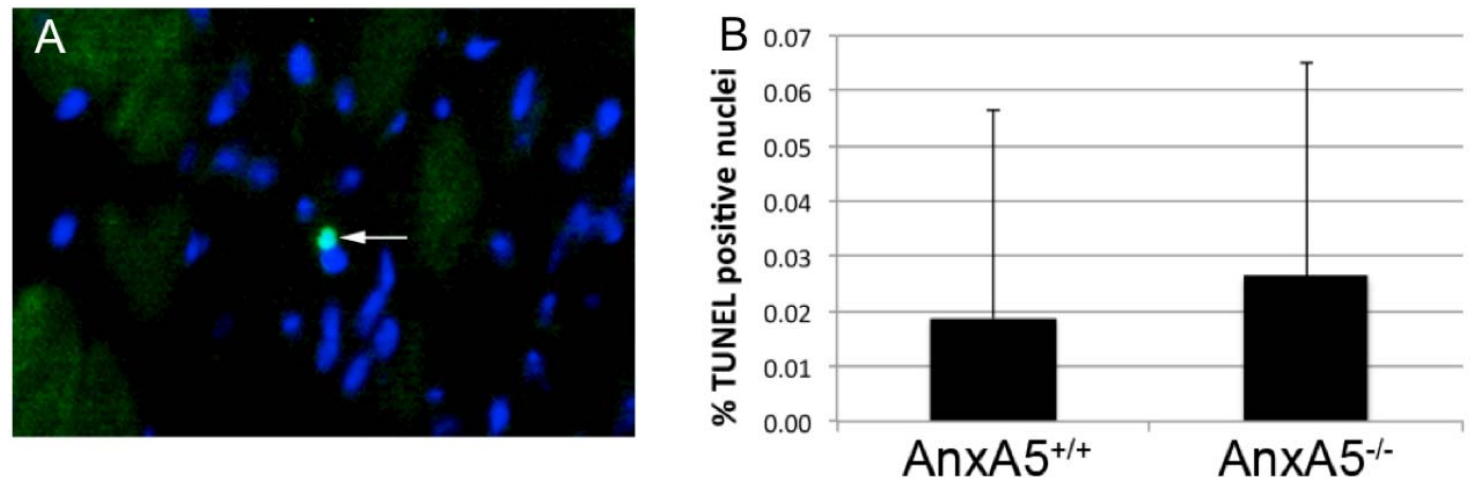

Figure 3: TUNEL-staining of an apical paraffin cross section $(4 \mu \mathrm{m})$ of the left ventricle of the heart. A) Visualization, B) quantification. In both the anx $\mathrm{A} 5^{+/+}$and ${ }^{-/-}$groups a very low equal level of TUNEL-positive cells was found. 
AnxA5-deficiency induces hypertrophy after TAC - Although no differences were found in geometry using the ultrasound measurements, we found an increased thickening of the left ventricular wall by more accurate post mortum histochemical analysis. Herein we observed a trend $(\mathrm{p}=0.11)$ that anxA5 $5^{--}$-mice $(51$ pixels \pm 8$)$ submitted to TAC have a thicker left ventricular wall compared to the anxA5 $5^{+/+}$-mice $(45$ pixels \pm 7 ) submitted to TAC (Fig. 4AD). These data show that anxA5-deficiency is associated with more hypertrophy and point towards a role of anxA5 in regulating hypertrophy of stressed cardiomyocytes.
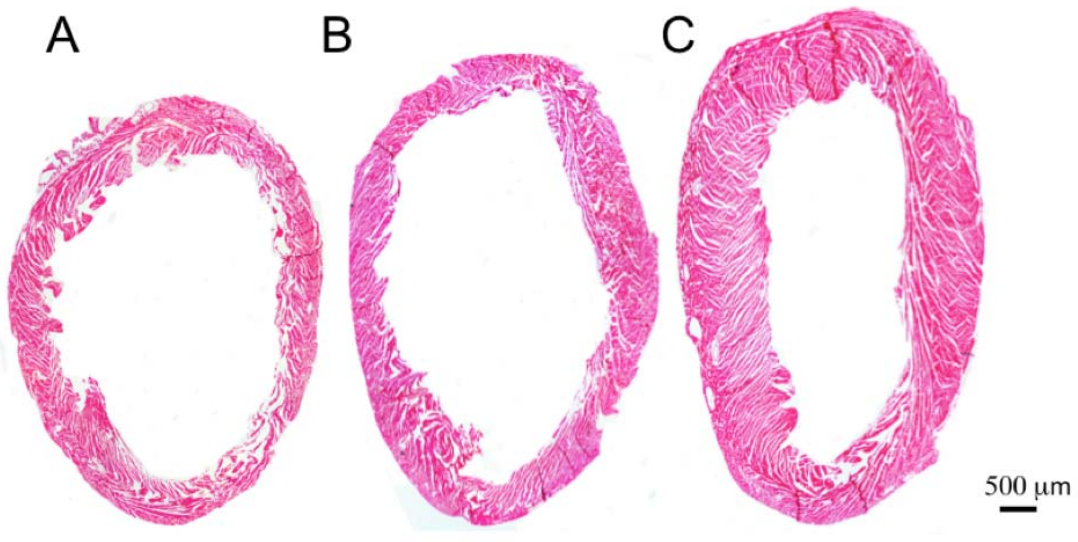

$\mathrm{D}$

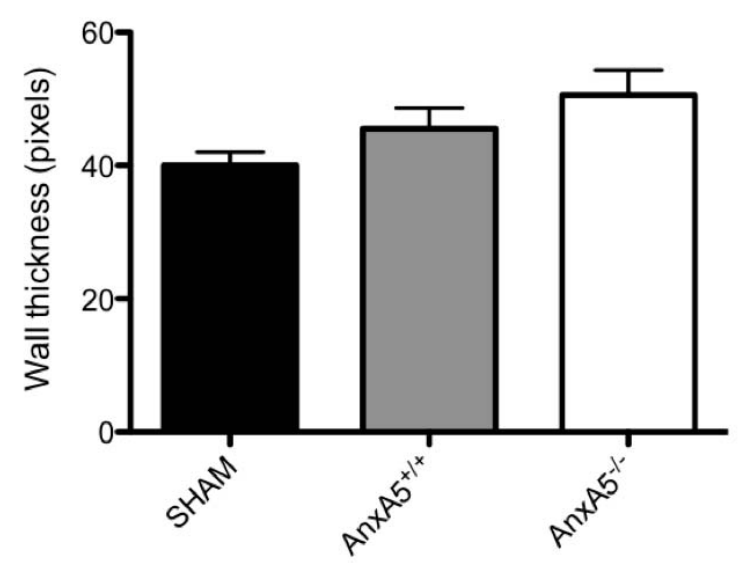

Figure 4: Left ventricular wall thickness measured on masson trichrome stained sections (4 $\mu \mathrm{m})$ using ImageJ software. A-C) Visualization of the left ventricle obtained from a SHAM operated mouse (A), an anxA5 ${ }^{+/+}$TAC operated mouse (B) and an anxA5 ${ }^{-/}$TAC operated mouse; D) Quantification. Error bars in graph D represent SEM.

AnxA5-deficiency does not alter plasma cTNT-levels - Cardiomyocyte damage is accompanied by release of cardiac troponins ${ }^{25}$. We reasoned that if anxA5 is crucial for repair of damaged sarcolemma, anxA5-deficiency would be associated with increased circulating cTnT levels following TAC. SHAM-operated mice of both groups had no detectable cTnT in blood circulation (cTnT $<3 \mathrm{pg} / \mathrm{ml})$. TAC induced an increase of circulating cTnT up to and $6.18 \pm 6.0 \mathrm{pg} / \mathrm{ml}$ and $8.4 \pm 5.8 \mathrm{pg} / \mathrm{ml}$ for the anxA5 ${ }^{-/-}$and anxA $5^{+/+}$-mice, respectively. No significant differences were observed between the two groups suggesting that a lack of membrane-repair activity of anxA5 and myocardial infarction does not account for the observed aggravation of diastolic function during anxA5-deficiency. 


\section{DISCUSSION}

Currently therapeutic strategies against HF are very limited. Over the past 20 years the survival of patients with systolic heart failure has slightly improved, whereas the prognosis of diastolic heart failure patients unfortunately has not changed ${ }^{26}$. AnxA5, which binds externalized PS with high affinity, has been shown to be involved in the development of HF. Recently we discovered that circulating anxA5 levels predict mortality in high-risk HF patients (unpublished observation, chapter 2). Others found that elevated circulating anxA5 levels are associated with LV dysfunction and remodeling ${ }^{17,27}$. Interestingly, HF patients responding to cardiac resynchronization therapy also showed a decrease in circulating anxA5 levels ${ }^{28}$. The origin of the circulating anxA5 is unknown but interpretive reasoning pointed towards the heart as a potential source ${ }^{17}$. Hypertrophic LV-cardiomyocytes of HF patients have elevated anxA5 protein expression without showing an increase in anxA5 mRNA levels ${ }^{17}$. Recently, it was found that microRNA-1 (miR-1), which is decreased during hypertrophy, has a binding site to the highly conserved 3' untranslated region of anxA5 ${ }^{29}$ causing an inhibition of anxA5 synthesis. Sayed et al. showed that TAC induced hypertrophy decreases miR-1 expression already one day after ligation and systematically decreases in time ${ }^{30}$. The molecular link between anxA5 and LV remodeling remains to be identified. It has been proposed that anxA5 constitutes an essential part of the membrane-repair kit repairing sarcolemma of living injured cardiomyocytes ${ }^{20}$. This relationship is of minor importance in our experimental set-up because low amounts of ciculating cTNT concentrations were measured. Interestingly, we found that anxA5 deficiency in the TAC-mice is associated with an increased hypertropic left ventricular wall. The molecular link between anxA5 and hypertrophy has not been reported before but we would like to speculate on an interplay between anxA5 and the $\mathrm{Na}^{+}-\mathrm{Ca}^{2+}$-exchanger or autophagy. It was reported that both an overexpression of the cardiac $\mathrm{Na}^{+}-\mathrm{Ca}^{2+}$-exchanger ${ }^{31}$ and an inhibition of autophagy induces cardiomyocyte hypertrophy ${ }^{32}$. Others reported that anxA5; I) is able to decrease the activity of the $\mathrm{Na}^{+}-\mathrm{Ca}^{2+}$ exchanger ${ }^{29}$ and; II) is required for autophagy ${ }^{33}$. The mechanistic links and the importance in our experimental set-up needs to be evaluated by future experiments. In the present study we clearly showed that anxA5 deficiency, in a C57BL/6 background animal, transforms the animals from a pseudonormal to a restrictive left ventricular filling pattern 10 weeks after thoracic aorta constriction. This restrictive left ventricular filling pattern is seen in congestive HF patients with moderate to severe aortic valve stenosis ${ }^{34,35}$. This phenotype is very often seen in patients but no animal model is available that resembles this diastolic dysfunction phenotype at this time. In addition no adequate therapy is available to treat these patients. Hence, the anx $5^{-/-}$mouse model submitted to TAC delivers a novel platform to test novel therapeutic strategies that bear potential for treatment of HF patients suffering from diastolic dysfunction. 


\section{REFERENCES}

1. Haider N, Narula N, Narula J. Apoptosis in heart failure represents programmed cell survival, not death, of cardiomyocytes and likelihood of reverse remodeling. J Card Fail 2002; 8(6 Suppl): S512-7.

2. Narula J, Haider N, Arbustini E, Chandrashekhar Y. Mechanisms of disease: apoptosis in heart failure-seeing hope in death. Nat Clin Pract Cardiovasc Med 2006; 3(12): 681-8.

3. Kenis H, Zandbergen HR, Hofstra L, Petrov AD, Dumont EA, Blankenberg FD et al. Annexin a5 uptake in ischemic myocardium: demonstration of reversible phosphatidylserine externalization and feasibility of radionuclide imaging. $J$ Nucl Med 2010; 51(2): 259-67.

4. Khalil H, Peltzer N, Walicki J, Yang JY, Dubuis G, Gardiol N et al. Caspase-3 protects stressed organs against cell death. Molecular and cellular biology 2012.

5. Andree HA, Reutelingsperger CP, Hauptmann R, Hemker HC, Hermens WT, Willems GM. Binding of vascular anticoagulant alpha (VAC alpha) to planar phospholipid bilayers. J Biol Chem 1990; 265(9): 4923-8.

6. Schutters K, Reutelingsperger C. Phosphatidylserine targeting for diagnosis and treatment of human diseases. Apoptosis 2010; 15(9): 1072-82.

7. Boersma HH, Kietselaer BL, Stolk LM, Bennaghmouch A, Hofstra L, Narula J et al. Past, present, and future of annexin A5: from protein discovery to clinical applications. J Nucl Med 2005; 46(12): 203550 .

8. Kenis H, van Genderen H, Deckers NM, Lux PA, Hofstra L, Narula J et al. Annexin A5 inhibits engulfment through internalization of PS-expressing cell membrane patches. Exp Cell Res 2006; 312(6): 719-26.

9. Schutters K, Kusters DH, Chatrou ML, Montero-Melendez T, Donners M, Deckers NM et al. Cell surface-expressed phosphatidylserine as therapeutic target to enhance phagocytosis of apoptotic cells. Cell Death Differ 2012.

10. Gidon-Jeangirard C, Solito E, Hofmann A, Russo-Marie F, Freyssinet JM, Martinez MC. Annexin V counteracts apoptosis while inducing $\mathrm{Ca}(2+)$ influx in human lymphocytic $\mathrm{T}$ cells. Biochemical and biophysical research communications $1999 ; \mathbf{2 6 5}(3)$ : 709-15.

11. Bouter A, Gounou C, Berat R, Tan S, Gallois B, Granier T et al. Annexin-A5 assembled into twodimensional arrays promotes cell membrane repair. Nat Commun 2011; 2: 270.

12. Brachvogel B, Dikschas J, Moch H, Welzel H, von der Mark K, Hofmann C et al. Annexin A5 is not essential for skeletal development. Mol Cell Biol 2003; 23(8): 2907-13.

13. Rockman HA, Ross RS, Harris AN, Knowlton KU, Steinhelper ME, Field LJ et al. Segregation of atrial-specific and inducible expression of an atrial natriuretic factor transgene in an in vivo murine model of cardiac hypertrophy. Proceedings of the National Academy of Sciences of the United States of America 1991; 88(18): 8277-81.

14. Baurand A, Zelarayan L, Betney R, Gehrke C, Dunger S, Noack C et al. Beta-catenin downregulation is required for adaptive cardiac remodeling. Circ Res 2007; 100(9): 1353-62.

15. van Empel VP, Bertrand AT, van der Nagel R, Kostin S, Doevendans PA, Crijns HJ et al. Downregulation of apoptosis-inducing factor in harlequin mutant mice sensitizes the myocardium to oxidative stress-related cell death and pressure overload-induced decompensation. Circ Res 2005; 96(12): e92-e101.

16. Mingels A, Jacobs L, Michielsen E, Swaanenburg J, Wodzig W, van Dieijen-Visser M. Reference population and marathon runner sera assessed by highly sensitive cardiac troponin $\mathrm{T}$ and commercial cardiac troponin T and I assays. Clin Chem 2009; 55(1): 101-8.

17. Ravassa S, Gonzalez A, Lopez B, Beaumont J, Querejeta R, Larman M et al. Upregulation of myocardial Annexin A5 in hypertensive heart disease: association with systolic dysfunction. Eur Heart $J$ 2007; 28(22): 2785-91.

18. Funck RC, Wilke A, Rupp H, Brilla CG. Regulation and role of myocardial collagen matrix remodeling in hypertensive heart disease. Adv Exp Med Biol 1997; 432: 35-44.

19. Drakes ML, Lu L, McKenna HJ, Thomson AW. The influence of collagen, fibronectin, and laminin on the maturation of dendritic cell progenitors propagated from normal or Flt3-ligand-treated mouse liver. Adv Exp Med Biol 1997; 417: 115-20.

20. Bouter A, Gounou C, Berat R, Tan S, Gallois B, Granier T et al. Annexin-A5 assembled into twodimensional arrays promotes cell membrane repair. Nat Commun 2011; 2: 270.

21. Khalil H, Peltzer N, Walicki J, Yang JY, Dubuis G, Gardiol N et al. Caspase-3 protects stressed organs against cell death. Mol Cell Biol 2012; 32(22): 4523-33.

22. Kenis H, Zandbergen HR, Hofstra L, Petrov AD, Dumont EA, Blankenberg FD et al. Annexin A5 uptake in ischemic myocardium: demonstration of reversible phosphatidylserine externalization and feasibility of radionuclide imaging. J Nucl Med 2010; 51(2): 259-67. 
23. Kenis H, van Genderen H, Deckers NM, Lux PA, Hofstra L, Narula J et al. Annexin A5 inhibits engulfment through internalization of PS-expressing cell membrane patches. Exp Cell Res 2006; 312(6): 719-26.

24. Schutters K, Kusters DH, Chatrou ML, Montero-Melendez T, Donners M, Deckers NM et al. Cell surface-expressed phosphatidylserine as therapeutic target to enhance phagocytosis of apoptotic cells. Cell Death Differ 2013; 20(1): 49-56.

25. Gao D, Zhang L, Dhillon R, Hong TT, Shaw RM, Zhu J. Dynasore protects mitochondria and improves cardiac lusitropy in Langendorff perfused mouse heart. PLoS one 2013; 8(4): e60967.

26. Owan TE, Hodge DO, Herges RM, Jacobsen SJ, Roger VL, Redfield MM. Trends in prevalence and outcome of heart failure with preserved ejection fraction. N Engl J Med 2006; 355(3): 251-9.

27. Lai CT, Chow PC, Wong SJ, Chan KW, Cheung YF. Circulating annexin a5 levels after atrial switch for transposition of the great arteries: relationship with ventricular deformation and geometry. PLoS One 2012; 7(12): e52125.

28. Ravassa S, Garcia-Bolao I, Zudaire A, Macias A, Gavira JJ, Beaumont J et al. Cardiac resynchronization therapy-induced left ventricular reverse remodelling is associated with reduced plasma annexin A5. Cardiovasc Res 2010; 88(2): 304-13.

29. Tritsch E, Mallat Y, Lefebvre F, Diguet N, Escoubet B, Blanc J et al. An SRF/miR-1 axis regulates NCX1 and Annexin A5 protein levels in the normal and failing heart. Cardiovasc Res 2013.

30. Sayed D, Hong C, Chen IY, Lypowy J, Abdellatif M. MicroRNAs play an essential role in the development of cardiac hypertrophy. Circ Res 2007; 100(3): 416-24.

31. Reuter H, Han T, Motter C, Philipson KD, Goldhaber JI. Mice overexpressing the cardiac sodiumcalcium exchanger: defects in excitation-contraction coupling. J Physiol 2004; 554(Pt 3): 779-89.

32. Nakai A, Yamaguchi O, Takeda T, Higuchi Y, Hikoso S, Taniike M et al. The role of autophagy in cardiomyocytes in the basal state and in response to hemodynamic stress. Nat Med 2007; 13(5): 619-24.

33. Ghislat G, Aguado C, Knecht E. Annexin A5 stimulates autophagy and inhibits endocytosis. J Cell Sci 2012; 125(Pt 1): 92-107.

34. Bruch C, Stypmann J, Grude M, Gradaus R, Breithardt G, Wichter T. Tissue Doppler imaging in patients with moderate to severe aortic valve stenosis: clinical usefulness and diagnostic accuracy. $A m$ Heart J 2004; 148(4): 696-702.

35. Xie GY, Berk MR, Smith MD, DeMaria AN. Relation of Doppler transmitral flow patterns to functional status in congestive heart failure. Am Heart J 1996; 131(4): 766-71. 



\section{CHAPTER 4}

\section{CELL SURFACE EXPRESSED PHOSPHATIDYLSERINE AS THERAPEUTIC TARGET TO ENHANCE PHAGOCYTOSIS OF APOPTOTIC CELLS}

Based on: Schutters K, Kusters DH, Chatrou ML, Montero-Melendez T, Donners M, Deckers NM, et al. Cell surface-expressed phosphatidylserine as therapeutic target to enhance phagocytosis of apoptotic cells. Cell Death Differ. 2013 Jan 


\begin{abstract}
Impaired efferocytosis has been shown to be associated with, and even to contribute to progression of chronic inflammatory diseases such as atherosclerosis. Enhancing efferocytosis has been proposed as strategy to treat diseases involving inflammation. Here we present the strategy to increase "eat me" signals on the surface of apoptotic cells by targeting cell surface expressed phosphatidylserine (PS) with a variant of annexin A5 (RGD-anxA5) that has gained the function to interact with $\alpha_{v} \beta_{3}$ receptors of the phagocyte. We describe design and characterization of RGD-anxA5 and show that introduction of RGD transforms anxA5 from an inhibitor into a stimulator of efferocytosis. RGD-anxA5 enhances engulfment of apoptotic cells by PMAstimulated THP-1 cells in vitro and resident peritoneal mouse macrophages in vivo. In addition, RGD-anxA5 augments secretion of IL-10 during efferocytosis in vivo thereby possibly adding to an anti-inflammatory environment. We conclude that targeting cell surface expressed PS is an attractive strategy for treatment of inflammatory diseases and that the rationally designed RGD-anxA5 is a promising therapeutic agent.
\end{abstract}

\title{
INTRODUCTION
}

Efferocytosis, the phagocytosis of apoptotic cells, proceeds rapidly and efficiently in healthy tissues ${ }^{1}$. It is of great importance to tissue homeostasis since it prevents leakage of potentially cytotoxic or antigenic contents into the extracellular environment, which would initiate inflammation and might cause tissue injury, and it counteracts inflammation by secretion of anti-inflammatory cytokines ${ }^{2}$. Diseased tissues are characterized by a sustained presence of dead cells due to an imbalance between apoptosis and phagocytosis. Impaired efferocytosis has been demonstrated to contribute to progression of chronic inflammatory diseases such as atherosclerosis ${ }^{3}$ and systemic lupus erythematosus ${ }^{4}$. Enhancing efferocytosis has been proposed as strategy to treat chronic inflammation ${ }^{4-6}$.

Efferocytosis depends on recognition of the apoptotic cell by the phagocyte. Different "eat me" signals on the apoptotic cell surface, also called ACAMP (apoptotic cell associated molecular patterns) have been identified ${ }^{7}$. Cell surface expressed phosphatidylserine (PS) is the best characterized and one of the most important "eat me" signals for efferocytosis ${ }^{8,9}$. PS binds directly to a phagocyte receptor or via bridging molecules including Gas6, MFG-E8 and annexin A1 9 .

Annexin A5 (anxA5), a structurally and biophysically well-characterized member of the annexin multigene family, binds PS with high affinity in a $\mathrm{Ca}^{2+}$-dependent manner ${ }^{10}$. It is employed broadly as molecular imaging agent to measure apoptosis in vitro ${ }^{11}$ and in vivo in animal models and patients ${ }^{10}$. AnxA5 does not act as a bridging molecule but inhibits efferocytosis by shielding the PS expressing surface of apoptotic cells ${ }^{12,13}$. The molecular imaging experience with anxA5 triggered us to explore whether anxA5 could be transformed into a therapeutic agent enhancing efferocytosis. It has been shown that the PS-receptor TIM- 4 and integrin $\alpha_{v} \beta_{3 /}$ act cooperatively during efferocytosis ${ }^{14}$. Here we report the transformation of anxA5 from an inhibitory into a stimulatory protein of efferocytosis by introduction of an Arg-GlyAsp (RGD) motif into its N-terminal tail, which is located apical to the PS-binding sites. We show that RGD-anxA5 interacts with $\alpha_{v} \beta_{5 / 5}$ on the phagocyte, stimulates efferocytosis in vitro and in vivo and enhances anti-inflammatory cytokine 
production. We conclude that RGD-anxA5 is a promising strategy for treatment of diseases with impaired efferocytosis.

\section{MATERIALS AND METHODS}

Design, expression and purification of the different anxA5-variants - E.Coli M15 (pREP4) (Qiagen, Valencia, USA) were transformed with pQE30Xa (Qiagen) containing cDNA of the anxA5-variants. Bacteria were grown to 0.8 OD600 and expression was induced by adding $0.5 \mathrm{mM}$ isopropyl $\beta$--D-1-thiogalactopyrano-side (IPTG, Eurogentec, Seraing, Belgium). After 3 hours, bacteria were harvested and resuspended in phosphate buffer $(20 \mathrm{mM}$, pH 7.4) containing $500 \mathrm{mM} \mathrm{NaCl}, 20 \mathrm{mM}$ imidazole and $1 \%$ Triton X-100. Bacteria were lysed by sonification at $12 \mu \mathrm{m}$ amplitude for $6 \times 10 \mathrm{~s}$. Lysis was continued at room temperature for 3 hours. Cell debris was removed by centrifugation. His-tagged proteins were isolated from supernatant by chromatography using nickel columns (GE Healthcare, Amersham, USA) and an imidazole gradient. Figure 1 depicts an endotoxin free RGD-anxA5variant and a representative MALDI-TOF/TOF mass spectrometric analysis of a purified recombinantly expressed batch of this variant.

Cell culture - THP1-cells, a human monocytic cell line (American Type Culture Collection (ATCC), Manassas, USA), were cultured in RPMI 1640 without indicator (GIBCO-BRL, Invitrogen Corp., Carlsbad, USA) supplemented with $2 \mathrm{mM}$ glutamine (GIBCO-BRL), 10\% heat-inactivated fetal bovine serum (GIBCO-BRL), 100 units $/ \mathrm{ml}$ penicillin (GIBCO -BRL) and $100 \mathrm{mg} / \mathrm{ml}$ streptomycin (GIBCO -BRL). Differentiation of THP-1 cells in adherent macrophages was achieved by addition of $50 \mathrm{nM}$ phorbol-12-myristate-13-acetate (PMA, Promega, Madison, USA) for 72 hours. PMA induced adhesion and spreading was monitored real-time using xCELLigence apparatus (Roche, Almere, The Netherlands). The T-cell lymphoma Jurkat cell line (ATCC) was cultured in RPMI 1640 (Gibco BRL) supplemented with $10 \%$ heat-inactivated fetal bovine serum (GIBCO-BRL), 100 units $/ \mathrm{ml}$ penicillin (GIBCO-BRL), $100 \mu \mathrm{g} / \mathrm{ml}$ streptomycin (GIBCO-BRL). L929 cells, a mouse fibroblast cell line (ATCC) were cultured in DMEM with high glucose (GIBCOBRL) supplemented with 10\% heat-inactivated fetal bovine serum (GIBCO-BRL), 100 units/ml penicillin (GIBCO -BRL) and $100 \mu \mathrm{g} / \mathrm{ml}$ streptomycin (GIBCO -BRL).

Bone Marrow derived macrophages isolation and differentiation - BMDM were isolated as described by Goossens et al. $^{15}$. After isolation, macrophages were stimulated with $10 \mathrm{U} / \mathrm{ml}$ mouse recombinant IFN $\gamma, 20 \mathrm{ng} / \mathrm{ml}$ mouse recombinant IL-4 or $10 \mathrm{ng} / \mathrm{ml}$ mouse recombinant IL-10 (to induce M1, M2a and M2c macrophages, respectively) or no cytokines (M0). After $24 \mathrm{hrs}$ stimulation, macrophages were used in the efferocytosis assay. 
A
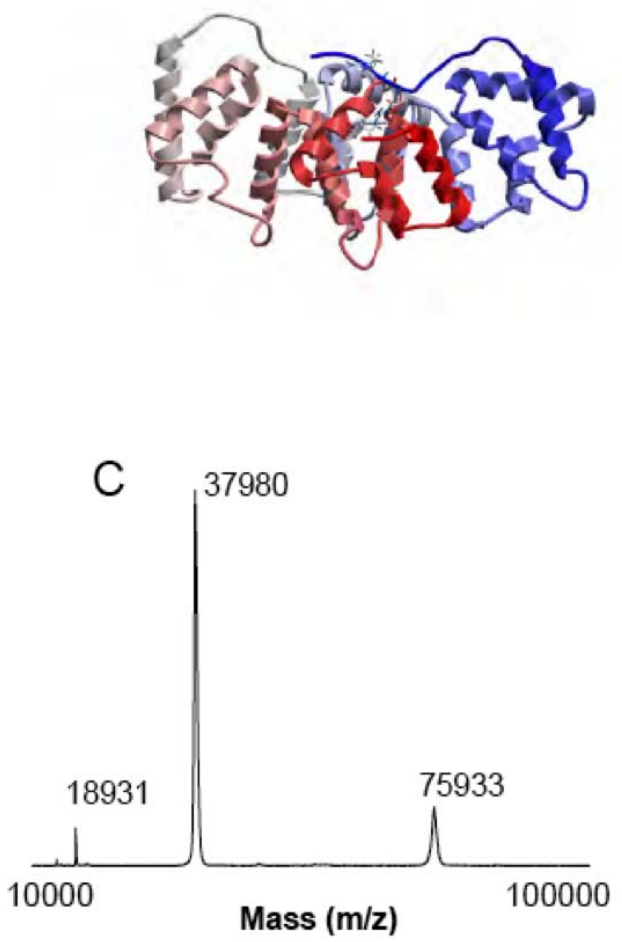

B

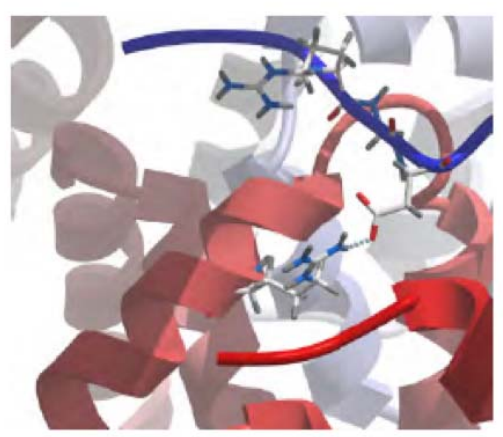

D

\begin{tabular}{|c|c|}
\hline Variant & Amino-acid-replacements \\
\hline RGT - anxA5 & G166C, C316S \\
\hline RGD - anxA5 & T8D, G166C,C316S \\
\hline RGD - M1234 & T8D, E72D, D144N, E228A, D303N \\
\hline
\end{tabular}

Figure 1: (a) The ribbon structure is given for human anxA5, colored from $\mathrm{N}$ to $\mathrm{C}$ terminus following blue-to-red standard coloring. The wild-type sequence from human anxA5 (PDB accession number 1anw.pdb) was mutated in silico by the introduction of a Thr8Asp missense mutation after which the structure was regularized and minimized using the ICM Promolecular modeling package (Molsoft LLC). In this minimized structure Asp8 is involved in hydrogen bonding to Arg 285, which may help in stabilization of the $\mathrm{N}$ terminus. The side chains are indicated for the RGD motif. (b) The interaction between Asp 8 and Arg 285 is shown in detail. (c) MALDI-TOF/TOF analysis of a representative batch of purified RGD-anxA5 showing monomer (37980 Da), the bis-protonated monomer (18931 Da) and the dimer $(75933 \mathrm{Da})$. (d) anxA5 variants and their modifications, all variants are extended with an $\mathrm{N}$-terminal histidine tag.

Labeling of anxA5-variants with optical probes - RGD-anxA5 and RGT-anxA5 were labeled with maleimide-fluorescein (Pierce, Rockford, USA) and maleimidealexa568 (Invitrogen, Cergy Pontoise, France) while RGD-M1234 was labeled with fluorescein isothiocyanate (FITC, Invitrogen) according to the protocols of the manufacturers. FITC-labeled RGD-M1234 was purified by MonoQ ion exchange chromatography (Akta Explorer, GE. Healthcare) to obtain 1:1 stoichiometric complexes. Stoichiometry of the complexes was verified with MALDI-TOF/TOFanalysis. (Applied Biosystems, Foster City, USA).

Ellipsometry - PS-binding characteristics of the anxA5-variants was determined by ellipsometry using a bilayer of 20 mole\% dioleoyl-phosphatidylserine/80 mole\% dioleoyl-phosphatidylcholine (20 mole\% DOPS/80 mole\% DOPC) (Avanti Polar Lipids, Alabama, USA) as described previously ${ }^{16}$. 
Binding to apoptotic jurkat cells - Jurkat cells $\left(1 * 10^{6}\right.$ cells $\left./ \mathrm{ml}\right)$ were triggered in culture medium to execute apoptosis by incubation with anti-Fas antibody $(200 \mathrm{ng} / \mathrm{ml}$ clone 7C11, Beckman-Coulter, Marseille, France) for 3 hours. The course of apoptosis was determined by flow cytometry (Beckman-Coulter) using the anxA5FITC staining protocol (Nexins Research, Kattendijke, The Netherlands). An aliquot of $25 \mathrm{ml}$ cell suspension was added to $220 \mathrm{ml}$ binding buffer $(10 \mathrm{mM}$ Hepes/NaOH, $\mathrm{pH} 7.4,150 \mathrm{mM} \mathrm{NaCl}, 5 \mathrm{mM} \mathrm{KCl}, 1 \mathrm{mM} \mathrm{MgCl}_{2}$ and $2.5 \mathrm{mM} \mathrm{CaCl}_{2}$ ) and $5 \mathrm{ml}$ with different concentrations of fluorescein-labeled anxA5.

Integrin binding in vitro - Accessibility of the RGD-motif for ligation with integrin receptors was determined by flow cytometry and fluorescence microscopy. By Flow cytometry PMA stimulated THP1-cells were scraped and refreshed in complete RPMI 1640 (Gibco BRL) at a concentration of $1 * 10^{6}$ cells $/ \mathrm{ml}$. An aliquot of $50 \mathrm{ml}$ of the cell suspension was added to $445 \mathrm{ml}$ EGTA-containing buffer $(20 \mathrm{mM}$ Hepes, $140 \mathrm{mM}$ $\mathrm{NaCl}, 1 \mathrm{mM}$ EGTA $\mathrm{pH}$ 7.4) and $5 \mathrm{ml}$ fluorescein labeled anxA5-variants solution $(200 \mu \mathrm{g} / \mathrm{ml})$. The assay was performed in EGTA-containing buffer to chelate $\mathrm{Ca}^{2+}$ ions and prevent $\mathrm{Ca}^{2+}$-dependent PS-binding. After $30 \mathrm{~min}$ incubation at room temperature, binding of the variants to THP1-macrophages was analysed by flow cytometry. Results were calculated offline with WinMDI 2.8-software. By fluorescence microscopy the binding of the RGD-motif in the presence of physiological concentrations of $\mathrm{Ca}^{2+}$ was studied. Fluorescein labeled RGT-anxA5 and RGD-anxA5 $(10 \mu \mathrm{g} / \mathrm{ml})$ were incubated for 30 minutes with the adherent THP1cells in $10 \mathrm{mM}$ Hepes/ $\mathrm{pH} 7.4,150 \mathrm{mM} \mathrm{NaCl}, 5 \mathrm{mM} \mathrm{KCl}, 1 \mathrm{mM} \mathrm{MgCl}_{2}$ and $1 \mathrm{mM}$ $\mathrm{CaCl}_{2}$ in the absence and in the presence of cRGD (100-fold molar excess). After nucleus staining, overview pictures were taken and fluorescence was quantified using Leica QWin-software. Fluorescence was normalized for the number of cells.

Efferocytosis assay in vitro with THP1-cells - Efferocytosis was quantified by flow cytometry as described ${ }^{13}$. Briefly, THP1-cells were differentiated with PMA to adherent macrophages as described. PMA-stimulated cells were washed twice with phosphate buffered saline (PBS, Braun Melsungen, Germany). Jurkat cells were preincubated for 10 min with carboxyfluorescein succinimidyl ester (CFSE) (Invitrogen) in serum free RPMI 1640-medium, washed twice with PBS, refreshed in complete RPMI1640-medium $\left(1 * 10^{6} \mathrm{cell} / \mathrm{s} / \mathrm{ml}\right)$ and treated with or without anti-Fas antibody $(200 \mathrm{ng} / \mathrm{ml}$ clone $7 \mathrm{C} 11)$. Apoptotic jurkat cells were added to the differentiated THP1-cells at a ratio $2.5: 1$ in the presence of anxA5-variant $(10 \mathrm{mg} / \mathrm{ml})$ and cRGD (100 times molar excess) if stated in the text. After 20 hours of incubation, THP1macrophages were washed twice with PBS and harvested with $0.5 \%$ trypsin/EDTA (GIBCO-BRL). Efferocytosis of CFSE-Jurkat cells and subsequent processing in the phagolysosome induces a left shift of Fl-1 signal in the Fl-1 versus Fl-3 plot due to acidification of the phagolysosome (Figure 2). 


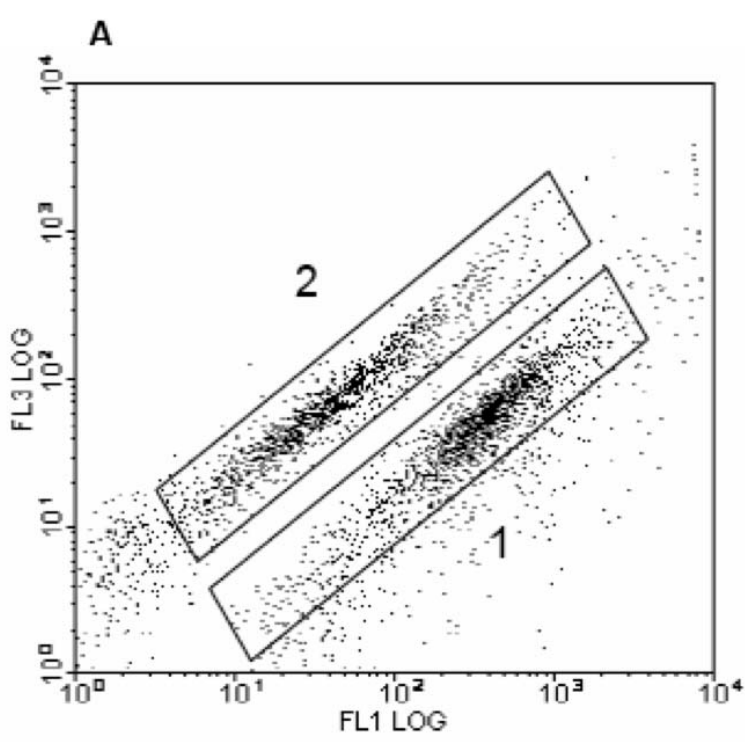

B

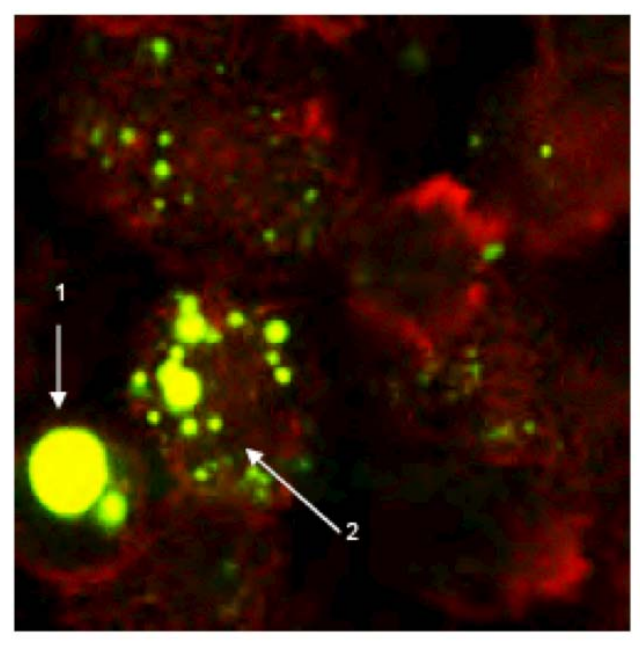

C

D

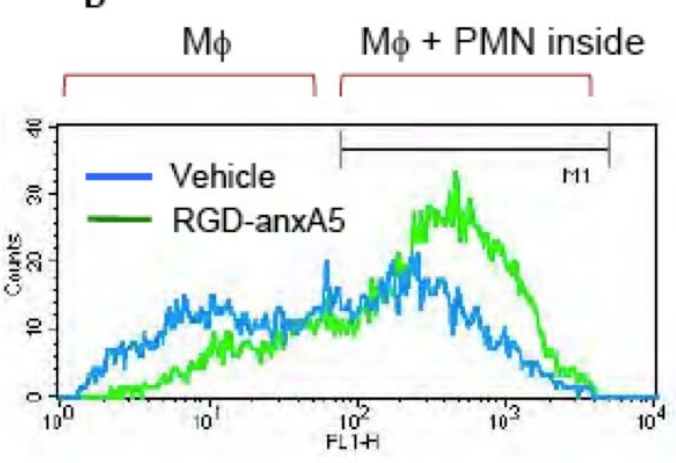

Figure 2: A) In vitro efferocytosis of CFSE-stained apoptotic Jurkat cells by PMAstimulated THP-1 cells. Fl-1 fluorescence versus Fl-3 fluorescence dotplot reveals a left shift of Fl-1 fluorescence after efferocytosis of CFSE-labeled apoptotic Jurkat cells. Free Jurkat cells (1) and phagocytosed Jurkat cells (2) are indicated. B) Twophoton laser scanning microscopy (TPLSM) of THP1-macrophages that were incubated with CFSE-labeled apoptotic Jurkat cells. THP-1 cells were counterstained with Phalloidin-Texas-Red. Free Jurkat cells (1) and engulfed Jurkat cells (2) are indictated. C,D) In vivo efferocytosis of CFSE-stained apoptotic neutrophils by resident peritoneal macrophages of $\mathrm{C} 57 \mathrm{Bl} / 6$ mice. Harvested peritoneal macrophages were inspected by staining myeloperoxidase (MPO)-activity (C). White arrow shows macrophage with engulfed apoptotic neutrophil and black arrows show macrophages that have not engulfed neutrophils. MPO-staining and CFSE-fluorescence co-localize demonstrating the specificity of the Flow Cytometric assay. D) Representative histogram of flow cytometric analyses of peritoneal macrophages measuring the extent of engulfment and showing effect of RGD-anxA5 on efferocytosis.

xCELLigence cell adhesion assay - Cell adhesion and spreading of THP1-cells were measured in 96-well plates with xCELLigence RTCA apparatus (Roche) as described previously ${ }^{17}$. Impedance is expressed in terms of a Cell Index (CI). CI is a dimensionless value representing the impedance between sensing electrodes. Impedance changed by adhesion of cells to the surface and was monitored in time. Using this technique, we monitored adherence of 50000 THP-1 cells/well during differentiation with $50 \mathrm{nM}$ PMA. 
Efferocytosis assay in vitro with bone marrow derived macrophages (BMDM)After 24 hrs stimulation, macrophages were used in the efferocytosis assay. L929 were stimulated to undergo apoptosis with doxorubicin $(10 \mu \mathrm{M})$ overnight at a concentration of $2.0^{*} 10^{6}$ cells $/ \mathrm{ml}$. Apoptotic L929 cells were washed twice with PBS and added to M0-M1-M2a or M2c macrophages at a ratio $2.5: 1$ in the presence or absence of anxA5-variants $(10 \mu \mathrm{g} / \mathrm{ml})$. After 3 hours of incubation, BMDM were washed twice with PBS and harvested for mRNA isolation. RNA was isolated with the High Pure RNA Isolation Kit (Roche, Basel, Switzerland). 200 ng total RNA was reverse-transcribed using the iScript cDNA Synthesis Kit (BioRad, Veenendaal, The Netherlands). Quantitative PCR (Q-PCR) was performed using $10 \mathrm{ng}$ cDNA, $300 \mathrm{nM}$ of each primer, and IQ SYBR Green Supermix (BioRad) in a total volume of $20 \mathrm{ml}$. Results are compared to each subtype without apoptotic jurkat cells.

Ischemia/reperfusion of mouse heart in vivo - Induction of cardiac ischemia and subsequent reperfusion were performed as described previously ${ }^{18}$. After left thoracotomy and exposure of the heart, the left anterior descending coronary artery was ligated for 30 minutes and subsequently reperfusion was established for 24 hours. At the start of reperfusion RGT-anxA5-alexa568 (red, $70 \mu \mathrm{g}$ ) was injected intravenously. $20 \mathrm{~min}$ before sacrifice RGD-anxA5-fluorescein (green, $70 \mu \mathrm{g}$ ) was injected intravenously. The heart was taken out, frozen, sectioned and analysed by fluorescence microscopy. (Leica DMRBE, Rijswijk, the Netherlands).

Efferocytosis assay in vivo - Efferocytosis was performed with apoptotic neutrophils in C57BL/6J mice (Charles River Laboratories) as described elsewhere ${ }^{19}$. To study in vivo efferocytosis by resident peritoneal macrophages, mice were injected i.p. with CFSE-labeled apoptotic human neutrophils $\left(3 * 10^{6}\right.$ cells per mouse). Neutrophils were pre-incubated with the anxA5 variants (RGT-anxA5 and RGD-anxA5) for 5 minutes in buffer (20 mM Hepes, $140 \mathrm{mM} \mathrm{NaCl}, 1,8 \mathrm{mM} \mathrm{CaCl}_{2} \mathrm{pH}$ 7.4) before i.p. injection. Mice were sacrificed 30 minutes after i.p injection, and peritoneal cells were collected by lavage with $3 \mathrm{~mL}$ of icecold PBS containing $3 \mathrm{mmol} / \mathrm{L}$ EDTA. Efferocytosis was assessed by flow cytometry using a BD FACS Calibur platform. After in vivo efferocytosis the macrophages were cultured in a 24 wells plate and supernatant was taken for cytokine determination. To show the phagocytosis, the macrophages were stained with myeloperoxidase (MPO) according the protocols of the manufacturers to show the specificity of the assay (Figure 2).

All animal experiments were approved by the local Animal Experimental Committee.

Cytokine analysis - Efferocytosis with THP-1 macrophages was performed as described above with the exception that the Jurkat cells were not stained with CFSE. After efferocytosis, supernatant was centrifuged at $300 \mathrm{xg}$ for $3 \mathrm{~min}$ to remove free Jurkat cells. Human TNF $\alpha$-ELISA was performed as described elsewhere ${ }^{20}$.

Immunoreactive levels of murine Il-10 and TNF $\alpha$ (MCYTOMAG-70K-04) were measured in the supernatant of cultured peritoneal macrophages by using Milliplex mouse cytokines (Merck Millipore, Billerica, MA, USA). The samples were prepared according to the manufacturers' instructions and analyzed on Bio-Plex 200 Systems (Bio-Rad, Hercules, CA, USA).

Endotoxin determination - The endotoxin content was measured with the Endosafe PTS spectrophotometer using the Endosafe PTS cartridge (0.1 EU sensitivity, Charles River, Wilmington, MA, USA) 
Statistics - Statistics were performed by the non-parametric Mann-Witney t-test. One, two and three asterisks represent $\mathrm{P}$-values $<0.05,<0.01$ and $<0.001$, respectively.

\section{RESULTS}

PS-binding in vitro - Firstly we investigated effects of mutation on PS-binding properties in vitro. RGD-anxA5 exhibited $\mathrm{Ca}^{2+}$-dependent PS-binding similar to RGT-anxA5 while RGD-M1234, which is an anxA5-variant lacking functional $\mathrm{Ca}^{2+} / \mathrm{PS}$-binding sites ${ }^{21}$, showed no phospholipid-binding activity (Figure 3A). The $\mathrm{Ca}^{2+}$-sensitivity of PS-binding was not changed by the introduction of RGD into anxA5's N-terminal tail (Figure 3B). In order to assess binding to apoptotic cells by flow cytometry RGT-anxA5 and RGD-anxA5 were labeled with fluorescein, which yielded 1:1 stoichiometric complexes as determined by MALDI-TOF/TOF (data not shown). RGD-anxA5 and RGT-anxA5 show comparable dose-response curves for binding apoptotic cells and the amount of surface bound anxA5 depended on functional $\mathrm{Ca}^{2+}$-binding sites and was unaffected by the RGD-motif (Figure 3C). Furthermore the $\mathrm{Ca}^{2+}$-chelator EDTA prevented binding and dissociated bound RGDanxA5 from the cell (data not shown). On basis of these results we conclude that the T8D substitution changes anxA5 binding neither to PS embedded in a synthetic bilayer nor to PS in its natural environment of the plasma membrane of apoptotic cells. These results also indicate that the concave side of anxA5 is adjustable, allowing structural changes without interfering allosterically with the convex PSbinding side.

Integrin-binding in vitro - Next, accessibility and functionality of the RGD-motif was investigated using Phorbol 12-Myristate 13-Acetate (PMA)-stimulated human monocytic THP-1 cells, which upregulate integrin $\alpha_{\mathrm{v}} \beta_{3}$ expression in response to phorbol esters ${ }^{22}$. Using xCELLigence technology PMA-induced adherence and spreading of THP-1 cells could be monitored over time. Based on these analyses 72 hours stimulation with $50 \mathrm{nM}$ PMA was chosen. RGD-anxA5-fluorescein but not RGT-anxA5-fluorescein bound to PMA-stimulated THP-1 cells (Figure 3D) in the presence of EGTA. Binding was performed in the presence of EGTA to avoid PSdependent binding. EGTA-conditions were chosen such that no dissociation of the alpha and beta subunit of the integrin receptor occurred ${ }^{23}$. Binding of RGD-M1234fluorescein to THP-1 cells (Figure 3D) confirmed that the RGD motif mediated binding and not the $\mathrm{Ca}^{2+} / \mathrm{PS}$ binding sites. Similar results were found with MCF-7 cells expressing $\alpha_{v} \beta_{5}$ integrins $^{24}$ (data not shown). At physiological $\mathrm{Ca}^{2+}$ concentrations the RGD-motif causes extra binding to THP-1 cells on top of the PS binding as shown in Figure 3E. This extra binding is blocked by a 100 -fold molar excess of cRGD showing that RGD-anxA5 binds to integrins of THP-1 cells in the presence of $1 \mathrm{mM} \mathrm{Ca}^{2+}$. 

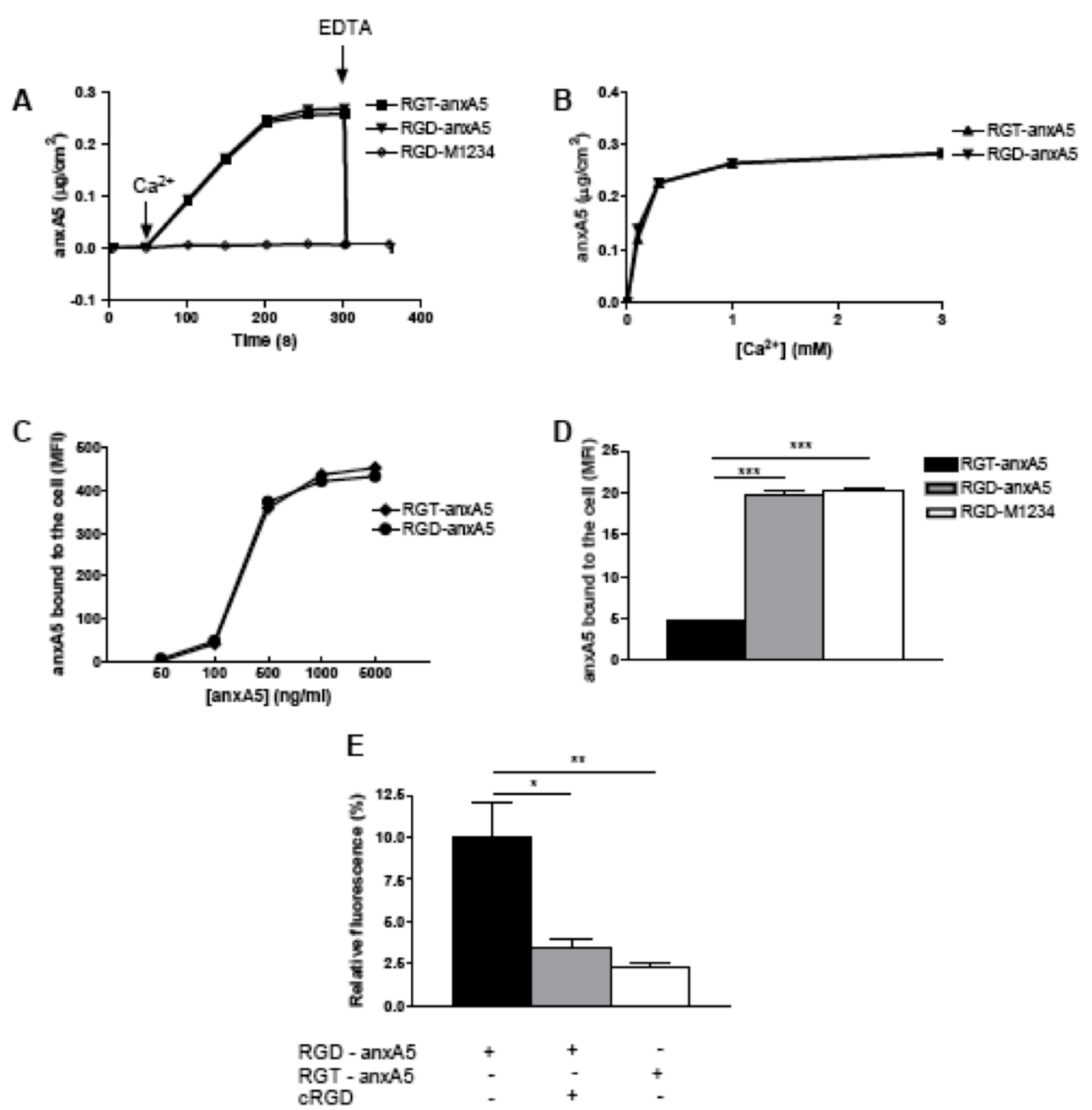

Figure 3: (a) Time courses of anxA5 variants $(1 \mu \mathrm{g} / \mathrm{ml})$ binding to a 20 mole $\%$ DOPS $/ 80$ mole\% DOPC bilayer measured by ellipsometry. At the indicated time points (arrows) $3 \mathrm{mM} \mathrm{Ca}^{2+}$ and $6 \mathrm{mM}$ EDTA were added. (b) $\mathrm{Ca}^{2+}$-dependent binding curves for RGT-anxA5 $(1 \mu \mathrm{g} / \mathrm{ml})$ and RGD-anxA5 $(1 \mu \mathrm{g} / \mathrm{ml})$ to a 20 mole $\%$ DOPS/80 mole\% DOPC bilayer. (c) Dose-response curve of fluorescein-labeled RGT-anxA5 and RGD-anxA5 binding to apoptotic Jurkat cells measured by flow cytometry. (d) Binding of $10 \mu \mathrm{g} / \mathrm{ml}$ fluorescein-labeled RGT-anxA5, RGD-anxA5 and RGD-M1234 to PMA-stimulated THP-1 cells $\left(1 \times 10^{6}\right.$ cells/ml $)$ in the presence of EGTA ( $1 \mathrm{mM})$. Mean \pm S.E.M. is shown. (e) Adherent THP-1 cells were incubated with fluorescein-labeled RGT-anxA5 and RGD-anxA5 $(10 \mu \mathrm{g} / \mathrm{ml})$ in $10 \mathrm{mM}$ HEPES/pH 7.4, $150 \mathrm{mM} \mathrm{NaCl}, 5 \mathrm{mM} \mathrm{KCl}, 1 \mathrm{mM} \mathrm{MgCl}_{2}$ and $1 \mathrm{mM} \mathrm{CaCl}_{2}$ in the absence and presence of cRGD $(28 \mu \mathrm{M})$ during $30 \mathrm{~min}$. Cells were stained with 4,6diamidino-2-phenylindole. Fluorescein was measured and number of cells were counted. Fluorescence was normalized for the number of cells. One, two and three asterisks represent $P$-values $<0.05,<0.01$ and $<0.001$, respectively. 
RGD-anxA5 enhances efferocytosis by THP1 macrophages in vitro - RGD-anxA5 stimulated efferocytosis by THP1-macrophages with $40 \%$ whereas RGT-anxA5 inhibited it with 33\% (Figure 4A) and lactadherin stimulates efferocytosis with $60 \%$ (data not shown) as measured with a recently described efferocytosis assay (Figure 2A-B) ${ }^{13}$. This $40 \%$ stimulation can completely be inhibited by a 100 -fold molar excess of cRGD (figure 4B). Hence, introduction of RGD into the N-terminal tail transformed anxA5 from an inhibitor into a stimulator of efferocytosis.

TNF $\alpha$-secretion during efferocytosis in vitro - TNF $\alpha$-secretion by PMA-stimulated THP-1 cells was slightly reduced by the presence of apoptotic cells either in the absence or presence of RGT-anxA5 and RGD-M1234 (Figure 4C). The combination of apoptotic cells and RGD-anxA5 dramatically increased secretion of TNF $\alpha$ (Figure 4C). None of the annexins affected the basal secretion of TNF $\alpha$ by PMA-stimulated THP-1 cells in the absence of apoptotic cells (data not shown). These results demonstrate that RGD-anxA5 affects cytokine secretion only in the presence of apoptotic cells, likely by bridging between cell surface expressed PS of the apoptotic cell and $a_{v} b_{3}$ of the THP-1 cell, a property that is not possessed by RGT-anxA5 and RGD-M1234. 2-Dimensional crystallization of RGD-anxA5 on the cell surface may contribute to enhanced outside-in signaling by integrin receptor clustering ${ }^{25}$. The enhanced TNFa-secretion presumably precludes a therapeutic role for RGD-anxA5. However, PMA-stimulated THP-1 cells upregulate pro-inflammatory cytokines during efferocytosis ${ }^{26}$ in contrast to blood derived macrophages, which suppress proinflammatory cytokine production when engulfing apoptotic cells ${ }^{27}$. Therefore we analysed effects of apoptotic cells and annexins on upregulation of TNF $\alpha$ mRNA by bone marrow derived macrophages that were differentiated into various phenotypes. Neither RGD-anxA5 nor RGT-anxA5 caused an upregulation of TNF $\alpha$ mRNA in any of the phenotypes studied (Figure 4D). These findings opened the door to in vivo studies. 
A
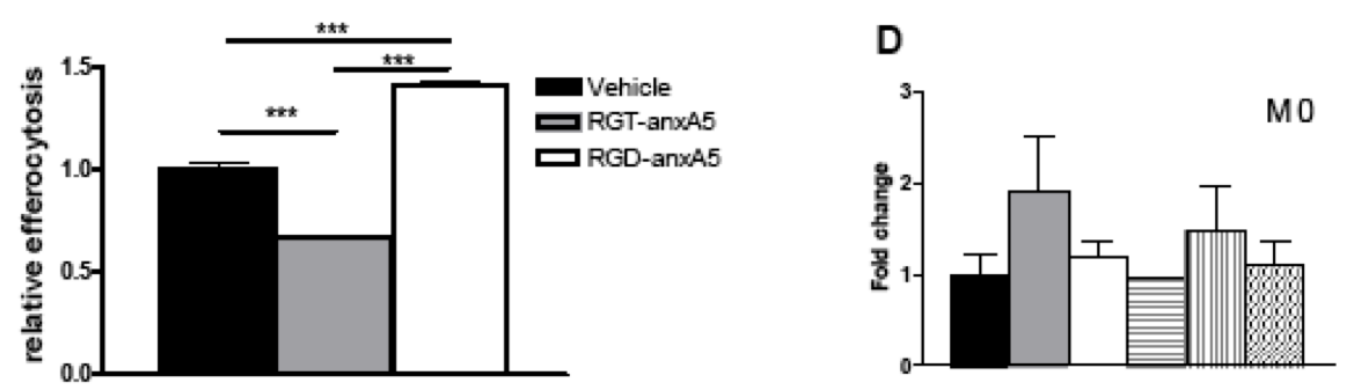

B

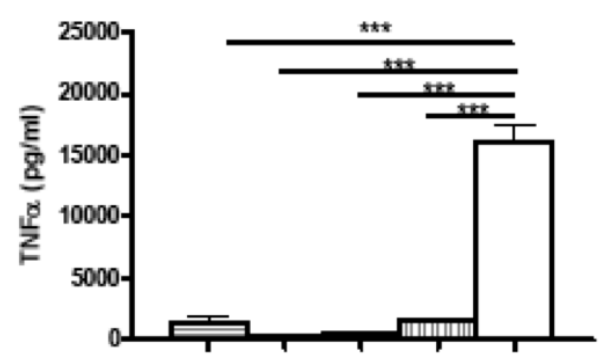

$\begin{array}{llllll}\text { THP-1M } & + & + & + & + & + \\ \text { apopt. cells } & - & + & + & + & + \\ \text { RGT-anxA5 } & - & - & + & - & - \\ \text { RGD -M1234 } & - & - & - & + & - \\ \text { RGD - anxA5 } & - & - & - & - & +\end{array}$

C

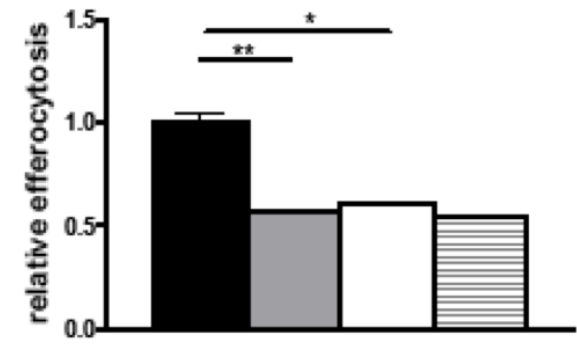

RGD - anxA5

RGT - anxA5 cRGD

Figure 4 (a) Effects of anxA5 variants $(10 \mu \mathrm{g} / \mathrm{ml})$ on efferocytosis of apoptotic Jurkat cells $\left(2.5 \times 10^{6}\right.$ cells $\left./ \mathrm{ml}\right)$ by PMA-stimulated THP- 1 cells $\left(10^{6}\right.$ cells $\left./ \mathrm{ml}\right)$. (b) Effect of 100 -fold molar excess of cRGD on efferocytosis of apoptotic Jurkat cells $(2.5 \times$ $10^{6}$ cells $\left./ \mathrm{ml}\right)$ by PMA-stimulated THP- 1 cells $\left(10^{6}\right.$ cells $\left./ \mathrm{ml}\right)$ in the presence of RGDanxA5. (c) Effects of anxA5 variants $(10 \mu \mathrm{g} / \mathrm{ml})$ on TNF $\alpha$ secretion by PMAstimulated THP-1 cells $\left(10^{6}\right.$ cells $\left./ \mathrm{ml}\right)$ in the absence and presence of apoptotic Jurkat cells $\left(2.5 \times 10^{6}\right.$ cells $\left./ \mathrm{ml}\right)$. (d) Effects of anxA5 variants $(10 \mu \mathrm{g} / \mathrm{ml})$ on TNF $\alpha$ mRNA expression by M0, M1, M2a and M2c $\left(2.5 \times 10^{5}\right.$ cells/well $)$ in the presence of apoptotic L929 cells $\left(6.3 \times 10^{5}\right.$ cells/well $)$. Mean \pm S.E.M. is shown. One, two and three asterisks represent $P$-values $<0.05,<0.01$ and $<0.001$, respectively. 
PS-binding in vivo - Next, PS-binding in vivo was determined in a mouse model of ischemia/reperfusion injury of the heart. We showed previously that murine cardiomyocytes exposed to ischemic/reperfusion stress externalized and internalized PS continuously during a period of more than 60 minutes ${ }^{28}$. RGD-anxA5-fluorescein and RGT-anxA5-alexa568 stained the same cardiomyocytes in the area at risk if administered intravenously (Figure 5). No uptake of RGD-anxA5 and RGT-anxA5 was observed in control mouse hearts (data not shown) and RGD-M1234 failed to bind stressed cardiomyocytes (data not shown). These findings indicate that insertion of the RGD-motif into the N-terminal tail was without effect on the in vivo PS-target finding activity of anxA5.
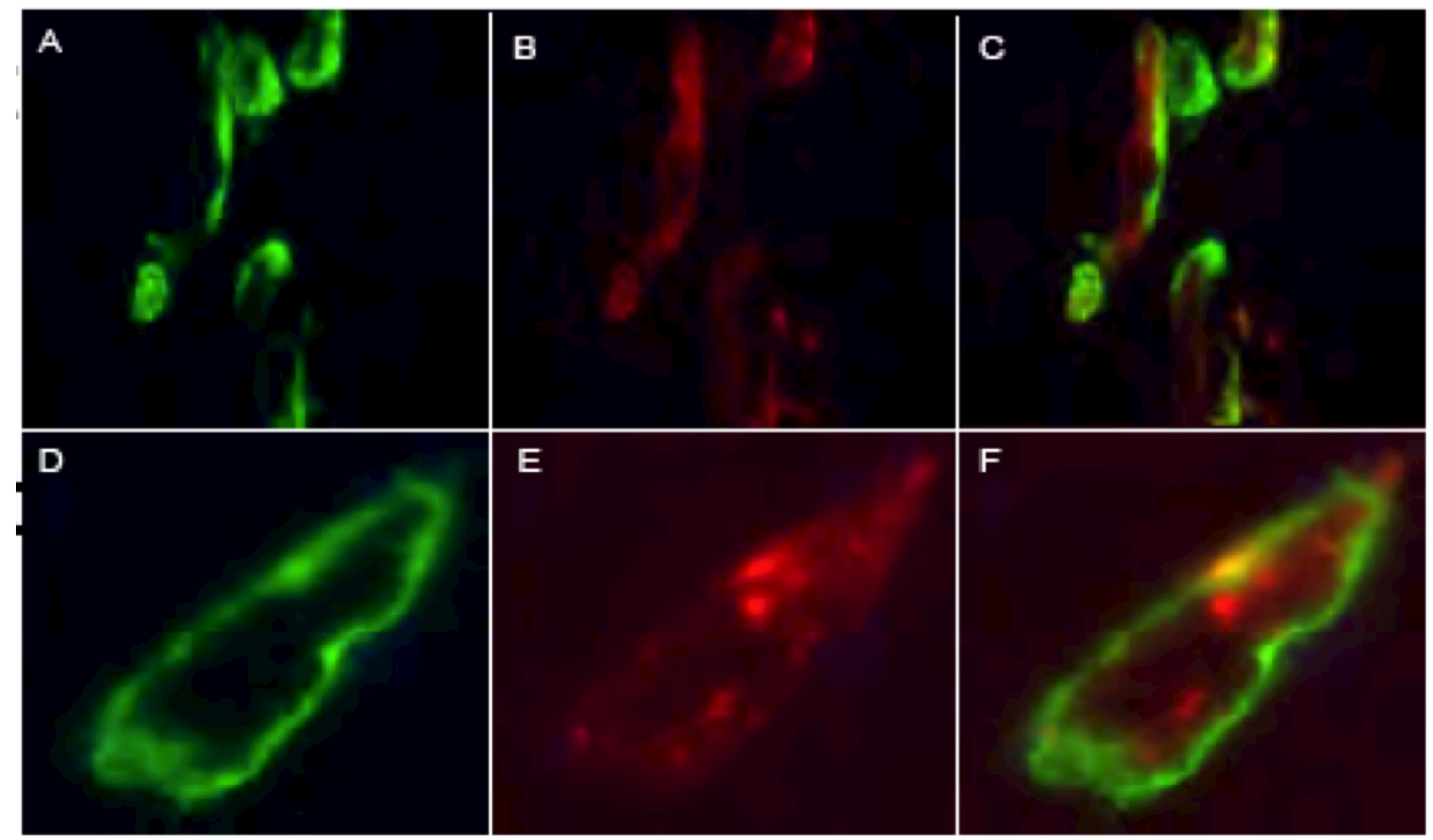

Figure 5 (a-c) Ex vivo images of sections of a mouse heart that was exposed to $30 \mathrm{~min}$ ischemia and $24 \mathrm{~h}$ of reperfusion. At the start of reperfusion RGT-anxA5-alexa568 (red, $70 \mu \mathrm{g}$ ) was injected intravenously. Twenty minutes before sacrifice RGDanxA5-fluorescein (green, $70 \mu \mathrm{g}$ ) was injected intravenously. The heart was taken out, frozen, sectioned and analyzed by fluorescence microscopy. (d-f) A higher magnification image of the infarcted area showing a single stained cardiomyocyte.

RGD-anxA5 enhances efferocytosis in vivo - In order to assess the impact of RGDanxA5 on efferocytosis in vivo fluorescent apoptotic neutrophils were injected intraperitoneally into wildtype C57BL/6J mice. Resident peritoneal macrophages engulfed apoptotic neutrophils, a process that was quantified by flow cytometry (Figure 2). RGD-anxA5 enhanced efferocytosis with $20 \%$ while RGT-anxA5 had no effect on phagocytosis (Figure 6A). 

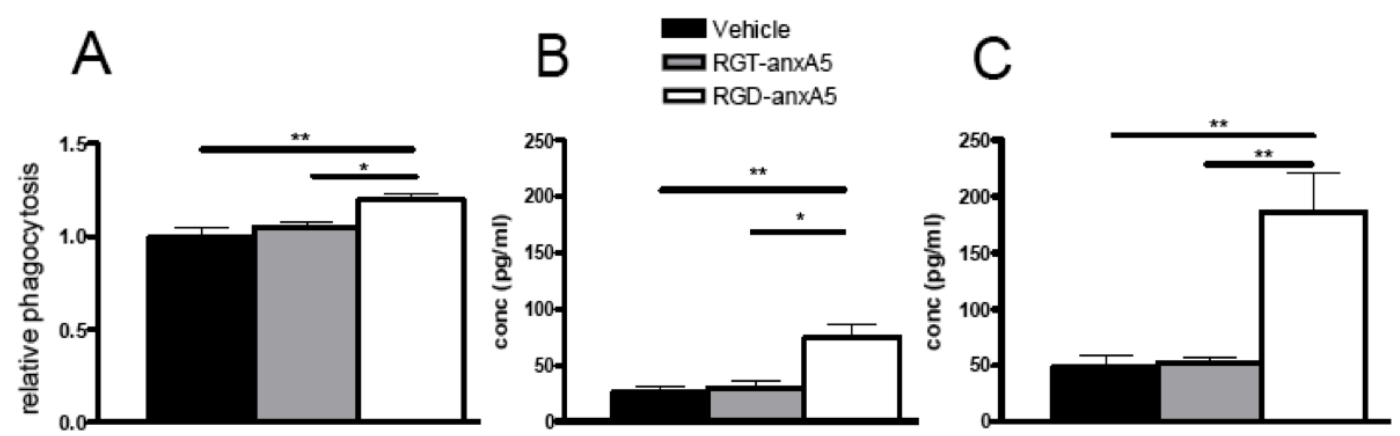

Figure 6: Effects of anxA5 variants $(24 \mu \mathrm{g})$ on efferocytosis of CFSE-stained apoptotic neutrophils $\left(3.0 \times 10^{6}\right.$ cells $)$ by resident peritoneal macrophages of C57BL/6J mice. (a) Collected peritoneal macrophages were analyzed by flow cytometry and relative phagocytosis was determined. Collected peritoneal macrophages were cultured during $20 \mathrm{~h}$ and TNF $\alpha$ (b) and IL-10 release (c) were quantified. Mean \pm S.E.M. is shown. One and two asterisks represent $P$-values $<0.05$ and $<0.01$, respectively.

Cytokine release after efferocytosis in vivo - The effect of efferocytosis on cytokine production was determined by harvesting peritoneal macrophages 30 minutes post-injection of apoptotic neutrophils in absence or presence of annexins. Harvested macrophages were cultured for $20 \mathrm{~h}$ and levels secreted TNF $\alpha$ and IL-10 were measured in the culture medium. RGD-anxA5 induced an increase of cytokine secretion from $30 \mathrm{pg} / \mathrm{ml}$ to $75 \mathrm{pg} / \mathrm{ml}$ (TNF $\alpha$, Figure 6B) and from $40 \mathrm{pg} / \mathrm{ml}$ to 185 $\mathrm{pg} / \mathrm{ml}$ (IL-10, Figure 6C). RGT-anxA5 did not alter cytokine secretion.

Endotoxin determination - All anxA5 variants contain less then one endotoxin units per ml.

\section{DISCUSSION}

Enhancing phagocytosis has been proposed as therapeutic strategy to treat inflammation ${ }^{4-6}$. Strategies could focus on the phagocyte and aim to stimulate the molecular machinery executing phagocytosis ${ }^{29}$ or focus on the phagocytic prey and label it with additional "eat me" signals ${ }^{30}$. Here we present the strategy to add additional "eat me" signals to the apoptotic cell by targeting PS, which is a ubiquitous hallmark of apoptosis independent of cell type and cell death-inducing trigger ${ }^{31}$. PS can interact directly or indirectly via PS binding proteins with receptors on the phagocyte ${ }^{9}$. The variety of engulfment receptors and apoptotic ligands led to the proposal of a "tether and tickle" model in which PS could mediate both tethering of the apoptotic cell to the phagocyte and tickling of the phagocyte by engaging different receptors ${ }^{32}$. TIM-4, a member of the T cell immunoglobulin and mucin family, was identified as a PS receptor mediating tethering ${ }^{33,34}$. The integrin $\alpha_{v} \beta_{3}$ acts as ticklingreceptor through binding PS via the opsonin MFG-E8 ${ }^{35}$ and activating Rac1 and Rab5-dependent pathways ${ }^{14}$. Both phagocytic receptors cooperate to engulf the PS expressing apoptotic cell ${ }^{14}$, indicating that apoptotic cell expresses sufficient PS to allow multiple interactions with different receptors and bridging molecules. Recently it was shown that $\alpha_{\mathrm{v}} \beta_{3}$-dependent efferocytosis is a crucial process in dampening aggravation of chronic inflammation such as atherosclerosis ${ }^{3}$. Therefore we reasoned that targeting PS with "eat me" signals engaging $\alpha_{\mathrm{v}} \beta_{3}$ could be a viable strategy to 
treat inflammation. We selected anxA5 as PS-targeting agent and modified it into an $\alpha_{\mathrm{v}} \beta_{3}$ ligand (RGD-anxA5) because of i) the Molecular Imaging experience with anxA5 ${ }^{10}$, ii) its elucidated 3 -dimensional structure ${ }^{36}$ and iii) its property to form a 2dimensional network on the apoptotic cell surface thereby clustering receptors with which it interacts ${ }^{37}$.

In this paper we demonstrate that anxA5 can be successfully transformed from an inhibitor into a stimulator of efferocytosis. This was accomplished by a T8D substitution that introduces an RGD-motif in the N-terminal tail, which is located at the concave surface of anxA5 apical to the convex side harboring the PS-binding sites ${ }^{38}$. The T8D substitution had no deleterious effects on anxA5's PS-binding properties in vitro and its apoptotic cell targeting-function in vivo. In contrast to wildtype anxA5 (RGT-anxA5), RGD-anxA5 possessed the property of binding to $\alpha_{v} \beta_{3}$ and $\alpha_{v} \beta_{5^{-}}$ expressing cells and stimulating efferocytosis. The flexible loop conformation of the $\mathrm{N}$-terminal tail and the amino acids flanking the RGD-motif likely facilitated ligation of the RGD-motif with the integrin receptor ${ }^{39}$. RGD-anxA5 stimulated engulfment of apoptotic cells in vitro and in vivo. The latter was determined in a model that exposes resident peritoneal macrophages to apoptotic neutrophils. It is remarkable and promising that RGD-anxA5 was capable of stimulating efferocytosis by $20 \%$ in this system since resident peritoneal macrophages already utilize TIM-4 for tethering and MFG-E8 to engage $\alpha_{v} \beta_{5}$ for tickling ${ }^{14}$.

In addition to stimulating efferocytosis, RGD-anxA5 appeared to cause upregulation of TNF $\alpha$ in PMA-stimulated THP-1 cells. This would preclude RGD-anxA5 as a therapeutic agent since a shift towards pro-inflammation aggravates inflammatory pathologies such as atherosclerosis ${ }^{40}$. We reasoned that RGD-anxA5-induced upregulation of TNF $\alpha$ could be a consequence of the in vitro model system we selected to study efferocytosis. It has been shown that $\alpha_{\mathrm{v}} \beta_{3}$ signaling augments TNF $\alpha$ -production by PMA-stimulated THP- 1 cells ${ }^{41}$. In agreement with our reasoning we demonstrated that RGD-anxA5 was without noticeable effects on TNF $\alpha$ production by bone marrow-derived macrophages of different phenotypes. Furthermore, RGDanxA5 caused only a modest stimulation of TNF $\alpha$ production $(75 \mathrm{pg} / \mathrm{ml})$ in vivo by resident peritoneal macrophages that were exposed to apoptotic cells. Activated peritoneal macrophages can produce TNF $\alpha$ up to levels of several 1000's pg/ml ${ }^{42,43}$. Adequate efferocytosis is required for resolution of inflammation and suppression of progressive inflammation such as atherosclerosis ${ }^{40}$. It is generally accepted that adequate efferocytosis involves secretion of anti-inflammatory cytokines such as IL$10^{2}$. PS mediated tethering and tickling is intimately linked to efferocytosis and the secreted cytokine profile. Blocking PS with wildtype anA5 (RGT-anxA5) resulted in reduced efferocytosis and increased secretion of pro-inflammatory cytokines by activated peritoneal macrophages ${ }^{12}$. Interestingly, we observed no effect of RGTanxA5 on phagocytosis and cytokine secretion by resident macrophages whereas RGD-anxA5 stimulated efferocytosis and enhanced TNF $\alpha$ secretion \pm 2 -fold and IL10 secretion \pm 4 -fold. These results support the model that contribution of PS to efferocytosis depends on the macrophage population ${ }^{44}$. Whether RGD-anxA5 exhibits therapeutic effects during inflammation is currently being investigated in a mouse model of atherosclerosis. We hypothesize that RDG-anxA5 protects against atherosclerosis because an RGD-dependent mechanism triggers IL-10 release during efferocytosis ${ }^{45}$, knock-out of the RGD-opsonin MFG-E8 culminates in reduced IL-10 levels and aggravation of atherosclerosis ${ }^{3}$ and intravenously administered anxA5 accumulates in atherosclerotic plaques ${ }^{46}$. 
In conclusion, targeting cell surface expressed PS to enhance efferocytosis is an attractive strategy for treatment of inflammatory diseases and the rationally designed RGD-anxA5 is a promising therapeutic agent.

\section{ACKNOWLEDGEMENT}

Supported in part by the European Union grant Euregional PACT II from the Interreg IV program of Grensregio Vlaanderen-Nederland (IVA-VLANED-1.20) and by project grants from the Fund for Scientific Research Flanders (FWO-Vlaanderen, G.0728.10, G067512N to DVK) and Methusalem grant (BOF09/01M00709 to PV) from the Flemish Government. DVK is a postdoctoral fellow paid by fellowship from FWO-Vlaanderen. The authors are indebted to Nicole Bitsch for her technical assistance and to Dr. Gerry Nicolaes (Dept. Biochemistry, Molecular Modeling and Structure Analysis, Maastricht University) for preparing figures $1 \mathrm{~A}$ and $1 \mathrm{~B}$. Lactadherin was obtained as a kind gift from Dr. J. Rasmussen.

\section{REFERENCES}

1. Krysko DV, D'Herde K, Vandenabeele P. Clearance of apoptotic and necrotic cells and its immunological consequences. Apoptosis 2006; 11(10): 1709-26.

2. Savill J, Dransfield I, Gregory C, Haslett C. A blast from the past: clearance of apoptotic cells regulates immune responses. Nature reviews. Immunology 2002; 2(12): 965-75.

3. Ait-Oufella H, Kinugawa K, Zoll J, Simon T, Boddaert J, Heeneman S et al. Lactadherin deficiency leads to apoptotic cell accumulation and accelerated atherosclerosis in mice. Circulation 2007; 115(16): 2168-77.

4. Gaipl US, Beyer TD, Baumann I, Voll RE, Stach CM, Heyder P et al. Exposure of anionic phospholipids serves as anti-inflammatory and immunosuppressive signal--implications for antiphospholipid syndrome and systemic lupus erythematosus. Immunobiology 2003; 207(1): 73-81.

5. Hanayama R, Tanaka M, Miyasaka K, Aozasa K, Koike M, Uchiyama Y et al. Autoimmune disease and impaired uptake of apoptotic cells in MFG-E8-deficient mice. Science 2004; 304(5674): 1147-50.

6. Tabas I. Consequences and therapeutic implications of macrophage apoptosis in atherosclerosis: the importance of lesion stage and phagocytic efficiency. Arterioscler Thromb Vasc Biol 2005; 25(11): 2255-64.

7. Nakanishi Y, Henson PM, Shiratsuchi A. Pattern recognition in phagocytic clearance of altered self. Advances in experimental medicine and biology 2009; 653: 129-38.

8. Fadok VA, Voelker DR, Campbell PA, Cohen JJ, Bratton DL, Henson PM. Exposure of phosphatidylserine on the surface of apoptotic lymphocytes triggers specific recognition and removal by macrophages. J Immunol 1992; 148(7): 2207-16.

9. Ravichandran KS. Beginnings of a good apoptotic meal: the find-me and eat-me signaling pathways. Immunity 2011; 35(4): 445-55.

10. Boersma HH, Kietselaer BL, Stolk LM, Bennaghmouch A, Hofstra L, Narula J et al. Past, present, and future of annexin A5: from protein discovery to clinical applications. J Nucl Med 2005; 46(12): 2035-50.

11. Vermes I, Haanen C, Steffens-Nakken H, Reutelingsperger C. A novel assay for apoptosis. Flow cytometric detection of phosphatidylserine expression on early apoptotic cells using fluorescein labelled Annexin V. J Immunol Methods 1995; 184(1): 39-51.

12. Bondanza A, Zimmermann VS, Rovere-Querini P, Turnay J, Dumitriu IE, Stach CM et al. Inhibition of phosphatidylserine recognition heightens the immunogenicity of irradiated lymphoma cells in vivo. J Exp Med 2004; 200(9): 1157-65.

13. Kenis H, van Genderen H, Deckers NM, Lux PA, Hofstra L, Narula J et al. Annexin A5 inhibits engulfment through internalization of PS-expressing cell membrane patches. Exp Cell Res 2006; 312(6): 719-26.

14. Toda S, Hanayama R, Nagata S. Two-step engulfment of apoptotic cells. Molecular and cellular biology 2012; 32(1): 118-25. 
15. Goossens P, Gijbels MJ, Zernecke A, Eijgelaar W, Vergouwe MN, van der Made I et al. Myeloid type I interferon signaling promotes atherosclerosis by stimulating macrophage recruitment to lesions. Cell Metab 2010; 12(2): 142-53.

16. Cuypers PA, Corsel JW, Janssen MP, Kop JM, Hermens WT, Hemker HC. The adsorption of prothrombin to phosphatidylserine multilayers quantitated by ellipsometry. J Biol Chem 1983; 258(4): 2426-31.

17. Atienza JM, Yu N, Kirstein SL, Xi B, Wang X, Xu X et al. Dynamic and label-free cell-based assays using the real-time cell electronic sensing system. Assay Drug Dev Technol 2006; 4(5): 597-607.

18. Dumont EA, Reutelingsperger CP, Smits JF, Daemen MJ, Doevendans PA, Wellens HJ et al. Real-time imaging of apoptotic cell-membrane changes at the single-cell level in the beating murine heart. Nat Med 2001; 7(12): 1352-5.

19. Montero-Melendez T, Patel HB, Seed M, Nielsen S, Jonassen TE, Perretti M. The melanocortin agonist AP214 exerts anti-inflammatory and proresolving properties. Am J Pathol 2011; 179(1): 259-69.

20. Engelberts I, Moller A, Schoen GJ, van der Linden CJ, Buurman WA. Evaluation of measurement of human TNF in plasma by ELISA. Lymphokine Cytokine Res 1991; 10(1-2): 69-76.

21. Mira JP, Dubois T, Oudinet JP, Lukowski S, Russo-Marie F, Geny B. Inhibition of cytosolic phospholipase A2 by annexin V in differentiated permeabilized HL-60 cells. Evidence of crucial importance of domain I type II Ca2+-binding site in the mechanism of inhibition. $J$ Biol Chem 1997; 272(16): 10474-82.

22. Prieto J, Eklund A, Patarroyo M. Regulated expression of integrins and other adhesion molecules during differentiation of monocytes into macrophages. Cell Immunol 1994; 156(1): 191-211.

23. Ma Y, Wong K. Reassociation and translocation of glycoprotein IIB-IIIA in EDTA-treated human platelets. Platelets 2007; 18(6): 451-9.

24. Andersen MH, Graversen H, Fedosov SN, Petersen TE, Rasmussen JT. Functional analyses of two cellular binding domains of bovine lactadherin. Biochemistry 2000; 39(20): 6200-6.

25. Hato T, Pampori N, Shattil SJ. Complementary roles for receptor clustering and conformational change in the adhesive and signaling functions of integrin alphallb beta3. The Journal of cell biology 1998; 141(7): 1685-95.

26. Kurosaka K, Watanabe N, Kobayashi Y. Production of proinflammatory cytokines by phorbol myristate acetate-treated THP-1 cells and monocyte-derived macrophages after phagocytosis of apoptotic CTLL-2 cells. Journal of immunology 1998; 161(11): 6245-9.

27. Fadok VA, Bratton DL, Konowal A, Freed PW, Westcott JY, Henson PM. Macrophages that have ingested apoptotic cells in vitro inhibit proinflammatory cytokine production through autocrine/paracrine mechanisms involving TGF-beta, PGE2, and PAF. J Clin Invest 1998; 101(4): 890-8.

28. Kenis H, Zandbergen HR, Hofstra L, Petrov AD, Dumont EA, Blankenberg FD et al. Annexin a5 uptake in ischemic myocardium: demonstration of reversible phosphatidylserine externalization and feasibility of radionuclide imaging. J Nucl Med 2010; 51(2): 259-67.

29. Hodrea J, Majai G, Doro Z, Zahuczky G, Pap A, Rajnavolgyi E et al. The glucocorticoid dexamethasone programs human dendritic cells for enhanced phagocytosis of apoptotic neutrophils and inflammatory response. Journal of Leukocyte Biology 2011; 91(1): 127-136.

30. Chvanov M, Petersen OH, Tepikin AV. Pharmacologically directed cell disposal: labeling damaged cells for phagocytosis as a strategy against acute pancreatitis. Mol Interv 2010; 10(2): 80-5.

31. Martin SJ, Reutelingsperger CP, McGahon AJ, Rader JA, van Schie RC, LaFace DM et al. Early redistribution of plasma membrane phosphatidylserine is a general feature of apoptosis regardless of the initiating stimulus: inhibition by overexpression of Bcl-2 and Abl. J Exp Med 1995; 182(5): 1545-56.

32. Henson PM, Bratton DL, Fadok VA. The phosphatidylserine receptor: a crucial molecular switch? Nat Rev Mol Cell Biol 2001; 2(8): 627-33.

33. Miyanishi M, Tada K, Koike M, Uchiyama Y, Kitamura T, Nagata S. Identification of Tim4 as a phosphatidylserine receptor. Nature 2007; 450(7168): 435-9.

34. Park D, Hochreiter-Hufford A, Ravichandran KS. The phosphatidylserine receptor TIM-4 does not mediate direct signaling. Current biology : CB 2009; 19(4): 346-51.

35. Hanayama R, Tanaka M, Miwa K, Shinohara A, Iwamatsu A, Nagata S. Identification of a factor that links apoptotic cells to phagocytes. Nature 2002; 417(6885): 182-7. 
36. Huber R, Romisch J, Paques EP. The crystal and molecular structure of human annexin V, an anticoagulant protein that binds to calcium and membranes. Embo J 1990; 9(12): 3867-74.

37. Ungethum L, Kenis H, Nicolaes GA, Autin L, Stoilova-McPhie S, Reutelingsperger CP. Engineered annexin A5 variants with impaired cell entry for molecular imaging of apoptosis using pretargeting strategies. J Biol Chem 2011; 286(3): 1903-1910.

38. Huber R, Schneider M, Mayr I, Romisch J, Paques EP. The calcium binding sites in human annexin $\mathrm{V}$ by crystal structure analysis at 2.0 A resolution. Implications for membrane binding and calcium channel activity. FEBS Lett 1990; 275(1-2): 15-21.

39. Haubner R, Wester HJ, Reuning U, Senekowitsch-Schmidtke R, Diefenbach B, Kessler H et al. Radiolabeled alpha(v)beta3 integrin antagonists: a new class of tracers for tumor targeting. J Nucl Med 1999; 40(6): 1061-71.

40. Van Vre EA, Ait-Oufella H, Tedgui A, Mallat Z. Apoptotic cell death and efferocytosis in atherosclerosis. Arteriosclerosis, Thrombosis, and Vascular Biology 2012; 32(4): 887-93.

41. Kurihara Y, Nakahara T, Furue M. alphaVbeta3-integrin expression through ERK activation mediates cell attachment and is necessary for production of tumor necrosis factor alpha in monocytic THP-1 cells stimulated by phorbol myristate acetate. Cellular immunology 2011; 270(1): 25-31.

42. Filardy AA, Pires DR, Nunes MP, Takiya CM, Freire-de-Lima CG, Ribeiro-Gomes FL et al. Proinflammatory clearance of apoptotic neutrophils induces an IL-12(low)IL-10(high) regulatory phenotype in macrophages. J Immunol 2010; 185(4): 2044-50.

43. Michlewska S, Dransfield I, Megson IL, Rossi AG. Macrophage phagocytosis of apoptotic neutrophils is critically regulated by the opposing actions of pro-inflammatory and antiinflammatory agents: key role for TNF-alpha. FASEB J 2009; 23(3): 844-54.

44. Fadok VA, Savill JS, Haslett C, Bratton DL, Doherty DE, Campbell PA et al. Different populations of macrophages use either the vitronectin receptor or the phosphatidylserine receptor to recognize and remove apoptotic cells. Journal of immunology 1992; 149(12): 4029-35.

45. Asano K, Miwa M, Miwa K, Hanayama R, Nagase H, Nagata S et al. Masking of phosphatidylserine inhibits apoptotic cell engulfment and induces autoantibody production in mice. J Exp Med 2004; 200(4): 459-67.

46. Kietselaer BL, Reutelingsperger CP, Heidendal GA, Daemen MJ, Mess WH, Hofstra L et al. Noninvasive detection of plaque instability with use of radiolabeled annexin A5 in patients with carotid-artery atherosclerosis. N Engl J Med 2004; 350(14): 1472-3. 



\section{CHAPTER 5}

\section{THE PRO-EFFEROCYTOTIC RGD-ANNEXIN A5 INHIBITS DE NOVO ATHEROSCLEROTIC PLAQUE FORMATION IN APOE ${ }^{-/-}$- MICE}

Based on: The pro-efferocytotic RGD-annexin A5 inhibits de novo atherosclerotic plaque formation in $\mathrm{ApoE}^{-/-}$-mice. Kristof Schutters, Dianne Cooper, Jeroen Otten, Marjo Donners, Nicole J. Bitsch, Marijke De Saint-Hubert, Matthias Bauwens, Dmitri V. Krysko, Peter Vandenabeele, Erik A.L. Biessen, Alfons Verbruggen, Mauro Perretti, Leon J. Schurgers, Chris P.M. Reutelingsperger. Submitted for publication. 


\begin{abstract}
Objective - Impaired efferocytosis has been shown to contribute to progression of atherosclerotic lesion formation. Recently we described Arg-Gly-Asp-annexin A5 (RGD-anxA5) which displayed pro-efferocytotic properties through its acquired ability to interact with $\alpha_{v} \beta_{3}$ receptors of the phagocyte. Here we investigated its effect on early atherogenesis in the apoE ${ }^{-/-}$mouse model of atherosclerosis.
\end{abstract}

Approach and results - Atherosclerotic plaque formation was induced in apoE ${ }^{-/-}$ mice by perivascular carotid artery collar placement. AnxA5 wildtype (RGT-anxA5) and RGD-anxA5 were administered intraperitoneally three times per week starting one week after collar placement. Lesions were allowed to develop during 4 weeks. Analysis of developed lesions revealed that RGD-anxA5 is a potent inhibitor of early atherogenesis, with a complete prevention of atherosclerotic lesion formation in seven out of nine mice. WT AnxA5 WT had no effect on plaque size but favors a more stable phenotype, increasing both vascular smooth cell (VSMC) and collagen content of the plaque while significantly reducing the plaque's acellular area. In vitro RGDanxA5 reduced monocyte adhesion to endothelial cells, indicating an interference with monocyte infiltration as additional mechanism contributing to inhibition of atherogenesis. Of note, RGD-AnxA5 did not affect platelet aggregation, VSMC migration and blood coagulation.

Conclusion - RGD-anxA5 is a potent therapeutic tool to inhibit de novo atherosclerotic lesion formation.

\title{
INTRODUCTION
}

Atherosclerosis is a chronic inflammatory disease affecting the vascular wall of arteries and is the major cause of morbidity and mortality in both developed and developing nations ${ }^{1}$. Most acute cardiovascular events such as myocardial infarction and ischemic stroke are caused by rupture of unstable atherosclerotic lesions. Histochemical analyses of culprit atherosclerotic lesions in patients with acute myocardial infarction led to the proposal that apoptotic cells make the plaque vulnerable to rupture ${ }^{2}$. Recent studies point out opposing roles for apoptosis in atherosclerotic plaque progression and indicate the importance of efferocytosis, the phagocytic clearance of dying cells ${ }^{3}$. In advanced lesions macrophage apoptosis promotes development of the necrotic core and, hence, contributes to vulnerability of the plaque ${ }^{4}$. In early lesions, apoptosis is beneficial through suppression of lesion cellularity ${ }^{5-7}$. In both phenotypes efficient efferocytosis of apoptotic inflammatory cells is a fundamental process for the resolution phase of inflammation ${ }^{8-10}$. Collectively, these observations support the proposition that enhancing efferocytosis can be a viable strategy to avoid post-apoptotic necrosis, reduce inflammation and ultimately limit atherogenesis ${ }^{3,11,12}$.

Efferocytosis depends on recognition of the apoptotic cell by the phagocyte. Cell surface-expressed phosphatidylserine (PS) is the best characterized and one of the most important 'eat me' signals for efferocytosis ${ }^{13,14}$. The $35 \mathrm{kDa}$ human protein annexin A5 (anxA5) binds PS with high affinity in a $\mathrm{Ca}^{2+}$-dependent manner ${ }^{15,}{ }^{16}$. Apoptosis imaging with labeled anxA5 has been applied in animal models and patients ${ }^{14,17}$. These studies show that anxA5 accumulates in unstable atherosclerotic lesions where phagocytosis and apoptosis are out of balance ${ }^{18,19}$ and they point towards potential therapeutic applications of anxA5 ${ }^{20}$ generated a new annexin A5 (anxA5) variant carrying an Arg-Gly-Asp (RGD)-motif ${ }^{21}$. AnxA5 Wild Type ((Arg- 
Gly-Thr)-annexin A5 or RGT-anxA5) binds with high affinity to PS exposed on apoptotic cells and inhibits efferocytosis by shielding PS and other 'eat me'-signals in the vicinity ${ }^{22}$. The introduction of RGD in the N-terminal tail of the anxA5 molecule ligates the apoptotic cell to $\alpha_{V} \beta_{3 / 5}$-integrin receptors expressed on professional phagocytes ${ }^{23-25}$ and transforms anxA5 from an inhibitor into a stimulator of efferocytosis, as demonstrated in vitro and following acute administration in vivo ${ }^{21}$.

Here we investigated the therapeutic effect of RGD-anxA5 on de novo carotid atherogenesis in atherosclerosis-prone apoE knockout $\left(\mathrm{apoE}^{-/}\right)$mice. We clearly show that RGD-anxA5 acts as a potent inhibitor of early atherogenesis in contrast to RGTanxA5. RGT-anxA5 had no effect on lesion size but induced a more stable phenotype with decreased necrotic core burden and increased smooth muscle cell and collagen content.

\section{MATERIALS AND METHODS}

Design, expression and purification of the different anxA5-variants - The anxA5variants were prepared as described previously ${ }^{21}$. Briefly, E.Coli M15 (pREP4) (Qiagen, Valencia, USA) is transformed with pQE30Xa (Qiagen) containing cDNA of the anxA5-variants. Bacteria were grown to 0.8 OD600 and expression was induced by adding $0.5 \mathrm{mM}$ isopropyl $\beta$-D-1-thiogalactopyrano-side (IPTG, Eurogentec, Seraing, Belgium). After 3 hours, bacteria were harvested and resuspended in phosphate buffer $(20 \mathrm{mM}$, pH 7.4) containing $500 \mathrm{mM} \mathrm{NaCl}, 20 \mathrm{mM}$ imidazole and $1 \%$ Triton X-100. Bacteria were lysed by sonication at $12 \mu \mathrm{m}$ amplitude for $6 \times 10 \mathrm{~s}$. Lysis was continued at room temperature for 3 hours. Cell debris was removed by centrifugation. His-tagged proteins were isolated from supernatant by chromatography using nickel columns (GE Healthcare, Amersham, USA) and an imidazole gradient. Purified proteins were checked on homogeneity (MALDI-TOF/TOF) and phosphatidylserine binding activity (ellipsometry) as described elsewhere ${ }^{21}$.

Flow chamber assay with human monocytes and activated HUVEC cells Human umbilical vein endothelial cells (HUVEC) were seeded on gelatin-coated $\mu$ Slides VI0.4 (Ibidi, Germany) and confluent monolayers were stimulated with TNF- $\alpha$ (10ng/ml; R\&D Systems, United Kingdom) overnight. Human peripheral blood mononuclear cells (PBMCs) were freshly isolated from healthy volunteers by doubledensity gradient centrifugation as described ${ }^{26,27}$. PBMCs were diluted to $1 * 10^{6} / \mathrm{mL}$ in Dulbecco phosphate buffered saline (DPBS) supplemented with $\mathrm{Ca}^{2+}$ and $\mathrm{Mg}^{2+}$, and incubated with or without anxA5 - variants $(20 \mathrm{nM})$ at $37^{\circ} \mathrm{C} 10$ minutes before the start of the flow experiment. PBMCs were perfused over the endothelial monolayers at a constant shear stress of $1 \mathrm{dyne} / \mathrm{cm}^{2}$ using a syringe pump (Harvard Apparatus, South Natick, MA). After 8 minutes of perfusion, 6 random fields were recorded for 10 seconds ready for off-line analysis. Video sequences were transferred to a computer and loaded into ImageJ software. PBMCs were manually tagged and their movements on the endothelium monitored. The total number of interacting cells was quantified as described ${ }^{28}$.

Thrombin generation - Effects of anxA5 variants on blood coagulation were determined in plasma from healthy volunteers. Endogenous thrombin potential (ETP) was measured in platelet poor (PPP) and in platelet rich plasma (PRP) as described previously ${ }^{29}$. PPP and PRP were triggered with 5 pM tissue factor (Dade Innovin, Liederbach, Germany) in presence and absence of $10 \mu \mathrm{M} 20$ mole\% dioleoyl- 
phosphatidylserine/ $\quad 60$ mole $\%$ dioleoyl-phosphatidylcholine/ 20 mole $\%$ dioleoylphosphatidylethanolamine (Avanti Polar Lipids, Alabama, USA). PRP was additionally triggered with horm collagen (Bicton, Cambs., U.K.).

Platelet aggregation - Washed human platelets were prepared in the presence of apyrase as described previously (29). $230 \mu 1$ of washed platelet suspension were incubated with anxA5 variants $(10 \mu \mathrm{M})$ in a 2-channel aggregometer (Chronolog aggregometer Labor, Hamburg, Germany) for $3 \mathrm{~min}$ at $37^{\circ} \mathrm{C}$. Platelets were stimulated with $10 \mu \mathrm{M}$ methyl-S-ADP in the presence of $1.8 \mathrm{mM} \mathrm{Ca}^{2+}$. Changes in light transmission were recorded during constant stirring of the samples $(900$ r.p.m., $37^{\circ} \mathrm{C}$ ). Shape change and aggregation were assessed by measuring the change in light transmission.

Vascular Smooth Muscle Cell migration - Smooth muscle cell migration was examined using xCELLigence technology with the real time cell analyzer dual plate instrument (Roche, Almere, The Netherlands) according to manufacturers instructions. In brief, $50 \mathrm{ml}$ of M199 medium (GIBCO-BRL, Carlsbad, USA) containing 20\% heat-inactivated fetal calf serum (GIBCO-BRL) and $20 \mathrm{ng} / \mathrm{ml}$ human platelet derived growth factor (sigma-aldrich, Zwijndrecht, The Netherlands) was added to the lower chamber. The upper chamber was then carefully assembled on top of the lower chamber and 40000 human primary vascular smooth muscle cells per well (American Type Culture Collection, Manassas, VA, USA) were added in M199 medium containing $0,5 \%$ FCS in the presence of $10 \mathrm{mg} / \mathrm{ml}$ anxA5 variant or in the presence of a 100 times molar excess of cyclic RGD. Cell migration to the lower chamber was monitored in time and expressed as cell migration in arbitrary units.

Biodistribution of RGD-anxA5 and RGT-anxA5 in mice - AnxA5-variants were labeled with ${ }^{99 \mathrm{~m}} \mathrm{Technetium}$, through histidin tag (6xHis) chelation of ${ }^{99 \mathrm{~m}} \mathrm{Tc}(\mathrm{CO})_{3}$, as described elsewhere ${ }^{30} .1 \mathrm{MBq}$ of ${ }^{99 \mathrm{~m}}$ Tc-labeled anxA5 was injected per mouse via the tail vein. Mice were sacrificed 4 hours post injection (p.i.). The organs were removed, weighed and their radioactivity was measured in an automated $\mathrm{NaI}(\mathrm{Tl})$ gamma counter (Wallac Wizard, Turku, Finland). Uptake was expressed as percentage of injected dose of the radioactivity per gram of organ $(\% \mathrm{ID} / \mathrm{g})$.

Blood clearance of intraperitoneally-administered anxA5 variants in apoE $\mathrm{E}^{-/ \text {- }}$ mice - 12 weeks old $\mathrm{ApoE}^{-/-}$-mice were fed a Western type diet $(0.25 \%$ cholesterol $)$ for 4 weeks. Mice were then injected intraperitoneally (IP) with $1 \mathrm{MBq}{ }^{99 \mathrm{~m}}$ Tc-labeled anxA5-variant. Blood was taken at 1, 2, 4, 6, 8 and 24 hours p.i.. Blood was weighed and its radioactivity was measured in an automated $\mathrm{NaI}(\mathrm{Tl})$ gamma counter (Wallac Wizard, Turku, Finland). Blood levels are expressed as \%ID/g. Half-live of circulating anxA5 was calculated using the formula $\ln \mathrm{C}_{\mathrm{t}}=\ln \mathrm{C}_{0}-\mathrm{k}_{\mathrm{e}} \mathrm{t}$ and $\mathrm{k}_{\mathrm{e}}=\ln 2 /$ $t_{1 / 2}$ in which $C_{t}$ and $C_{0}$ are the concentration of anxA5 in the blood at time points $t$ and 0 respectively, and $\mathrm{k}_{\mathrm{e}}$ is the elimination rate constant. $\mathrm{t}_{1 / 2}$ is the half-life of the circulating anxA5-variant.

ApoE $^{-/-}$-mouse model of atherosclerosis - 12 weeks old male ApoE ${ }^{-/-}$mice were fed a Western type diet $(0.25 \%$ cholesterol). After 2 weeks a collar with an inner diameter of $0.3 \mathrm{~mm}$ was placed around the carotid arteries (Figure 1A) as described by von der Thüsen et al. ${ }^{31}$. One week after collar placement mice were randomly divided into three groups (control group: $\mathrm{n}=8$, RGT-anxA5 group: $\mathrm{n}=9$ and an RGD-anxA5 
group: $n=9$ ). Mice then received (Monday, Wednesday and Friday, Figure 1B) 1 $\mathrm{mg} / \mathrm{kg}$ anxA5 variant or vehicle 3 times per week by IP injection during a period of 4 weeks. Mice were sacrificed at the end of the experiment and the carotid arteries were removed for immunohistochemical analysis. Tibias, femurs and blood were collected for flow cytometric analysis of leukocyte subsets.
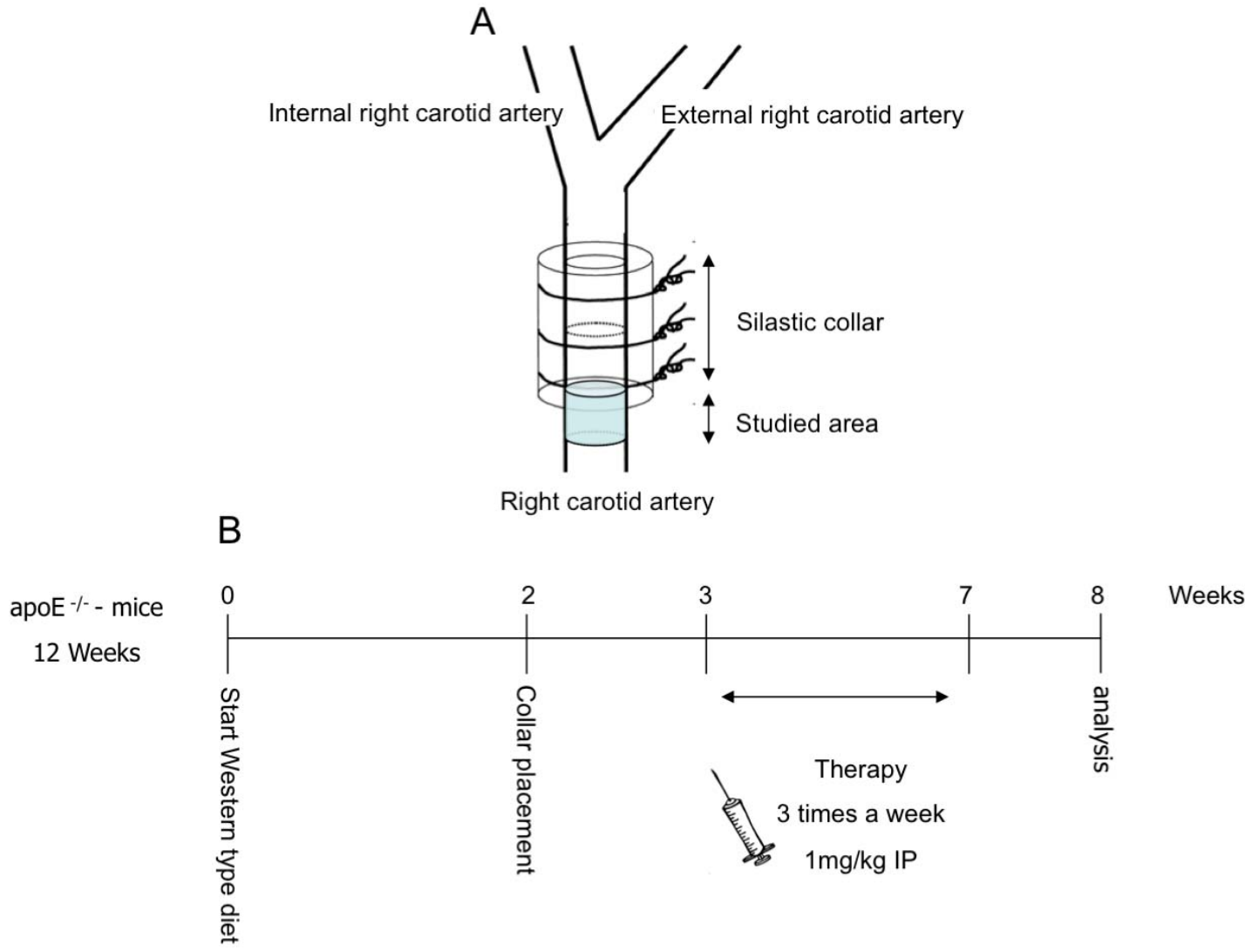

Figure 1: A) Schematic representation of carotid collar positioning and visualization of the studied area. (modified from von der Thüsen ${ }^{31}$ ) B) Schematic representation of the experimental set-up.

Flow Cytometric analysis of bone marrow and blood - Bone marrow cells were isolated from one tibia and one femur per mouse as described ${ }^{32}$. Bone marrow and blood samples were depleted from erythrocytes by incubation with a hypotonic buffer ( $8.4 \mathrm{~g} / 1 \mathrm{NH}_{4} \mathrm{Cl}$ and $0.84 \mathrm{~g} / \mathrm{N} \mathrm{NaHCO}_{3}, \mathrm{pH}$ 7). Non-specific Fc-receptor binding of antibodies was blocked by addition of anti-CD16/CD32 antibody (eBioscience, San Diego, USA). T-cells, B-cells, NK-cells, granulocytes, monocytes, and relevant subsets of these populations were determined using subset-specific antibodies (Table 1). Samples, antibodies and buffers were kept on ice throughout the experiments. All measurements were performed on a FACS Canto II (BD Biosciences) and analysis of acquired data was performed using FACS Diva software (BD Biosciences). 
Table 1 - Overview of flow cytometry antibodies for the different subsets of leukocytes used.

\begin{tabular}{lllllll}
\hline \hline Antibody & Conjugate & Clone & Company & $\begin{array}{l}\text { Leukocyte } \\
\text { subset }\end{array}$ & Tissue & \\
\hline \hline CD3e & FITC & $\begin{array}{l}145- \\
\text { 2C11 }\end{array}$ & eBioscience & T-cell & Blood & Bone \\
\hline CD4 & APC-H7 & GK1.5 & BD Biosciences & $\begin{array}{l}\text { T-helper } \\
\text { cell }\end{array}$ & Blood & \\
\hline CD8 & eFluor450 & $53-6.7$ & eBioscience & $\begin{array}{l}\text { Cytotoxic } \\
\text { T-cell }\end{array}$ & Blood & \\
\hline CD11b & PE-Cy7 & M1/70 & BD Biosciences & monocytes & Blood & Bone \\
\hline $\begin{array}{l}\text { CD45RA } \\
\text { (B220) }\end{array}$ & V500 & RA3- & BD Biosciences & B-cells & Blood & Bone \\
\hline Ly6C & APC & 1G7.G10 & Miltenyi Biotec & $\begin{array}{l}\text { Infiltrating } \\
\text { monocytes }\end{array}$ & Blood & Bone \\
\hline Ly6G & PE & 1A8 & BD Biosciences & granulocyte & Blood & Bone \\
\hline NK1.1 & PerCP- & PK136 & eBioscience & NK-cell & Blood & \\
\hline NK1.1 & eFluor450 & PK136 & eBioscience & NK-cell & & Bone \\
\hline \hline
\end{tabular}

Histology and immunohistochemistry - Paraffin sections were stained with hematoxylin (Klinipath) and eosin (Klinipath) to determine the volume of the lesions. Quantitative analysis of the lesions was performed using Qwin histomorphometry software on 7 sections $(60 \mu \mathrm{m}$ apart $)$ from each mouse. Parallel sections were stained with monoclonal rat anti- mouse Mac3 (dilution 1:50, BD Pharmingen), cleaved caspase-3 (1:100, Cell signaling tech) and a-smooth muscle cell actin (1:200, Abcam) to stain macrophages, apoptotic cells and smooth muscle cells respectively. Antibodies were visualized with a Nova-RED substrate (Vector Laboratories, Inc). Sections were counterstained with hematoxylin and mounted with imsol (Klinipath) and entellan (Merck). In negative controls, incubation with primary antibody was omitted. Masson's trichrome stain was performed to analyze the amount of collagen according the protocol of the manufacturers.

Cytokine analysis - Immunoreactive levels of murine TNF- $\alpha$ Il-10 and Il$1 \beta$ (MCYTOMAG-70K-04) were measured in EDTA drawn plasma samples using Milliplex mouse cytokines (Merck Millipore, Billerica, MA, USA). The samples were prepared according to the manufacturers' instructions and analyzed on Bio-Plex 200 Systems (Bio-Rad, Hercules, CA, USA).

Endotoxin determination - Endotoxin content in the anxA5 samples were measured with the Endosafe PTS spectrophotometer using the Endosafe PTS cartridge (0.1 EU sensitivity, Charles River, Wilmington, MA, USA). All anxA5 variants contained less than one endotoxin unit per ml.

Statistics - Statistics were performed by the non-parametric Mann-Whitney t-test. One, two and three stars represent $\mathrm{p}$-values $<0.05,<0.01$ and $<0.001$, respectively.

Ethics - The animal experiments were approved by the DEC, the animal experimental regulatory authority of Maastricht University. 


\section{RESULTS}

Biodistribution and blood clearance of the anxA5 variants - In order to assess whether the introduction of an RGD-motif in the N-terminal tail of anxA5 affects its biodistribution we injected mice intravenously with $1 \mathrm{MBq}{ }^{99 \mathrm{~m}} \mathrm{Tc}$-labeled anxA5 variant per mouse. Introduction of the RGD-motif did not significantly alter the biodistribution in healthy mice (Figure 2A). IP injection of radiolabeled anxA5variants in $\mathrm{apoE}^{-/-}$mice led to appearance of the variants into the blood circulation within 1 hour post injection Blood clearance of anxA5 was not significantly affected by the RGD-motif, (half-lives for RGT-anxA5 and RGD-anxA5 are 5.64 \pm 2.33 and $4.92 \pm 1.82$ hours, respectively (Figure $2 \mathrm{~B}$ ). Based on these results, we decided to administer anxA5 variants intraperitoneally 3 times per week.

RGD-anxA5 but not RGT-anxA5 inhibits atherosclerotic plaque formation - As expected collar placement combined with Western Type diet led to accelerated plaque formation proximal to the collar after 4 weeks (Figure 3 A, D, E). Treatment with the integrin-inert WT control, RGT-anxA5 had neither effect on plaque size nor on medial thickness under the plaque (Figure $3 \mathrm{~B}, \mathrm{D}, \mathrm{E}$ ). Intriguingly, RGD-anxA5 treatment profoundly inhibited atherogenesis. Out of 9 RGD-anxA5 treated mice 7 animals did not develop visible plaques within the time-frame of the experiment (Figure $3 \mathrm{C}$ and D). Moreover no thickening of the media was observed in these mice compared to vehicle and RGT-anxA5 controls (Figure 3E). The plaques of the 2 RGD-anxA5 treated mice that did develop lesions, showed intimal thickening with predominantly infiltrated macrophages (Figure 3F). Hence, RGD-anxA5 strongly inhibited initiation of atherogenesis in the collar-induced apoE ${ }^{-/-}$carotid atherosclerosis model. 

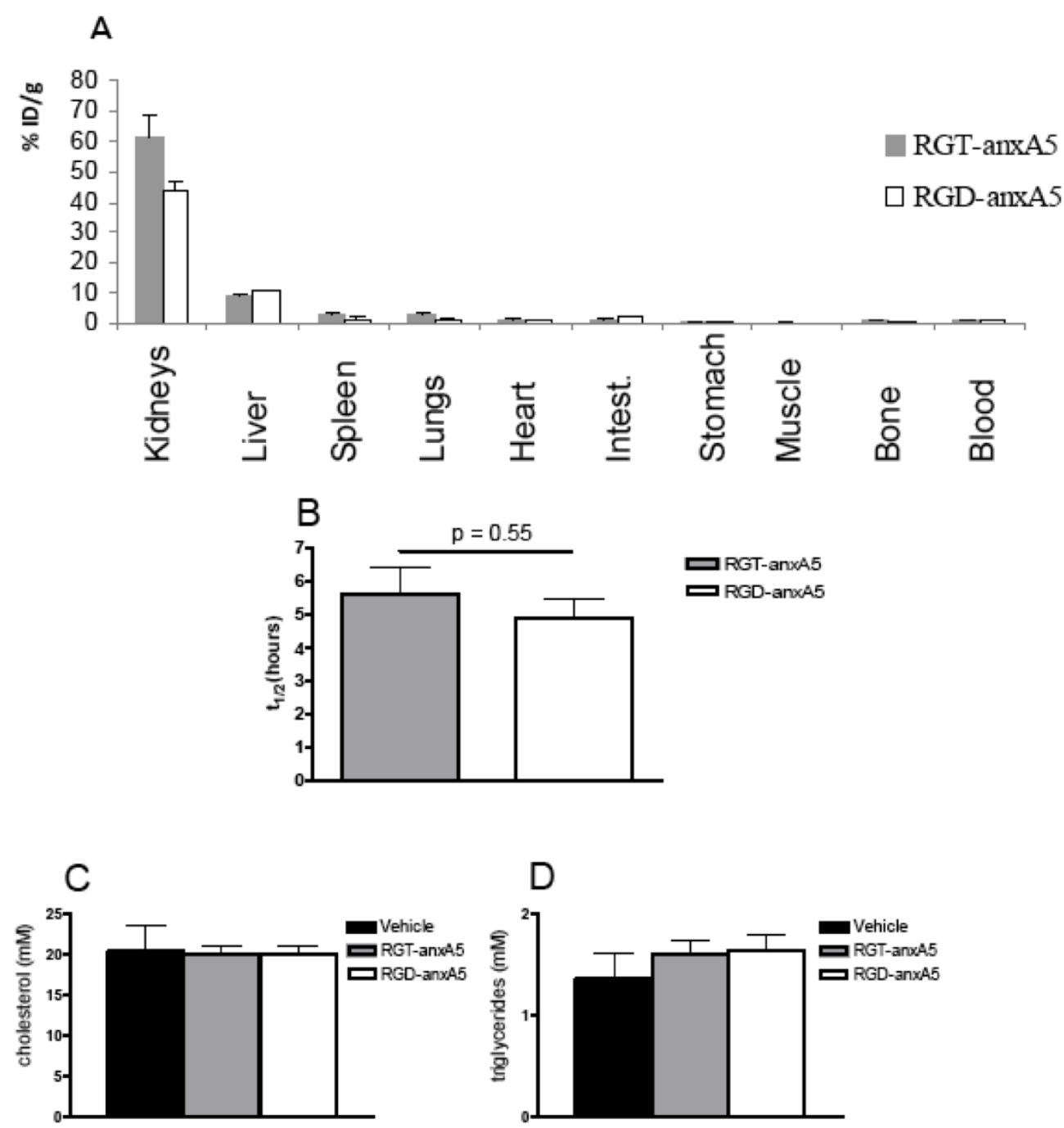

Figure 2: A) Biodistribution of ${ }^{99 \mathrm{~m}}$ Tc-labeled anxA5-variants. 6-weeks old healthy mice were injected intravenously with ${ }^{99 \mathrm{~m}} \mathrm{Tc}$-labeled anxA5-variants $(1 \mathrm{MBq})$. Organs were collected 4 hours p.i., weighed and measured for uptake of radioactivity. B) Half-lives of RGT- and RGD-anxA5 after intraperitoneal injection in apoE ${ }^{-/-}$mice. C) Plasma cholesterol and triglyceride levels (D) in EDTA-drawn blood after 4 weeks of therapy of $\mathrm{apoE}^{-/-}$mice. 

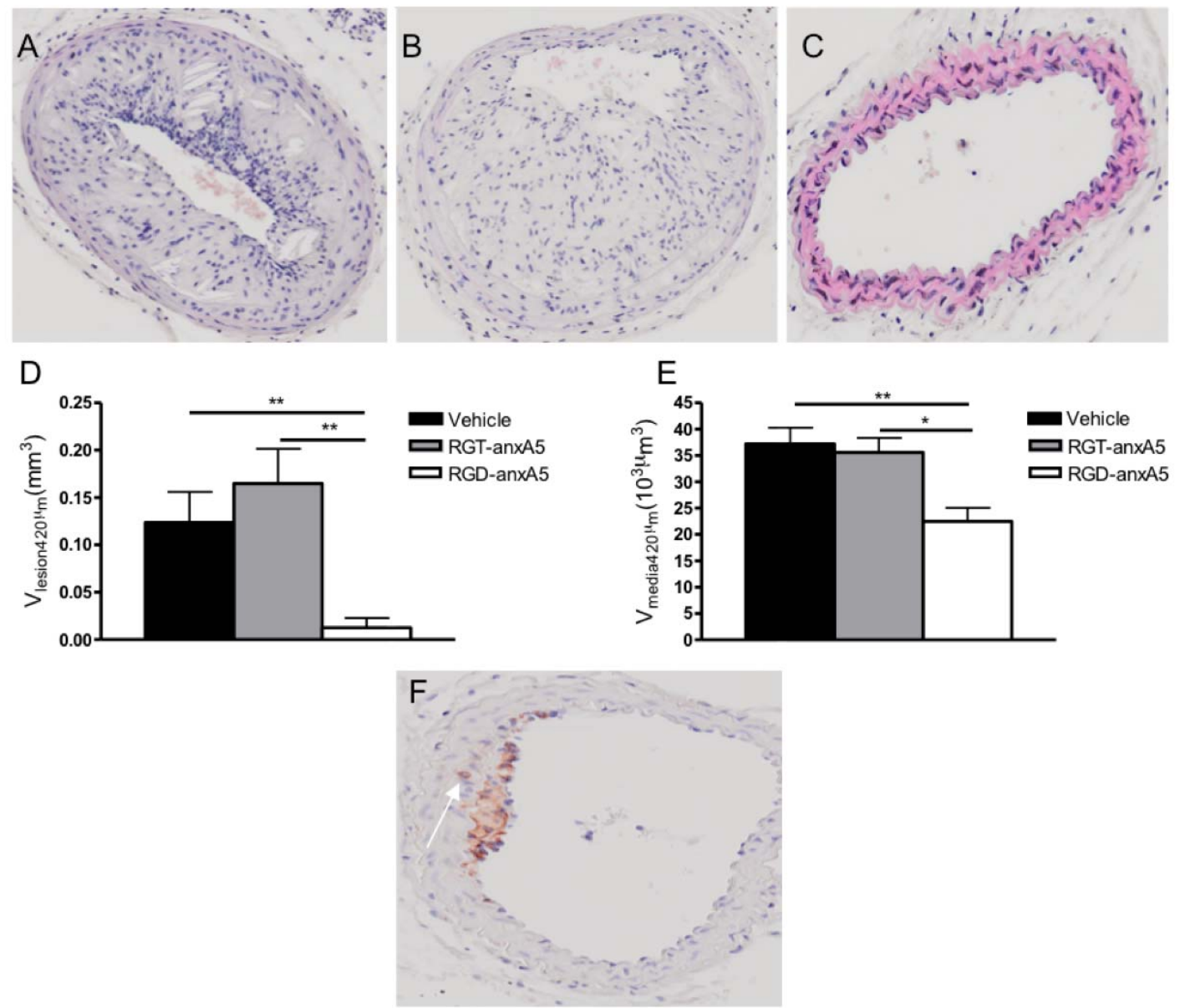

Figure 3: Plaque size analysis of cross-sections of the right carotid artery obtained from vehicle (A), RGT-anxA5 (B) and RGD-anxA5 (C) treated apoE ${ }^{-/-}$-mice (de novo atherosclerosis: representative visualization (A, B, C); quantification intima (D) and quantification media (E); Error bars represent SEM. Intimal plaque size and medial thickening of RGD-anxA5 treated mice are significantly reduced compared to the control mice. One and two asterisks represent P-values $<0.05$ and 0.01 , respectively F) MAC-3 staining of a cross-sections of the right carotid artery obtained from one RGD-anxA5 treated apoE ${ }^{-/-}$-mouse that developed a small lesion. The white arrow indicates MAC-3 positivity in the media.

RGT-anxA5 shifts plaques towards a more stable phenotype Immunohistochemical analyses revealed a striking effect of RGT-anxA5 on plaque phenotype. RGT-anxA5 treatment had no significant effects on plaque apoptotic index (Figure 4A) and plaque macrophage content (Figure 4C) compared to vehicle controls. However, RGT-anxA5 increased both VSMC (Figure 4D-G) and collagen content of the plaque (Figure $4 \mathrm{H}-\mathrm{K}$ ) while it reduced significantly the plaque's acellular area (lipid + necrotic core) (Figure 4B). Results of the immunohistochemical analyses are summarized in Table 2. 

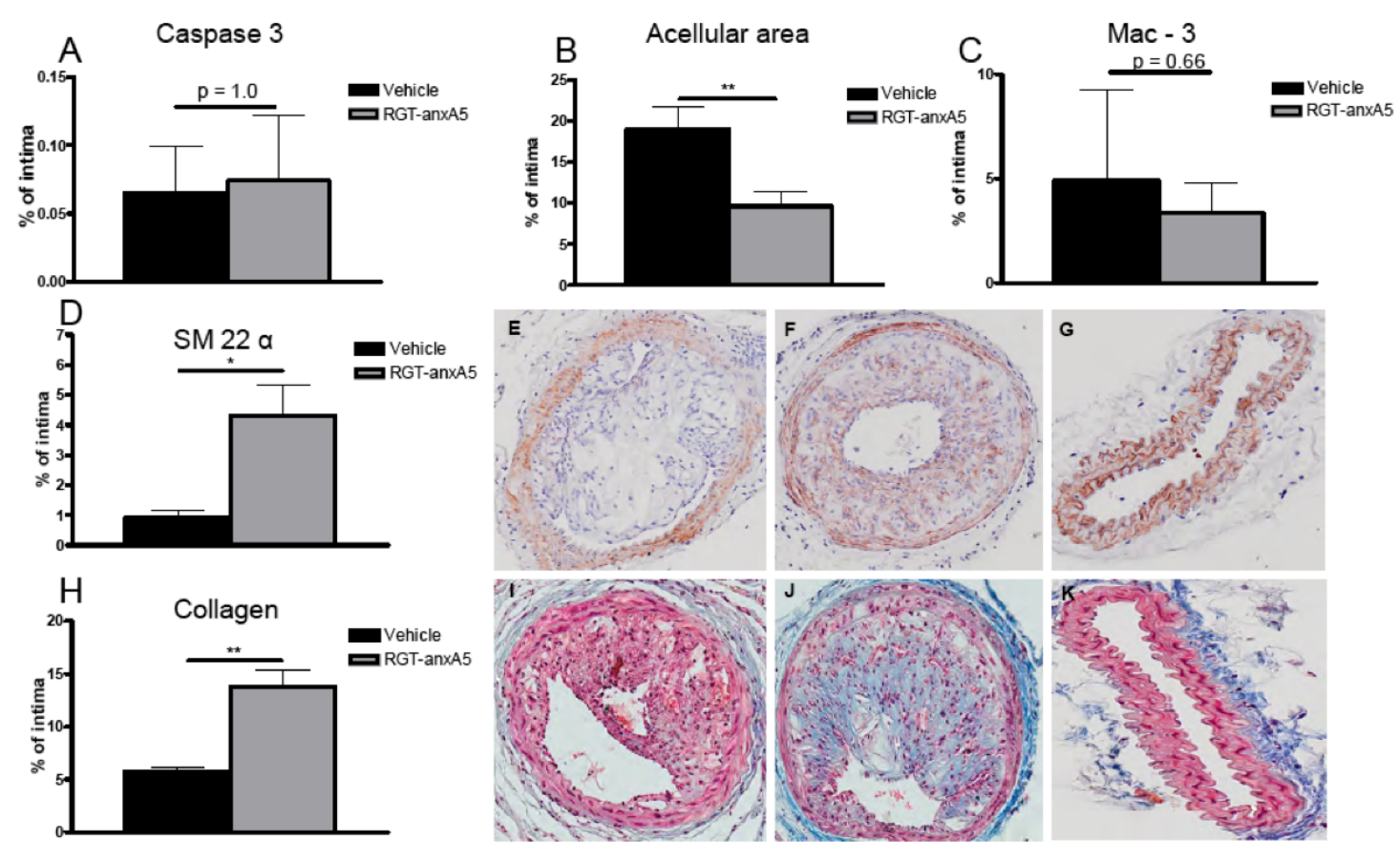

Figure 4: Immunohistochemical analysis of control and RGT-anxA5 treated groups on de novo atherogenesis. Results of A) cleaved caspase 3 staining, B) acellular area C) mac-3 staining D) alpha-smooth muscle actin staining and $\mathrm{H}$ ) collagen staining of vehicle and RGT-anxA5 treated mice. Content was calculated as percentage of staining area relative to the total plaque size. A significant decrease in acellular area was observed in the RGT-treated group while a significant increase of smooth muscle cells and collagen was found in the RGT-treated group. There was no observed effect on the proportion of apoptotic cells or macrophages in the control versus the RGTtreated group. Smooth muscle cell (E-G) and collagen (I-K) visualization of crosssections of the right carotid artery obtained from vehicle (E and I), RGT-anxA5 (F and $\mathrm{J}$ ) and RGD-anxA5 (G and $\mathrm{K}$ ) treated apoE ${ }^{-/-}$-mice.

AnxA5-variants do not alter body weight and plasma cholesterol and triglyceride levels - Plasma cholesterol and triglyceride levels are key to atherogenesis in the apoE $^{-/-}$model. In order to exclude that RGD- or RGT-anxA5 affects lipid profile in this model we measured body weight (Data not shown), total cholesterol (Figure 2C) and triglycerides (Figure 2D) at endpoint. Treatment with anxA5-variants did not cause significant changes in either parameter compared to vehicle treated animals. 
AnxA5-variants do not alter leukocyte profile in bone marrow and blood Recently it was reported that Western Type diet causes increased mobilization of bone marrow leukocytes into the blood stream of $\mathrm{apoE}^{-/-}$mice. Neutrophilia and monocytosis have been shown to promote initiation of atherosclerosis ${ }^{33,34}$. Therefore we analyzed leukocyte numbers and profile in bone marrow and circulation by flow cytometry. Neither RGD-anxA5 nor RGT-anxA5 caused a change in bone marrow leukocyte profile and circulating levels of T-cells (CD4 and CD8), B-cells, NK-cells, granulocytes and monocytes (ly6G-high and Ly6G-low) (Figure 5 A - O).

Table 2 - Overview of immunohistochemical analyses of resultant lesions for vehicle and RGT-anxA5 treated apoE ${ }^{-/-}$-mice.

\begin{tabular}{lll}
\hline \hline & Vehicle & RGT-anxA5 \\
\hline \hline Total cholesterol (mM) & $20.39 \pm 8.72$ & $18.53 \pm 4.96$ \\
\hline $\begin{array}{l}\text { Apoptosis: cleaved caspase } 3 \quad \% \text { of } \\
\text { intima) }\end{array}$ & $0.065 \pm 0.11$ & $0.11 \pm 0.12$ \\
\hline acellular area (\% of intima) & $18.95 \pm 6.94$ & $9.59 \pm 4.74$ \\
\hline Smooth muscle cells: SM22a (\% of intima) & $0.90 \pm 0.64$ & $4.30 \pm 2.70$ \\
\hline Collagen: Masson trichrome (\% of intima) & $5.77 \pm 0.97$ & $13.75 \pm 4.40$ \\
\hline Macrophages: Mac-3 (\% of intima) & $4.88 \pm 9.71$ & $3.37 \pm 3.51$ \\
\hline
\end{tabular}



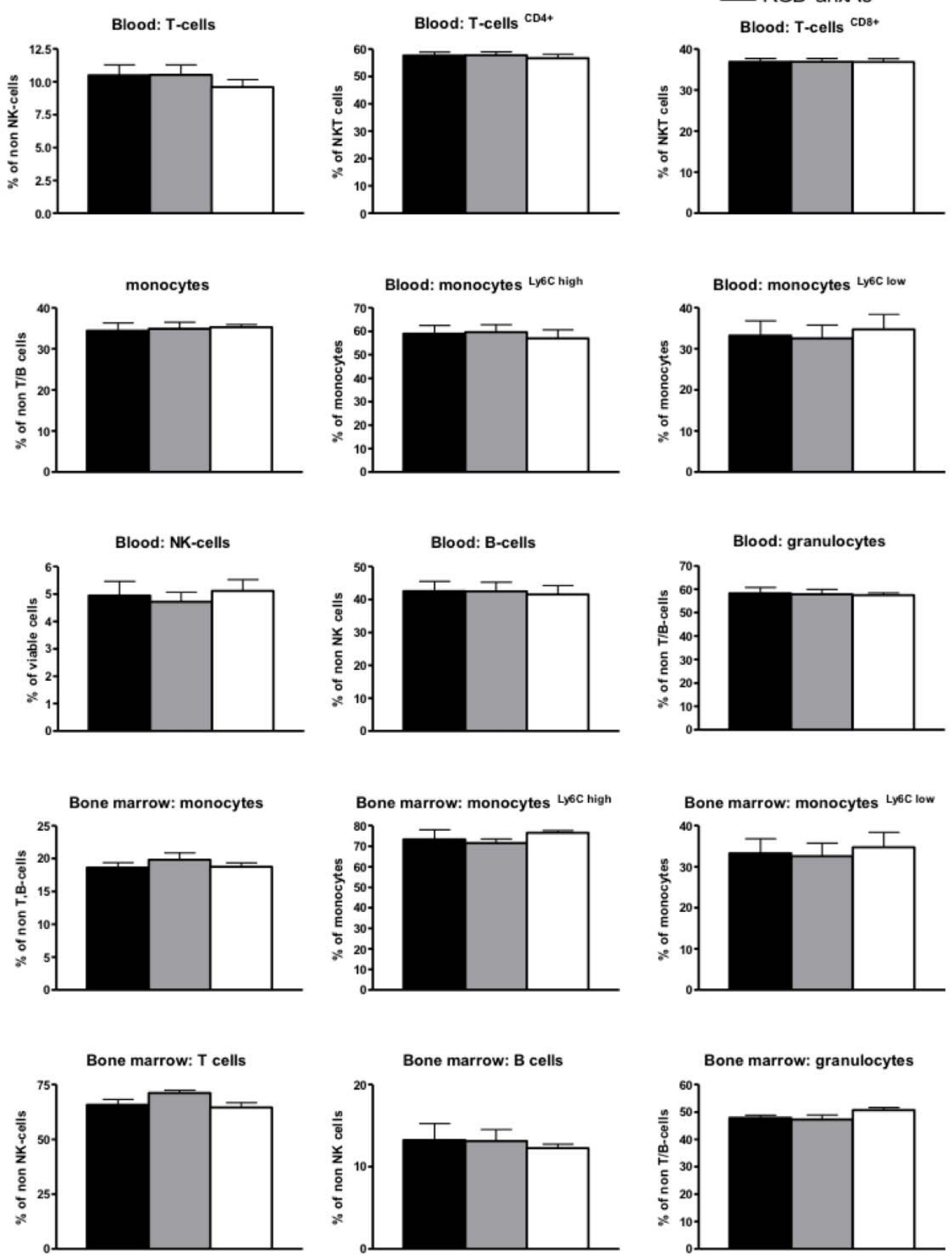

Figure 5: Relative fractions of leukocyte subsets were measured in blood (A-I) and bone marrow (J-O) using a flow cytometry analysis. A) Blood T-cells, B) Blood $\mathrm{CD}^{4+}$ T-cells, C) Blood $\mathrm{CD}^{8+}$ T-cells, D) Blood monocytes, E) Blood Ly ${ }^{6 \mathrm{C}}$ high monocytes, F) Blood Ly ${ }^{6 \mathrm{C}}$ low monocytes, G) Blood NK-cells H) Blood B-cells I) Blood granulocytes, J) Bone marrow monocytes, K) Bone marrow Ly ${ }^{6 \mathrm{C}}$ high monocytes, L) Bone marrow Ly ${ }^{6 \mathrm{C}}$ low monocytes, M) Bone marrow T-cells, N) Bone marrow Bcells and $\mathrm{O}$ ) Bone marrow Granulocytes. No significant differences were observed. 
RGT-anxA5 and RGD-anxA5 enhance plasma IL-10 levels - We showed before that RGD-anxA5 enhances efferocytosis in vivo and thereby augments secretion of interleukin-10 (IL-10) ${ }^{35}$. In order to assess the effect of the anxA5 variants on systemic inflammation we measured IL-10, TNFa and IL-1b levels in plasma at the end of the experiment. Both RGT-anxA5 and RGD-anxA5 caused a significant increase in the anti-inflammatory IL-10 levels compared to vehicle control (Figure 6A). Levels of the pro-inflammatory cytokines TNF- $\alpha$ and $1 \mathrm{~L}-1 \beta$ were not significantly altered by the anxA5-variants (Figure 6B and C). Hence, introduction of the RGD-motif into anxA5 does not affect the ability of anxA5 to suppress systemic inflammation ${ }^{36}$.
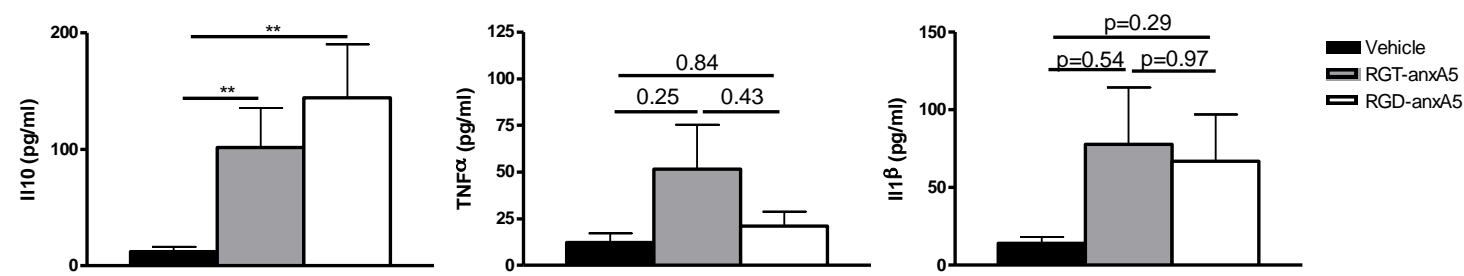

Figure 6: Cytokine analysis in EDTA drawn plasma samples from vehicle, RGTanxA5 and RGD-anxA5 treated apo ${ }^{-1-}$-mice using the milliplex system. Results are shown for A) Il-10 B) TNF- $\alpha$ and C) Il1- $\beta$. Mean \pm SEM is shown.

RGD-anxA5 and RGT-anxA5 exhibit similar effects on coagulation and platelet aggregation - The hemostatic system is intricately connected to atherogenesis 37 . Coagulation and platelet function enhance development of early-stage plaques ${ }^{38} 39$. AnxA5 is a strong anticoagulant that does not interfere with platelet aggregation and the RGD-motif may change its effect on the hemostatic system. Introduction of the RGD-motif did not change the anticoagulant properties as determined by measuring the endogenous thrombin potential (ETP) triggered with tissue factor and phospholipids in platelet free plasma (Figure 7A) and triggered with tissue factor in platelet rich plasma in absence (Figure 7B) and presence of the platelet agonist collagen (Figure 7C). Furthermore, similar to RGT-anxA5, RGD-anxA5 had no effect on methyl-S-ADP-induced platelet aggregation (Figure 7D). These findings strongly suggest that the potent inhibitory activity of RGD-anxA5 on initiation of atherosclerosis (in contrast to RGT-anxA5) does not arise from its interaction with the hemostatic system. 


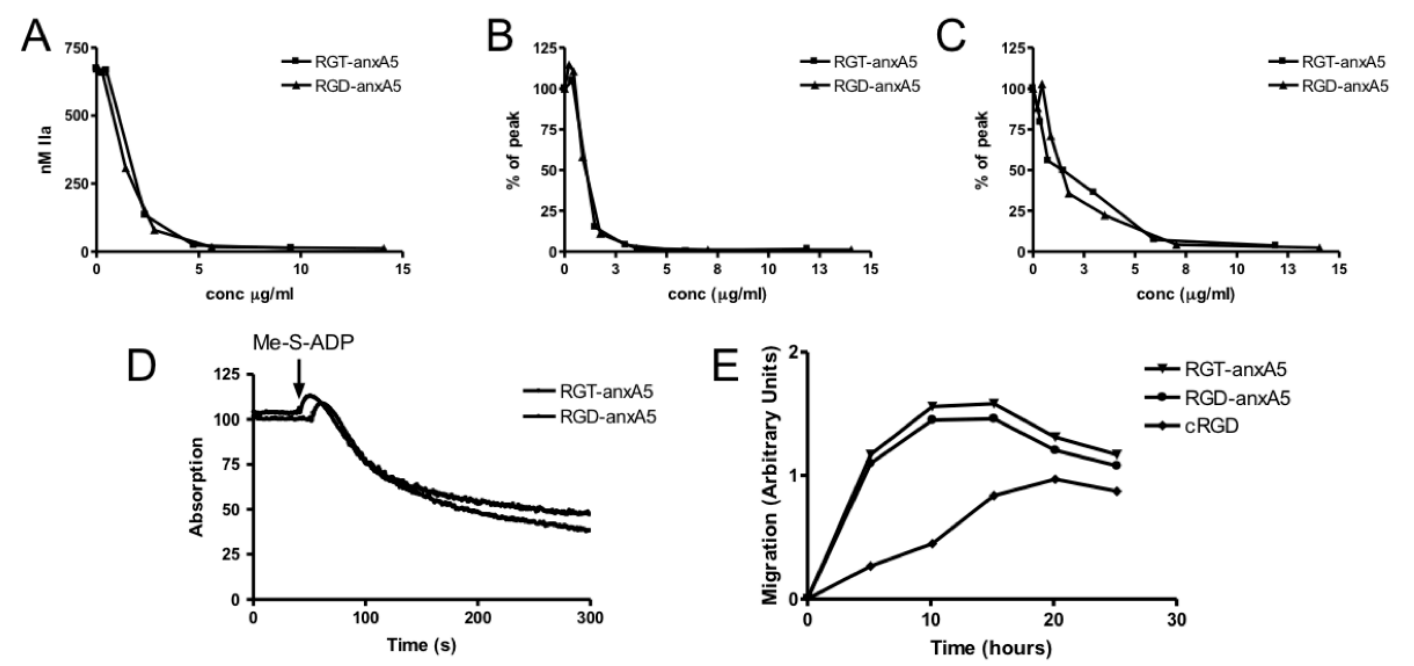

Figure 7: A) Effect of anxA5 variants on the endogenous thrombin potential triggered with $5 \mathrm{pM}$ tissue factor and $10 \mu \mathrm{M}$ phospholipids in normal plasma. B) Effect of anxA5 variants on the endogenous thrombin potential triggered with $5 \mathrm{pM}$ tissue factor in platelet rich plasma. (Results are shown as percentage of the peak) C) Effect of anxA5 variants on the endogenous thrombin potential triggered with $5 \mathrm{pM}$ tissue factor in platelets rich plasma in the presence of collagen. (Results are shown as percentage of peak) D) Effect of the anxA5 variants $(10 \mu \mathrm{M})$ on the platelet aggregation induced with stimulating the platelets with $10 \mu \mathrm{M}$ methyl-S-ADP. Changes in light transmission were recorded during constant stirring of the samples ( 900 r.p.m., $37^{\circ} \mathrm{C}$ ). Shape change responses were assessed by measuring changes in light transmission. E) Effect of the anxA5 variants $(12,5 \mu \mathrm{M})$ on the smooth muscle cell migration measured with xCELLigence technology using a real time cell analyzer dual plate. Cells were triggered to migrate in the presence of $20 \% \mathrm{FCS}$ and $\mathrm{mg} / \mathrm{ml}$ PDGF. Cell migration to the lower chamber was monitored in time and expressed as cell migration in arbitrary units.

RGD-anxA5 and RGT-anxA5 do not interfere with vascular smooth muscle cell migration - Pathological vascular smooth muscle cell migration is recognized as one of the driving forces of atherogenesis ${ }^{40-42}$. In this study we showed that RGT-anxA5 influences the VSMC content in the resultant lesions. In addition, adhesion of VSMCs to extracellular matrix proteins through integrins, appears to be essential for VSMC motility ${ }^{43}$. It is known that RGD-containing proteins can bind to these integrins thereby inhibiting neointima formation in damaged arteries thereby preventing VSMC migration into the vascular wall ${ }^{44,45}$. Therefore, we examined whether the RGDmotif in the anxA5 molecule has an effect on VSMC migration. We found that the RGD-motif in the anxA5 molecule does not influence the VSMC migration compared to the wild type RGT-AnxA5 (fig 7E) while cyclic RGD, a cyclic peptide containing an RGD-motif, is able to delay the migration in a 100 times molar excess. These observations show that the inhibitory effect of RGD-anxA5 on atherogenesis is not caused by the inhibition of VSMC.

RGD-anxA5 is a more potent inhibitor of monocyte adhesion to activated endothelial cells than RGT-anxA5 - It is known that cyclic RGD inhibits atherogenesis ${ }^{46}$, possibly by blocking the adhesion of monocytes to activated endothelium ${ }^{46}$. We determined whether RGD-anxA5 interferes with monocyte adhesion in vitro using a flow chamber based assay. Activated HUVEC and 
monocytes were incubated with anxA5-variants (20 nM) and cRGD (20nM) prior to flow for 10 minutes. Pre-incubation with the RGD-anxA5 variant led to a substantial decrease $(\sim 50 \%)$ in the initial capture of monocytes while cRGD and RGT-anxA5 elicited a $68 \%$ and $20 \%$ inhibition, respectively (Figure 8 ). These results indicate that inhibition of monocyte infiltration can be an additional mechanism in the inhibition of atherosclerotic lesion formation.
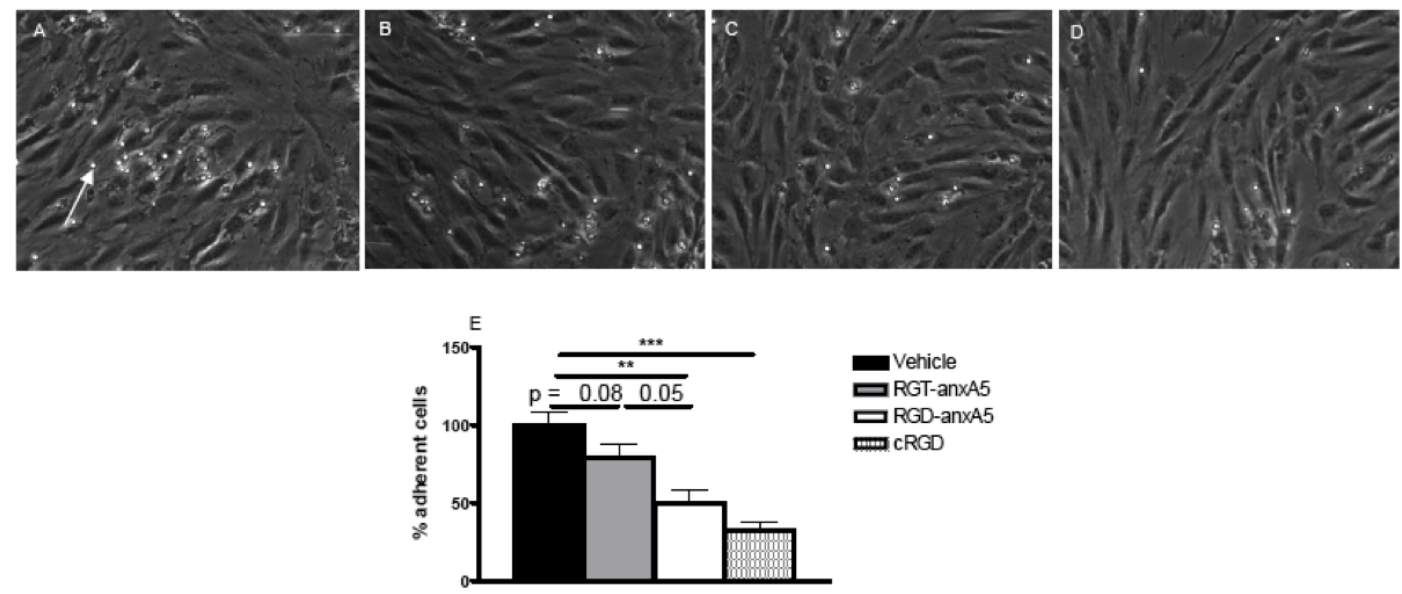

Figure 8: Effect of the different compounds on monocyte interaction with HUVECs under flow. Monocytes and TNF- $\alpha$-stimulated $(10 \mathrm{ng} / \mathrm{mL}$, overnight) HUVECS were incubated with the different compounds $(20 \mathrm{nM})$ for 10 minutes prior to the flow over. Monocyte-endothelium interactions were quantified and shown as percentage of captured monocytes compared to the vehicle group (F). Representative images following treatment with vehicle (A), RGT-anxA5 (B), RGD-anxA5 (C) and cRGD (D) are shown. The white arrow in figure 8 indicates one captured monocyte.

\section{DISCUSSION}

This study is the first to show that targeting the danger signal, cell surface expressed PS, with a pro-efferocytotic compound effectively inhibits initiation of atherogenesis in the apoE ${ }^{-/-}$collar model. Enhancing efferocytosis has gained interest as a viable approach to treat chronic inflammatory diseases such as atherosclerosis $3,11,12,47$. Recent studies have clearly shown that accumulation of apoptotic cells coincides with sites of plaque rupture ${ }^{48}$ and greatly determines its thrombogenicity ${ }^{49}$. Removal of apoptotic cells through efferocytosis is considered beneficial to dampen the inflammatory process by elimination of cell surfaces with pro-inflammatory and procoagulant activity (42) and by upregulation of anti-inflammatory cytokines 50 . Indeed, inhibition of efferocytosis exacerbated atherosclerotic lesion formation in the apoE $^{-/-}$mouse model 51,52 . Previously, we embarked on a strategy to enhance efferocytosis by transforming anxA5 from an inhibitor into a stimulator of efferocytosis through the introduction of an RGD-motif in its $\mathrm{N}$-terminal tail. This variant of anxA5, RGD-anxA5, stimulates efferocytosis and increases antiinflammatory IL-10 levels in vitro and in vivo ${ }^{21}$. In this study we show that the proefferocytotic RGD-anxA5 acts as a potent inhibitor of atherogenesis in the apoE ${ }^{-/-}$ collar model with standardized localization of plaque formation proximal to the collar (32). Recently, Ewing and co-workers reported that RGT-anxA5 suppresses vascular inflammation and remodeling in various mouse models ${ }^{53,54}$. In agreement with these reports we observed that RGT-anxA5 reduces inflammation and drives atherosclerotic 
plaque remodeling towards the stable phenotype. In addition we found an increased amount of smooth muscle cell content without a significant change in plaque size in the presence of RGT-anxA5. Introduction of the RGD-motif increased the inhibitory activity of anxA5 dramatically by annihilating plaque formation in almost all treated mice. In order to pinpoint mechanisms underlying this effect we interrogated effects of anxA5 on processes known to be important in atherogenesis. These included 1) the hemostatic system, platelet activation and thrombin formation in particular, which are key to onset and propagation of atherosclerosis 55,56 ;2) circulating monocytes and neutrophils, the levels of which determine atherogenesis $(33,34)$; and 3 ) vascular smooth muscle migration, which contributes to atherogenesis in an RGD-dependent manner ${ }^{57,58}$. None of the above processes revealed functional differences between RGD-anxA5 and RGT-anxA5. However, RGD-anxA5 appeared to be a stronger inhibitor of monocyte adhesion to activated endothelium than RGT-anxA5. This could explain the more effective action of RGD-anxA5 in suppressing atherogenesis. Notwithstanding, we reasoned that this could not be the full explanation for the absence of lesion formation in RGD-anxA5 treated mice. Chronic administration of cRGD yielding constant circulating levels of this peptide reduced macrophage infiltration of ligated carotid artery of $\mathrm{apoE}^{-/-}$mice on WTD but did not completely prevent infiltration (39). In addition, we found that cRGD inhibits monocyte adhesion to activated endothelium more effectively than RGD-anxA5 and inhibits VSMC migration. Hence, together these results strongly suggest that RGD-anxA5 also acts downstream of macrophage infiltration. Efferocytosis may be a crucial switch downstream of macrophage infiltration determining resolution or progression of early inflammation ${ }^{(9)}$. Whether enhanced efferocytosis contributes to the anti-atherogenic activity of RGD-anxA5 was difficult to establish due to absence of neo-intima formation in the majority of the treated mice. However, a significant role of such enhancement seems inevitable given the biological activities in vitro and in vivo acquired by the introduction of RGD into the N-terminal tail of anxA5 (21).

In conclusion we have demonstrated that; I) RGT-anxA5 reduces inflammation and drives atherosclerotic plaque remodeling towards the stable phenotype and; II) RGDanxA5 is a potent inhibitor of atherosclerotic lesion formation by reducing macrophage infiltration and, likely, by enhancing efferocytosis. RGD-anxA5, hence, represents a novel class of promising compounds to treat vascular inflammation by targeting cell surface expressed PS.

\section{ACKNOWLEDGEMENT}

The authors are indebted to Nicole Bitsch and Niko Deckers for their technical assistance and to Dr. Jack Cleutjens for writing the Qwin macros that were instrumental to our quantitative morphological analyses.

\section{REFERENCES}

1. Tuzcu EM, Kapadia SR, Tutar E, Ziada KM, Hobbs RE, McCarthy PM et al. High Prevalence of Coronary Atherosclerosis in Asymptomatic Teenagers and Young Adults : Evidence From Intravascular Ultrasound. Circulation 2001; 103(22): 2705-2710.

2. Virmani R, Burke AP, Farb A, Kolodgie FD. Pathology of the unstable plaque. Prog Cardiovasc Dis 2002; 44(5): 349-56.

3. Tabas I. Consequences and therapeutic implications of macrophage apoptosis in atherosclerosis: the importance of lesion stage and phagocytic efficiency. Arterioscler Thromb Vasc Biol 2005; 25(11): 2255-64. 
4. Schrijvers DM, De Meyer GR, Kockx MM, Herman AG, Martinet W. Phagocytosis of apoptotic cells by macrophages is impaired in atherosclerosis. Arterioscler Thromb Vasc Biol 2005; 25(6): 1256-61.

5. van Vlijmen BJ, Gerritsen G, Franken AL, Boesten LS, Kockx MM, Gijbels MJ et al. Macrophage p53 deficiency leads to enhanced atherosclerosis in APOE*3-Leiden transgenic mice. Circ Res 2001; 88(8): 780-6.

6. Liu J, Thewke DP, Su YR, Linton MF, Fazio S, Sinensky MS. Reduced macrophage apoptosis is associated with accelerated atherosclerosis in low-density lipoprotein receptor-null mice. Arterioscler Thromb Vasc Biol 2005; 25(1): 174-9.

7. Arai S, Shelton JM, Chen M, Bradley MN, Castrillo A, Bookout AL et al. A role for the apoptosis inhibitory factor AIM/Spalpha/Api6 in atherosclerosis development. Cell Metab 2005; 1(3): 201-13.

8. Huynh ML, Fadok VA, Henson PM. Phosphatidylserine-dependent ingestion of apoptotic cells promotes TGF-beta1 secretion and the resolution of inflammation. J Clin Invest 2002; 109(1): 41-50.

9. Tabas I. Macrophage death and defective inflammation resolution in atherosclerosis. Nat Rev Immunol 2010; 10(1): 36-46.

10. Savill J. Recognition and phagocytosis of cells undergoing apoptosis. Br Med Bull 1997; 53(3): 491-508.

11. Gaipl US, Beyer TD, Baumann I, Voll RE, Stach CM, Heyder P et al. Exposure of anionic phospholipids serves as anti-inflammatory and immunosuppressive signal--implications for antiphospholipid syndrome and systemic lupus erythematosus. Immunobiology 2003; 207(1): 73-81.

12. Hanayama R, Tanaka M, Miyasaka K, Aozasa K, Koike M, Uchiyama Y et al. Autoimmune disease and impaired uptake of apoptotic cells in MFG-E8-deficient mice. Science 2004; 304(5674): 1147-50.

13. Fadok VA, Savill JS, Haslett C, Bratton DL, Doherty DE, Campbell PA et al. Different populations of macrophages use either the vitronectin receptor or the phosphatidylserine receptor to recognize and remove apoptotic cells. J Immunol 1992; 149(12): 4029-35.

14. Ravichandran KS. Beginnings of a good apoptotic meal: the find-me and eat-me signaling pathways. Immunity $2011 ; 35(4)$ : 445-55.

15. Tait JF, Gibson D, Fujikawa K. Phospholipid binding properties of human placental anticoagulant protein-I, a member of the lipocortin family. J Biol Chem 1989; 264(14): 79449.

16. Andree HA, Reutelingsperger CP, Hauptmann R, Hemker HC, Hermens WT, Willems GM. Binding of vascular anticoagulant alpha (VAC alpha) to planar phospholipid bilayers. $J$ Biol Chem 1990; 265(9): 4923-8.

17. Boersma HH, Kietselaer BL, Stolk LM, Bennaghmouch A, Hofstra L, Narula J et al. Past, present, and future of annexin A5: from protein discovery to clinical applications. J Nucl Med 2005; 46(12): 2035-50.

18. Isobe S, Tsimikas S, Zhou J, Fujimoto S, Sarai M, Branks MJ et al. Noninvasive Imaging of Atherosclerotic Lesions in Apolipoprotein E-Deficient and Low-Density-Lipoprotein Receptor-Deficient Mice with Annexin A5. J Nucl Med 2006; 47(9): 1497-1505.

19. Kietselaer BL, Reutelingsperger CP, Heidendal GA, Daemen MJ, Mess WH, Hofstra L et al. Noninvasive detection of plaque instability with use of radiolabeled annexin A5 in patients with carotid-artery atherosclerosis. N Engl J Med 2004; 350(14): 1472-3.

20. Kenis H, Hofstra L, Reutelingsperger CP. Annexin A5: shifting from a diagnostic towards a therapeutic realm. Cell Mol Life Sci 2007; 64(22): 2859-62.

21. Schutters K, Kusters DH, Chatrou ML, Montero-Melendez T, Donners M, Deckers NM et al. Cell surface-expressed phosphatidylserine as therapeutic target to enhance phagocytosis of apoptotic cells. Cell Death Differ 2012.

22. Kenis H, van Genderen H, Deckers NM, Lux PA, Hofstra L, Narula J et al. Annexin A5 inhibits engulfment through internalization of PS-expressing cell membrane patches. Exp Cell Res 2006; 312(6): 719-26.

23. Hvarregaard J, Andersen MH, Berglund L, Rasmussen JT, Petersen TE. Characterization of glycoprotein PAS-6/7 from membranes of bovine milk fat globules. Eur J Biochem 1996; 240(3): 628-36.

24. Andersen MH, Berglund L, Rasmussen JT, Petersen TE. Bovine PAS-6/7 binds alpha v beta 5 integrins and anionic phospholipids through two domains. Biochemistry 1997; 36(18): 5441-6. 
25. Hanayama R, Tanaka M, Miwa K, Shinohara A, Iwamatsu A, Nagata S. Identification of a factor that links apoptotic cells to phagocytes. Nature 2002; 417(6885): 182-7.

26. Perretti M, Croxtall JD, Wheller SK, Goulding NJ, Hannon R, Flower RJ. Mobilizing lipocortin 1 in adherent human leukocytes downregulates their transmigration. Nat Med 1996; 2(11): 1259-62.

27. Hayhoe RP, Kamal AM, Solito E, Flower RJ, Cooper D, Perretti M. Annexin 1 and its bioactive peptide inhibit neutrophil-endothelium interactions under flow: indication of distinct receptor involvement. Blood 2006; 107(5): 2123-30.

28. Patel KD. Mechanisms of selective leukocyte recruitment from whole blood on cytokineactivated endothelial cells under flow conditions. J Immunol 1999; 162(10): 6209-16.

29. Castoldi E, Rosing J. Thrombin generation tests. Thromb Res 2011; 127 Suppl 3: S21-5.

30. De Saint-Hubert M, Mottaghy FM, Vunckx K, Nuyts J, Fonge H, Prinsen K et al. Sitespecific labeling of 'second generation' annexin V with $99 \mathrm{mTc}(\mathrm{CO}) 3$ for improved imaging of apoptosis in vivo. Bioorg Med Chem; 18(3): 1356-63.

31. von der Thusen JH, van Berkel TJ, Biessen EA. Induction of rapid atherogenesis by perivascular carotid collar placement in apolipoprotein E-deficient and low-density lipoprotein receptor-deficient mice. Circulation 2001; 103(8): 1164-70.

32. Kanters E, Pasparakis M, Gijbels MJ, Vergouwe MN, Partouns-Hendriks I, Fijneman RJ et al. Inhibition of NF-kappaB activation in macrophages increases atherosclerosis in LDL receptordeficient mice. J Clin Invest 2003; 112(8): 1176-85.

33. Combadiere C, Potteaux S, Rodero M, Simon T, Pezard A, Esposito B et al. Combined inhibition of CCL2, CX3CR1, and CCR5 abrogates Ly6C(hi) and Ly6C(lo) monocytosis and almost abolishes atherosclerosis in hypercholesterolemic mice. Circulation 2008; 117(13): 1649-57.

34. Drechsler M, Megens RT, van Zandvoort M, Weber C, Soehnlein O. Hyperlipidemiatriggered neutrophilia promotes early atherosclerosis. Circulation 2010; 122(18): 1837-45.

35. Schutters K, Kusters DH, Chatrou ML, Montero-Melendez T, Donners M, Deckers NM et al. Cell surface-expressed phosphatidylserine as therapeutic target to enhance phagocytosis of apoptotic cells. Cell Death Differ 2013; 20(1): 49-56.

36. Ewing MM, de Vries MR, Nordzell M, Pettersson K, de Boer HC, van Zonneveld AJ et al. Annexin A5 therapy attenuates vascular inflammation and remodeling and improves endothelial function in mice. Arterioscler Thromb Vasc Biol 2011; 31(1): 95-101.

37. Borissoff JI, Spronk HM, ten Cate H. The hemostatic system as a modulator of atherosclerosis. N Engl J Med 2011; 364(18): 1746-60.

38. Borissoff JI, Heeneman S, Kilinc E, Kassak P, Van Oerle R, Winckers K et al. Early atherosclerosis exhibits an enhanced procoagulant state. Circulation 2010; 122(8): 821-30.

39. Massberg S, Brand K, Gruner S, Page S, Muller E, Muller I et al. A critical role of platelet adhesion in the initiation of atherosclerotic lesion formation. J Exp Med 2002; 196(7): 887-96.

40. Majesky MW, Schwartz SM. Smooth muscle diversity in arterial wound repair. Toxicol Pathol 1990; 18(4 Pt 1): 554-9.

41. Kenagy RD, Fukai N, Min SK, Jalikis F, Kohler TR, Clowes AW. Proliferative capacity of vein graft smooth muscle cells and fibroblasts in vitro correlates with graft stenosis. $J$ Vasc Surg 2009; 49(5): 1282-8.

42. Back M, Bu DX, Branstrom R, Sheikine Y, Yan ZQ, Hansson GK. Leukotriene B4 signaling through NF-kappaB-dependent BLT1 receptors on vascular smooth muscle cells in atherosclerosis and intimal hyperplasia. Proc Natl Acad Sci U S A 2005; 102(48): 17501-6.

43. Kanda S, Kuzuya M, Ramos MA, Koike T, Yoshino K, Ikeda S et al. Matrix metalloproteinase and alphavbeta3 integrin-dependent vascular smooth muscle cell invasion through a type I collagen lattice. Arterioscler Thromb Vasc Biol 2000; 20(4): 998-1005.

44. Matsuno H, Stassen JM, Vermylen J, Deckmyn H. Inhibition of integrin function by a cyclic RGD-containing peptide prevents neointima formation. Circulation 1994; 90(5): 2203-6.

45. Choi ET, Engel L, Callow AD, Sun S, Trachtenberg J, Santoro S et al. Inhibition of neointimal hyperplasia by blocking alpha $\mathrm{V}$ beta 3 integrin with a small peptide antagonist GpenGRGDSPCA. J Vasc Surg 1994; 19(1): 125-34.

46. Elitok S, Brodsky SV, Patschan D, Orlova T, Lerea KM, Chander P et al. Cyclic arginineglycine-aspartic acid peptide inhibits macrophage infiltration of the kidney and carotid artery lesions in apo-E-deficient mice. Am J Physiol Renal Physiol 2006; 290(1): F159-66.

47. Hoffmann PR, deCathelineau AM, Ogden CA, Leverrier Y, Bratton DL, Daleke DL et al. Phosphatidylserine (PS) induces PS receptor-mediated macropinocytosis and promotes clearance of apoptotic cells. J Cell Biol 2001; 155(4): 649-59. 
48. Kolodgie FD, Narula J, Burke AP, Haider N, Farb A, Hui-Liang Y et al. Localization of apoptotic macrophages at the site of plaque rupture in sudden coronary death. Am J Pathol 2000; 157(4): 1259-68.

49. Mallat Z, Hugel B, Ohan J, Leseche G, Freyssinet JM, Tedgui A. Shed membrane microparticles with procoagulant potential in human atherosclerotic plaques: a role for apoptosis in plaque thrombogenicity. Circulation 1999; 99(3): 348-53.

50. Huynh ML, Fadok VA, Henson PM. Phosphatidylserine-dependent ingestion of apoptotic cells promotes TGF-betal secretion and the resolution of inflammation. J Clin Invest 2002; 109(1): 41-50.

51. Ait-Oufella H, Kinugawa K, Zoll J, Simon T, Boddaert J, Heeneman S et al. Lactadherin deficiency leads to apoptotic cell accumulation and accelerated atherosclerosis in mice. Circulation 2007; 115(16): 2168-77.

52. Doring Y, Soehnlein O, Drechsler M, Shagdarsuren E, Chaudhari SM, Meiler S et al. Hematopoietic interferon regulatory factor 8-deficiency accelerates atherosclerosis in mice. Arterioscler Thromb Vasc Biol 2012; 32(7): 1613-23.

53. Ewing MM, Karper JC, Sampietro ML, de Vries MR, Pettersson K, Jukema JW et al. Annexin A5 prevents post-interventional accelerated atherosclerosis development in a dosedependent fashion in mice. Atherosclerosis 2012; 221(2): 333-40.

54. Ewing MM, de Vries MR, Nordzell M, Pettersson K, de Boer HC, van Zonneveld AJ et al. Annexin A5 therapy attenuates vascular inflammation and remodeling and improves endothelial function in mice. Arterioscler Thromb Vasc Biol 2011; 31(1): 95-101.

55. Borissoff JI, Spronk HM, ten Cate H. The hemostatic system as a modulator of atherosclerosis. N Engl J Med 2011; 364(18): 1746-60.

56. Borissoff JI, Otten JJ, Heeneman S, Leenders P, van Oerle R, Soehnlein O et al. Genetic and pharmacological modifications of thrombin formation in apolipoprotein e-deficient mice determine atherosclerosis severity and atherothrombosis onset in a neutrophil-dependent manner. PLoS One 2013; 8(2): e55784.

57. Lacolley P, Regnault V, Nicoletti A, Li Z, Michel JB. The vascular smooth muscle cell in arterial pathology: a cell that can take on multiple roles. Cardiovasc Res 2012; 95(2): 194204.

58. Bilato C, Curto KA, Monticone RE, Pauly RR, White AJ, Crow MT. The inhibition of vascular smooth muscle cell migration by peptide and antibody antagonists of the alphavbeta3 integrin complex is reversed by activated calcium/calmodulin- dependent protein kinase II. $J$ Clin Invest 1997; 100(3): 693-704. 



\section{CHAPTER 6}

GENERAL DISCUSSION 
Phosphatidylserine (PS) is one of the most prominent and ubiquitous fingerprints of cells in diseased tissues and, therefore, an attractive target for molecular imaging and translation into clinical applications. Currently PS imaging has entered the process of translation from preclinical settings to the clinical area (chapter 1). In contrast to the versatile and well-studied PS-targeting strategies for imaging purposes, therapeutic applications are limited at this time. Annexin A5 (anxA5), a 35kD human protein that binds PS with high affinity is evaluated as a molecular imaging probe to visualize apoptosis non-invasively in animal models and in patients. In this thesis we tried to shift anxA5 from a molecular imaging tool towards a therapeutic agent in the development of cardiovascular diseases.

In the first part of this thesis we focused on the use of anxA5 as possible biomarker in heart failure (chapter 2) and on the role of anxA5 in the development of heart failure (chapter 3). In the second part of my thesis I focused on the development of a novel therapeutic strategy to enhance efferocytosis in pathologies where the balance between apoptosis and phagocytosis is lost (chapter 4 and 5).

\section{Future of annexin A5 as molecular imaging tool}

In chapter 1 the biomarker PS and various PS-binding compounds that have been employed to target PS for diagnostic purposes are highlighted. The ubiquity of PS has both advantages and disadvantages. On the one hand a broad spectrum of diseases can be imaged with a single compound but on the other hand ubiquity is accompanied by reduced specificity, requiring additional diagnostic steps in order to differentiate. At this moment ${ }^{99 \mathrm{~m}}$ Technetium-annexin A5 $\left({ }^{99 \mathrm{~m}} \mathrm{Tc}\right.$-anxA5) is evaluated as the only protocol to measure apoptosis non-invasively in patients ${ }^{1,2}$. Nevertheless, the pharmacokinetics of ${ }^{99 \mathrm{~m}} \mathrm{Tc}$-anxA5 require that imaging takes place at least 4 hours after injection of radioactive anxA5 into the patient. This decreases sensitivity and increases the radioactive burden for the patient, especially the kidneys where radioactivity accumulates ${ }^{3}$. Future efforts have to be directed to optimize the anxA5 non-invasive imaging protocol based on pretargeting strategies.

\section{Annexin A5 levels in plasma as biomarker in heart failure}

In chapter 2 we showed elevated anxA5 plasma levels in heart failure compared to control subjects. It is known that anxA5 levels in plasma can change under pathophysiological conditions. Increased plasma levels of anxA5 have previously been reported in patients with myocardial infarction ${ }^{4}$, cardiac arrest and severe trauma ${ }^{5}$. AnxA5 levels reflect the severity of the damage of the myocardium. In compensated hypertrophy, expression of anxA5 seems to be unchanged ${ }^{6,7}$ whereas during development of heart failure increased levels of anxA5 were detected in the left ventricle of hypertensive guinea pigs ${ }^{8}$ and of failing human hearts $9,10$. Interestingly, Ravassa et al. found that anxA5 levels are increased in plasma of patients with hypertensive heart disease and in the myocardium of these patients in the absence of upregulation of myocardial anxA5 mRNA ${ }^{11}$. The most obvious and tantalizing explanation for increased anxA5 levels and absence of an upregulation of myocardial anxA5 mRNA is because microRNA-1 (miR-1) is downregulated during heart failure ${ }^{12}$. MiR-1 has a binding site to the highly conserved 3' untranslated region of anxA5 ${ }^{13}$ causing inhibition of anxA5 production. We are the first to report that anxA5 levels are elevated in all stages of heart failure and predict all-cause mortality in HF patients independently from established predictors of mortality. The mechanism underlying increased anxA5 levels in HF patients remains speculative but likely result from release of anxA5 from injured myocardial tissue, vascular 
endothelial and smooth muscle cells 4, 5, 14-19. In conclusion, increased circulating anxA5 concentration may be used as a prognostic biomarker. Larger studies in variable severity of $\mathrm{HF}$ and with longer follow up will be required for conclusive application of the incremental role of anxA5 assessment in clinical practice. Furthermore, we hypothesized that anxA5 is functionally involved in the progression of HF through protecting stressed cardiomyocytes.

\section{The role of endogenous anxA5 in the development of heart failure}

In chapter 2 we postulated that elevated anxA5 plasma levels represent defense mechanisms for PS expressing stressed cardiomyocytes by inhibiting phagocytosis of PS expressing cells ${ }^{20}$, delaying apoptosis ${ }^{21}$ and promoting the repair of injured cellular membranes. Therefore we aimed in chapter 3 to unravel the role of endogenous anxA5 in the development of heart failure ${ }^{22}$. We found that anxA $5^{-1-}$ mice submitted to transversal aorta constriction (TAC) developed a more severe diastolic dysfunction as compared to the anxA $5^{+/+}$-mice. These observations point towards a defense mechanism of anxA5 in heart failure. According to the hypothesis postulated in chapter 2 we expected to find an increased apoptotic index in anxA5deficient mice. A very low rate of apoptosis was measured in the hearts of anx $5^{-1-}$ and anx $5^{+/+}$-mice showing no significant difference between the two groups. Hence, we had to rethink our hypothesis and to take other activities of anxA5 into account. The severe diastolic dysfunction in TAC-mice with anxA5-deficiency was not associated with an increase of collagen but with an increased hypertropic left ventricular wall. The molecular link between anxA5 and hypertrophy has never been reported in literature sofar. We anticipate such a link because of the reported interplay of anxA5 with the $\mathrm{Na}^{+}-\mathrm{Ca}^{2+}$-exchanger and regulatory role of anxA5 during autophagy. It was shown that overexpression of the cardiac $\mathrm{Na}^{+}-\mathrm{Ca}^{2+}$ exchanger causes cardiac hypertrophy ${ }^{23}$ while it is known that anxA5 can slow down the $\mathrm{Ca}^{2+}$ extrusion via decreasing the activity of the $\mathrm{Na}^{+}-\mathrm{Ca}^{2+}$ exchanger ${ }^{13}$. Others found that inhibition of autophagy, in which PS-exposition is involved in absence of caspases ${ }^{24}$, induces cardiomyocyte hypertrophy ${ }^{25}$. Recently it was shown that anxA5 is required for fusion of the autophagosome with the lysosome and that anxA5deficiency inhibits autophagy ${ }^{26}$. These mechanistic links have to be interrogated experimentally on their importance in the cause-consequence relationships of heart failure. Therefore we aim to generate transgenic animals with a specific overexpression of anxA5 in the myocardium itself. A similar transgenic animal with an overexpression of anxA5-M1234, an anxA5-variant that has no functional $\mathrm{Ca}^{2+} / \mathrm{PS}$ binding sites ${ }^{27}$, would give more insights in the role of anxA5 in relation to its PS binding properties. To exclude an epiphenomenon, we are planning a rescueexperiment with administration of exogenous anxA5 to anxA5 $5^{-/-}$-mice submitted to TAC to rescue the phenotype. AnxA5 can be administered in anxA5 $5^{-/-}$-mice via osmotic minipumps or via daily intraperitoneal injections. 
The symptoms found in TAC-mice with anxA5-deficiency correlates with patients with severe symptoms in congestive HF patients and diminished exercise tolerance ${ }^{28}$. Although this phenotype is frequently observed in patients with moderate to severe aortic valve stenosis ${ }^{29}$, no animal model is available that resembles this diastolic dysfunction phenotype. Hence, our mouse model could be of high value to accelerate the search for novel effective therapeutics.

\section{AnxA5 variants to selectively enhance efferocytosis}

Cell surface-expressed PS on apoptotic cells is an attractive target for therapeutic interventions using anxA5. In chapter 4 we report a novel strategy to selectively enhance phagocytosis of PS exposing cells using a novel designed RGD-anxA5 variant. We showed that RGD-anxA5 stimulates efferocytosis in vitro and in vivo and enhances anti-inflammatory cytokine production. Impaired efferocytosis has been shown to be associated with, and even contribute to, progression of chronic inflammatory diseases. It is known that some PS targeting agents, such as lactadherin can selectively enhance efferocytosis. Although lactadherin is a more potent stimulator of efferocytosis as compared to RGD-anxA5 in an isolated in vitro system, in vivo, lactadherin is used as an opsonin mainly secreted by macrophages at the location of efferocytosis. In atherosclerotic prone lactadherin knock-out mice it was clearly demonstrated that efferocytosis is impaired ${ }^{30}$. However, exogenously administrated lactadherin seems not able to penetrate in diseased tissues such as atherosclerotic lesions and therefore cannot be used in therapeutic interventions. In addition, biodistribution 31,32 and purification of exogenous lactadherin are considerably unfavorable as compared to the anxA5 variants. Regarding the antiinflammatory/pro-efferocytotic properties of the RGD-anxA5 variant it might be beneficial in other pathologies such as in systemic lupus erythematosus or in percutaneous coronary interventions as well.

\section{AnxA5 variants as inhibitor of de novo atherogenesis}

In chapter 5 we evaluated the effect of the RGD-anxA5 variant on de novo carotid atherogenesis in atherosclerosis-prone apoE knockout $\left(\mathrm{apoE}^{-/-}\right)$mice. We revealed that RGD-anxA5 acts as a potent inhibitor of early atherogenesis. In addition, we found that anxA5 wild type reduces inflammation and drives atherosclerotic plaque remodeling towards the stable phenotype. These results are remarkable because two different variants with opposing effects on efferocytosis have both a therapeutic effect on the initiation phase of atherosclerosis. These observations point towards multiple yet unknown biological activities of both anxA5 wild type and RGD-anxA5. To evaluate the pro-efferocytotic effects of RGD-anxA5 more in detail, future experiments have to be directed towards atherosclerotic models with a higher rate of apoptosis.

Although it is very interesting that RGD-anxA5 is inhibiting atherosclerotic plaque formation, most of the patients entering the clinical machinery have already severe atherosclerotic lesions. It would be of interest to evaluate the therapeutic efficacy of the RGD-anxA5 variant on pre-existing lesions. These experiments are currently being performed.

An important point of discussion is the blood clearance of anxA5. AnxA5 variants are rapidly cleared by the kidney, which is beneficial for imaging purposes but unfavorable for therapeutic strategies. In our therapeutic intervention experiments we prolonged the circulation half-life of anxA5 from several minutes to several hours by intraperitoneal administration. However, intraperitoneal injection is not a preferred 
route of administration in patients. Alternatively, prolongation time of intravenously administered anxA5 can be accomplished by pegylation ${ }^{33}$ or by increasing size. To increase size I would like to propose to generate a heterodimer of RGD-anxA5 with RGT-anxA5, which exceeds the renal threshold. Availability and functionality of the RGD-motif has to be evaluated in the heterodimer. Half-life of the heterodimer has to be estimated around 6,5 hours, the half-life of the homodimer of anxA5 ${ }^{34}$.

\section{FINAL CONCLUSSION}

At start of my $\mathrm{PhD}$-research project anxA5 was predominantly described as a noninvasive molecular imaging tool for PS-expressing cells in vitro and in vivo in animal models and in patients. My work shifted focus from molecular imaging tool to properties of anxA5 as I) biomarker and II) therapeutic agent.

I) We clearly showed that plasma anxA5 is an independent predictor of all-cause mortality in heart failure patients, which will result in a better diagnosis of this pathology. Furthermore, we showed that endogenous anxA5 has a protective role in the development of heart failure in mice. The anxA $5^{-/}$mouse model submitted to TAC delivers a novel platform to test numerous therapeutic strategies.

II) In addition we generated a novel anxA5 variant that carries an RGD-motif, which transforms anxA5 from an inhibitor into a stimulator of efferocytosis. We showed that this variant inhibits de novo atherosclerotic lesion formation completely.

The generation and testing of the RGD-anxA5 variant mark potential of a novel avenue to diagnose and treat diseases. In combination with the gradually unveiled pathophysiological significance of anxA5 we expect this novel platform to deliver anxA5-based diagnostics and therapeutics for a broad range of diseases in which cell surface expression of PS becomes manifest.

\section{REFERENCES}

1. Kietselaer BL, Reutelingsperger CP, Boersma HH, Heidendal GA, Liem IH, Crijns HJ et al. Noninvasive detection of programmed cell loss with 99mTclabeled annexin A5 in heart failure. J Nucl Med 2007; 48(4): 562-7.

2. Boersma HH, Kietselaer BL, Stolk LM, Bennaghmouch A, Hofstra L, Narula $\mathrm{J}$ et al. Past, present, and future of annexin A5: from protein discovery to clinical applications. J Nucl Med 2005; 46(12): 2035-50.

3. Kemerink GJ, Liem IH, Hofstra L, Boersma HH, Buijs WC, Reutelingsperger CP et al. Patient dosimetry of intravenously administered $99 \mathrm{mTc}$-annexin V. J Nucl Med 2001; 42(2): 382-7.

4. Kaneko N, Matsuda R, Hosoda S, Kajita T, Ohta Y. Measurement of plasma annexin $\mathrm{V}$ by ELISA in the early detection of acute myocardial infarction. Clin Chim Acta 1996; 251(1): 65-80.

5. Matsuda R, Kaneko N, Kikuchi M, Chiwaki F, Toda M, Ieiri T et al. Clinical significance of measurement of plasma annexin $\mathrm{V}$ concentration of patients in the emergency room. Resuscitation 2003; 57(2): 171-7.

6. Jans SW, de Jong YF, Reutelingsperger CP, van der Vusse GJ, van Bilsen M. Differential expression and localization of annexin $\mathrm{V}$ in cardiac myocytes during growth and hypertrophy. Mol Cell Biochem 1998; 178(1-2): 229-36.

7. Ravassa S, Garcia-Bolao I, Zudaire A, Macias A, Gavira JJ, Beaumont J et al. Cardiac resynchronization therapy-induced left ventricular reverse remodelling is associated with reduced plasma annexin A5. Cardiovasc Res; 88(2): 304-13. 
8. Trouve P, Legot S, Belikova I, Marotte F, Benevolensky D, Russo-Marie F et al. Localization and quantitation of cardiac annexins II, V, and VI in hypertensive guinea pigs. Am J Physiol 1999; 276(4 Pt 2): H1159-66.

9. Benevolensky D, Belikova Y, Mohammadzadeh R, Trouve P, Marotte F, Russo-Marie F et al. Expression and localization of the annexins II, V, and VI in myocardium from patients with end-stage heart failure. Lab Invest 2000; 80(2): 123-33.

10. Song G, Campos B, Wagoner LE, Dedman JR, Walsh RA. Altered cardiac annexin mRNA and protein levels in the left ventricle of patients with endstage heart failure. J Mol Cell Cardiol 1998; 30(3): 443-51.

11. Ravassa S, Gonzalez A, Lopez B, Beaumont J, Querejeta R, Larman M et al. Upregulation of myocardial Annexin A5 in hypertensive heart disease: association with systolic dysfunction. Eur Heart J 2007.

12. Sayed D, Hong C, Chen IY, Lypowy J, Abdellatif M. MicroRNAs play an essential role in the development of cardiac hypertrophy. Circ Res 2007; 100(3): 416-24.

13. Tritsch E, Mallat Y, Lefebvre F, Diguet N, Escoubet B, Blanc J et al. An $\mathrm{SRF} / \mathrm{miR}-1$ axis regulates NCX1 and Annexin A5 protein levels in the normal and failing heart. Cardiovasc Res 2013.

14. Ravassa S, Gonzalez A, Lopez B, Beaumont J, Querejeta R, Larman M et al. Upregulation of myocardial Annexin A5 in hypertensive heart disease: association with systolic dysfunction. Eur Heart J 2007; 28(22): 2785-91.

15. Romisch J, Schuler E, Bastian B, Burger T, Dunkel FG, Schwinn A et al. Annexins I to VI: quantitative determination in different human cell types and in plasma after myocardial infarction. Blood Coagul Fibrinolysis 1992; 3(1): 11-7.

16. Hrycek A, Cieslik P. Annexin A5 and anti-annexin antibodies in patients with systemic lupus erythematosus. Rheumatol Int 2012; 32(5): 1335-42.

17. Boyajyan AS, Mkrtchyan GM, Hovhannisyan LP, Hovsepyan TJ. Increased levels of circulating Annexin A5 in Familial Mediterranean fever. J Inflamm (Lond) 2010; 7: 55.

18. van Heerde WL, de Groot PG, Reutelingsperger CP. The complexity of the phospholipid binding protein Annexin V. Thromb Haemost 1995; 73(2): 1729.

19. van Tits LJ, van Heerde WL, Landburg PP, Boderie MJ, Muskiet FA, Jacobs $\mathrm{N}$ et al. Plasma annexin A5 and microparticle phosphatidylserine levels are elevated in sickle cell disease and increase further during painful crisis. Biochem Biophys Res Commun 2009; 390(1): 161-4.

20. Kenis H, van Genderen H, Deckers NM, Lux PA, Hofstra L, Narula J et al. Annexin A5 inhibits engulfment through internalization of PS-expressing cell membrane patches. Exp Cell Res 2006; 312(6): 719-26.

21. Gidon-Jeangirard C, Solito E, Hofmann A, Russo-Marie F, Freyssinet JM, Martinez MC. Annexin V counteracts apoptosis while inducing $\mathrm{Ca}(2+)$ influx in human lymphocytic T cells. Biochemical and biophysical research communications 1999; 265(3): 709-15.

22. Bouter A, Gounou C, Berat R, Tan S, Gallois B, Granier T et al. Annexin-A5 assembled into two-dimensional arrays promotes cell membrane repair. Nat Commun 2011; 2: 270. 
23. Reuter H, Han T, Motter C, Philipson KD, Goldhaber JI. Mice overexpressing the cardiac sodium-calcium exchanger: defects in excitation-contraction coupling. J Physiol 2004; 554(Pt 3): 779-89.

24. Martinet W, Knaapen MW, Kockx MM, De Meyer GR. Autophagy in cardiovascular disease. Trends Mol Med 2007; 13(11): 482-91.

25. Nakai A, Yamaguchi O, Takeda T, Higuchi Y, Hikoso S, Taniike M et al. The role of autophagy in cardiomyocytes in the basal state and in response to hemodynamic stress. Nat Med 2007; 13(5): 619-24.

26. Ghislat G, Aguado C, Knecht E. Annexin A5 stimulates autophagy and inhibits endocytosis. J Cell Sci 2012; 125(Pt 1): 92-107.

27. Mira JP, Dubois T, Oudinet JP, Lukowski S, Russo-Marie F, Geny B. Inhibition of cytosolic phospholipase $\mathrm{A} 2$ by annexin $\mathrm{V}$ in differentiated permeabilized HL-60 cells. Evidence of crucial importance of domain I type II Ca2+-binding site in the mechanism of inhibition. J Biol Chem 1997; 272(16): 10474-82.

28. Xie GY, Berk MR, Smith MD, DeMaria AN. Relation of Doppler transmitral flow patterns to functional status in congestive heart failure. Am Heart J 1996; 131(4): 766-71.

29. Bruch C, Stypmann J, Grude M, Gradaus R, Breithardt G, Wichter T. Tissue Doppler imaging in patients with moderate to severe aortic valve stenosis: clinical usefulness and diagnostic accuracy. Am Heart J 2004; 148(4): 696702.

30. Ait-Oufella H, Kinugawa K, Zoll J, Simon T, Boddaert J, Heeneman S et al. Lactadherin deficiency leads to apoptotic cell accumulation and accelerated atherosclerosis in mice. Circulation 2007; 115(16): 2168-77.

31. Falborg L, Waehrens LN, Alsner J, Bluhme H, Frokiaer J, Heegaard CW et al. Biodistribution of $99 \mathrm{mTc}-\mathrm{HYNIC}$-lactadherin in mice--a potential tracer for visualizing apoptosis in vivo. Scand J Clin Lab Invest 2010; 70(3): 209-16.

32. Poulsen RH, Rasmussen JT, Ejlersen JA, Flo C, Falborg L, Heegaard CW et al. Pharmacokinetics of the phosphatidylserine tracers $99 \mathrm{mTc}$-lactadherin and 99mTc-annexin V in pigs. EJNMMI Res 2013; 3(1): 15.

33. Veronese FM, Pasut G. PEGylation, successful approach to drug delivery. Drug Discov Today 2005; 10(21): 1451-8.

34. Kuypers FA, Larkin SK, Emeis JJ, Allison AC. Interaction of an annexin V homodimer (Diannexin) with phosphatidylserine on cell surfaces and consequent antithrombotic activity. Thromb Haemost 2007; 97(3): 478-86. 



\title{
CHAPTER 7
}

\author{
SUMMARY \\ SAMENVATTING \\ DANKWOORD / ACKNOWLEDGEMENTS \\ CURRICULUM VITAE
}





\section{SUMMARY}

Multicellular organisms regulate their cell number by a process of cell proliferation and cellular death. From a biological point of view, a cell has mainly two pathways to die: a gen regulated form (apoptosis) and a non-regulated form (necrosis).

In 1992 it was found that cells are able to expose phosphatidylserine (PS) during apoptotic cell death at their cell surface. PS is a negatively charged phospholipid which in healthy cells is mainly located at the inner leaflet of the cell membrane. Therefore, cell surface expressed PS serves as a target for the visualization of apoptotic cell death. To date anxA5, that binds PS with high affinity, is the only protein that has been used to visualize PS expressing cells in patients.

In this thesis the focus was not directed to improve the existing molecular imaging techniques but; I) towards the development of anxA5 as a biomarker in heart failure and; II) towards the development of anxA5 variants as a therapeutic agent in diseases where the balance between apoptosis and phagocytosis is disturbed.

In chapter 2 we measured anxA5 concentrations in the plasma of a divergent heart failure patient population. In heart failure, the heart is not able to pump sufficient amounts of blood to meet the tissues needs. Recently it was postulated that stressed cardiomyocytes of the failing heart can initiate apoptosis without progressing towards full execution. These insights indicate towards mechanisms that protect stressed PS expressing cardiomyocytes. Because anxA5 binds PS with high affinity, inhibits phagocytosis of PS expressing cells, delays apoptosis and promotes the repair of injured cellular membranes, we argued that anxA5 may contribute to dampening adverse effects of PS on the surface of stressed cardiomyocytes. Therefore we measured the anxA5 plasma levels in heart failure patients. In these measurements we clearly showed that plasma anxA5 levels are significantly elevated in patients with heart failure as compared with healthy controls. In addition we showed that the patients with the highest anxA5 levels died first with no association with established clinical and biochemical heart failure measures. Following from these observations, we would like to propose to add anxA5 as a novel biomarker on top of already established biomarkers in heart failure. An adequate early diagnosis is essential because at this moment no sufficient therapeutics are available to treat heart failure patients in a late stadium.

In chapter 3 we tried to get more insight into the physiological meaning of these elevated anxA5 levels. Therefore, we induced heart failure in mice that lack the anxA5 gene (anxA5 knock-out mice) and in mice that carry the anxA5 gene (anxA5 Wild Type mice). In these experiments we found that the anxA5 knock-out mice develop a more severe diastolic dysfunction as compared to the anxA5 Wild Type mice. This form of dysfunction is very often seen in patients but no animal model is available that resembles this diastolic dysfunction phenotype at this time. Hence, the anxA5 knock out mouse delivers a novel platform to test novel therapeutic strategies that bear potential for treatment of heart failure suffering from diastolic dysfunction.

In chapter 4 we tried to transform anxA5 from a molecular imaging tool into a therapeutic agent in diseases where the clean-up process is diminished. An inefficient phagocytosis of apoptotic cells will lead to the bursting of the apoptotic cells whereby intracellular components of the cell will leak into the extracellular environment. This will finally result into the startup of the inflammation cascade. We reasoned that targeting PS to ligate the apoptotic cell with phagocytes could be a viable strategy to treat inflammation.

AnxA5 itself inhibits phagocytosis but by site-directed mutagenesis we introduced an RGDmotif in the anxA5 molecule, which is known to ligate with receptors expressed on 
phagocytes. We showed in chapter 4 that the introduction of the RGD-motif transforms anxA5 from an inhibitor into a stimulator of the phagocytosis of apoptotic cells.

In chapter 5 we evaluated these pro-phagocytotic properties of RGD-anxA5 in atherosclerosis, a very well known inflammatory disease in which an inefficient removal of apoptotic cells leads to the destabilization of atherosclerotic lesions. In my thesis we evaluated the influence of RGD-anxA5 on the initial development of atherosclerotic lesions. Herein we found that the atherosclerotic lesion formation is fully inhibited in the RGD-anxA5 treated group. We reasoned that enhancing phagocytosis of apoptotic cells is not the only explanation for the complete inhibition of lesion formation. In the search for additional mechanisms we found that RGD-anxA5 is also able to inhibit monocyte infiltration. Monocyte infiltration plays an important role in the initial inflammation cascade in the vascular wall that cause the atherosclerotic lesion initiation. RGD-anxA5, hence, represents a novel promising therapeutic compound combining multiple biological activities to treat vascular inflammation. 


\section{SAMENVATTING}

Multicellulaire organismen reguleren hun celaantal door een proces van celaanmaak, proliferatie, aan de ene kant en celafbraak, celdood, aan de andere kant. Vanuit biologisch oogpunt bestaan er voor cellen hoofdzakelijk twee manieren om dood te gaan: een gengereguleerde vorm (apoptose) en een niet-gereguleerde vorm (necrose).

In 1992 werd een cel ontdekt die tijdens het apoptotische celdoodprogramma fosfatidylserine (PS) aan zijn celoppervlak kan tentoonstellen. Later werd aangetoond dat in principe alle cellen de moleculaire machinerie bezitten om PS te exposeren tijdens het apoptotische celdoodprogramma. PS is een negatief geladen fosfolipide dat in gezonde cellen hoofdzakelijk aan de binnenzijde van de celmembraan gelokaliseerd is.

Structuur/functie-analyse en bindingsproeven toonden aan dat PS aan de buitenzijde van de plasmamembraan als een 'eet mij'-signaal fungeert voor de 'opruimers van het organisme' (fagocyten). Deze bezitten specifieke receptoren voor PS welke na binding met PS het opruimproces (fagocytose) activeren. De PS-receptoren zijn tot op heden nog niet geïdentificeerd maar er zijn wel eiwitten bekend die met hoge affiniteit kunnen binden aan PS. Eén van deze eiwitten is annexine A5 (anxA5), dat door mijn promotor Prof. dr. Chris Reutelingsperger in Maastricht voor het eerst gekarakteriseerd werd. Vanwege deze biologische activiteit is anxA5 uitermate geschikt om celdood in vitro (in een proefbuis), in vivo (in een organisme) en in patiënten te meten. Gedurende de laatste decenia werd hoofdzakelijk onderzoek verricht naar deze 'imaging'-eigenschappen van anxA5. In dit proefschrift is de focus echter niet gericht naar de verbetering van deze moleculaire imaging eigenschappen van anxA5 maar enerzijds op de ontwikkeling van anxA5 als biomarker in hartfalen en anderzijds op de ontwikkeling van anxA5 varianten die als therapeuticum gebruikt kunnen worden in weefsels waar de verhouding tussen apoptose en fagocytose verstoort is.

In hoofdstuk 2 hebben we de hoeveelheid anxA5 in het plasma van een uitgebreide hartfaalpatiënten populatie gemeten. Bij hartfalen is het hart niet meer in staat om voldoende bloed rond te pompen om aan de behoeften van de weefsels te voldoen.

Hierbij stelden we verhoogde anxA5 concentraties vast in het plasma van deze hartfaalpatienten in vergelijking met gezonde personen. Verder toonden we aan dat de patiënten met de hoogste anxA5 plasma levels het eerste stierven terwijl geen enkele andere conventionele biomarker hetzelfde patroon laat zien. Hieruit volgt dat het toevoegen van anxA5 aan het pellet van huidige biomarkers in de toekomst kan leiden tot een betere diagnose bij deze hartfaalpatienten. Een adequate vroegtijdige diagnose is essentieel aangezien er op dit moment geen afdoende therapeutica voorhanden zijn om hartfaalpatienten in een laattijdig stadium te behandelen.

In hoofdstuk 3 hebben we getracht om meer inzicht te verkrijgen in de fysiologische betekenis van deze verhoogde anxA5 plasma levels bij deze hartfaalpatienten. Om deze invloed te toetsen, hebben we hartfalen geïnduceerd bij muizen die het anxA5 gen missen (anxA5 knock-out) en bij muizen die het anxA5 gen bezitten (anxA5 wilde type muizen). Uit deze experimenten blijkt dat de anxA5 knock-out muizen een verergerde vorm van hartfalen vertonen. Deze vorm van hartfalen is nooit eerder beschreven in een dierenmodel. Dit nieuwe dierenmodel biedt de mogelijkheid om zeer snel verschillende therapeutica te testen. 
In hoofdstuk 4 hebben we getracht om anxA5 om te vormen in een therapeutisch molecule ter behandeling van ziekten met een verlaagde opruiming van apoptotische cellen. Hiervoor hebben we in het anxA5 molecule een motief ingebracht dat bekend is om te ligeren met receptoren aanwezig op fagocyten. Met dit gemodificeerde anxA5 molecule hebben we getracht om een brug te vormen tussen fagocyt en de apoptotische cel. Met succes slaagden we erin om het anxA5 molecule om te vormen van een remmer naar een stimulator van de fagocytose.

In hoofdstuk 5 hebben we de therapeutische eigenschappen van dit gemodificeerde anxA5 molecule getoetst in een muizenmodel van aderverkalking (atherosclerose). Atherosclerose is een zeer bekend voorbeeld van een ontstekingsziekte waarbij een inefficiënte fagocytose van apoptotische cellen leidt tot het onstabieler worden van de atherosclerotische plaque. In hoofdstuk 5 hebben we ons enkel gefocussed op de initiële plaque ontwikkeling. Analyse van de gevormde plaques onthulde een volledige inhibitie van de atherosclerotische plaque formatie. Deze bevindingen maken van het anxA5 molecule een nieuw veelbelovend therapeuticum ter behandeling van vasculaire inflamatie. 


\section{DANKWOORD / ACKNOWLEDGEMENTS}

$\mathrm{Na}$ een lange vruchtbare rit ben ik uiteindelijk aangekomen bij het laatste stuk van mijn proefschrift; het dankwoord. Misschien is dit wel het belangrijkste gedeelte want zonder de steun en hulp van vele mensen was dit zeker niet gelukt.

Mijn bijzondere dank gaat hierbij dan ook uit naar mijn promotor, Prof. Dr. Chris Reutelingsperger, voor het aanreiken van het onderwerp, het verstrekken van onontbeerlijke kennis, het kritisch evalueren van alle teksten maar hoofdzakelijk voor de kans die je me gegeven hebt om me te ontwikkelen als promovendus in je lab. Je hebt me buiten theoretische kennis ook een gedeelte levenservaring bijgebracht. Hiervoor ben ik je uiterst dankbaar.

Verder zou ik ook mijn uiterste dank willen uitspreken voor Dr. Leon Schurgers. Beste Leon, de vele theoretische en praktische discussies over nieuwe experimenten en het nalezen van mijn teksten zijn een grote hulp voor me geweest. Je was altijd enorm enthousiast en vol met nieuwe ideeën. Je deur stond steeds voor mij en iedereen open! Heel erg bedankt voor je aanstekelijke enthousiasme.

Beste Niko, je was als het ware de kiem van dit proefschrift. Dankzij jou kwam ik niet alleen in contact met het lab maar je leerde me tijdens mijn bachelorstage ook de kneepjes van het vak. Als strenge maar rechtvaardige leermeester heb je dan ook een enorme impact gehad op mijn ontwikkeling. Je was tijdens mijn promotiestudie ook vaak mijn eerste hulp bij 'ongevallen'. Heel erg bedankt hiervoor.

Beste Cecile, Liset, Heidi en Petra. Ik kwam bij jullie terecht als jonkie tijdens mijn bachelorjaren. Jullie hebben me destijds met open armen ontvangen en dit is gedurende de jaren eigenlijk nooit veranderd. Ik moet zeggen dat ik me altijd erg welkom heb gevoeld. Jullie waren steeds een steunpilaar waaraan ik me aan kon vastklampen wanneer het dreigde scheef te gaan.

Dennis en Martijn, jullie waren gedurende verschillende jaren mijn 'partners in crime'. Jullie zijn twee erg verschillende types maar beide zijn jullie erg getalenteerd. Ik ben er zeker van dat er een mooie wetenschappelijke toekomst op jullie wacht. Heel erg bedankt dat jullie steeds paraat stonden op de belangrijke momenten.

Nicole, ik zou je heel graag uitvoerig willen danken voor alle hulp van de afgelopen jaren. Je stond steeds voor me klaar. Je hebt me enorm goed geholpen maar je hebt me ook enorm veel geleerd. Heel erg bedankt voor je gedrevenheid. I would like to extend my gratitude to Gustavo and Leon. Thanks a lot for the fantastic guidance during the heart failure experiments.

I also would like to thank Mauro Perretti, Trinidad Montero-Melendez and Dianne Cooper from the William Harvey Research Institute in London. I would like to thank you for the hospitality and the opportunity that you gave me to perform some key experiment in your lab. These experiments accelerated my research tremendously.

I also would like to express my gratitude to Dmitri Krysko, Peter Vandenabeele, Matthias Bauwens, Marijke De Saint-Hubert and Alfons Verbruggen from the University of Ghent and Leuven. 
Marjo, Jeroen, Jack, Judith en Erik, heel erg bedankt voor het delen van jullie expertise en kennis.

Bij de collega's van biochemie kon ik steeds terecht met uiteenlopende vragen. Ook zou ik jullie willen danken voor de aangename werkomgeving gedurende mijn promotiestudie. In het bijzonder zou ik Gerry willen danken voor het moduleren van verschillende mutante eiwitten. De voorkaft van dit proefschrift is hier een mooi voorbeeld van. Verder zou ik Stella, Marion, Pieter, Dennis, Johan, Tilman, Sarah en Paola extra willen bedanken voor de directe hulp bij diverse experimenten. Heel erg bedankt voor alle hulp.

I also would like to thank everybody of my new research group in Aachen guided by prof. dr. Willi Jahnen-Dechent. Vielen Dank für Ihre Gastfreundschaft !

Tijdens de start van mijn onderzoek speelde ik nog voetbal en tafeltennis. Gedurende de jaren ben ik hier spijtig genoeg mee moeten stoppen wegens tijdsgebrek. Graag zou ik mijn kameraden van voetbalclub Peer SV en tafeltennisclub fairplay Peer willen danken voor alle leuke ontspannende/inspannende tijden die we samen hebben beleefd. Ik sluit zeker niet uit dat ik ooit terug de draad zal opnemen en me terug bij jullie zal aansluiten.

Verder hebben we tijdens het afgelopen decenium een erg hechte vriendengroep opgebouwd waarmee we de gekste dingen mee hebben beleefd. De manier waarop we een 10 jaar geleden naar elkaar gegroeid zijn is wel erg speciaal. In het bijzonder zou ik hierbij Annemieke, Adrienne, Esther, Lindsy, Nathalie, Marco en Erik willen danken.

Ook zou ik mijn ouders willen danken voor de kans die ze me gegeven hebben om te studeren. Ook tijdens dit promotieonderzoek stonden jullie klaar waar nodig. Heel erg bedankt hiervoor. Graag zou ik deze bedanking willen doortrekken naar mijn broer Davy, mijn schoonouders Roger en Saskia, schoonbroer Rocky en schoonzus Julie die altijd voor me klaar stonden.

Als laatste zou ik graag mijn dank willen uitbrengen aan mijn vrouw en mijn kinderen. Schat, als ik heel eerlijk ben, was deze promotiestudie zonder jou zo veel makkelijk geweest. Aan de andere kant zou zonder jou mijn leven echter helemaal niet zo kwaliteitsvol zijn geweest. Gedurende dit promotie-traject hebben we een fantastisch gezin kunnen stichten. Zonder jou was dit absoluut niet mogelijk geweest, heel erg bedankt hiervoor. Je stond steeds klaar als ik weer een keertje laat thuis of er helemaal niet was. Buiten een geweldige partner ben je ook een fantaschische moeder voor Hayley en Romy. Tenslotte Hayley en Romy, jullie zijn gewoonweg geweldig! Een cliché maar helemaal waar; jullie zijn het beste wat me ooit is overkomen. Samen met jullie mama beloof ik dat we er alles aan zullen doen om een degelijk platvorm te bouwen waarop jullie verder kunnen bouwen.

Heel erg bedankt allemaal!!!

Kristof 


\section{CURRICULUM VITAE}

Kristof Schutters was born on June 11th 1984 in Hasselt, Belgium. He studied at the Katholic Highschool Limburg (KHLim) in Diepenbeek and graduated in 2005 as a Professional Bachelor in Chemistry with Biochemistry as specialization. For his graduate research project he did an internship at the University of Maastricht titled: , Annexine A5 as targeting molecule for therapeutic interventions.' This thesis was awarded as best thesis of the year in the department of Industrial Sciences and Technology of the KHLim.

For more in-depth knowledge on biochemistry he started the Master Industrial Engineering in Biochemistry in 2005 at the KHLim. After finishing his thesis project titled:' The study of the structure and activity of the microscopic community in the interface of ground- and surface water aiming bioremidiation' at the Flemish Institute for Technological Research (VITO) in Geel, he graduated in June 2007.

In August 2007 he started, under supervision of Prof. Dr. Chris Reutelingsperger, as a PhDstudent at the University of Maastricht on the department of biochemistry. He finished his research in July 2012 and currently works as a post-doctoral researcher in the lab of Prof. Dr. Willi Jahnen-Dechent at the University hospital in Aachen, Germany. 


\section{LIST OF PUBLICATIONS}

1. Schutters K, Reutelingsperger C. Phosphatidylserine targeting for diagnosis and treatment of human diseases. Apoptosis. 2010;15:1072-82.

2. Schutters K, Kusters DH, Chatrou ML, Montero-Melendez T, Donners M, Deckers $\mathrm{NM}$, et al. Cell surface-expressed phosphatidylserine as therapeutic target to enhance phagocytosis of apoptotic cells. Cell Death Differ. 2012 Sep 7. 


